\title{
THE EFFECTS OF FOLIAR NUTRIENT APPLICATIONS ON SPLIT, YIELD, AND INTERNAL FRUIT QUALITY OF 'WONDERFUL' POMEGRANATE \\ (PUNICA GRANATUM L.)
}

\author{
A Thesis \\ presented to \\ the Faculty of California Polytechnic State University, \\ San Luis Obispo
}

\author{
In Partial Fulfillment \\ of the Requirements for the Degree \\ Master of Science in Agriculture
}

by

John Matthew Chater

December 2015 
(C) 2015

John Matthew Chater

ALL RIGHTS RESERVED 


\section{COMMITTEE MEMBERSHIP}

TITLE:

The Effects of Foliar Nutrient Applications on Split, Yield, and

Internal Fruit Quality of 'Wonderful' Pomegranate (Punica

granatum $\mathrm{L}$.

AUTHOR: John Matthew Chater

DATE SUBMITTED: December 2015

COMMITTEE CHAIR: $\quad$ Lauren Garner, Ph.D.

Associate Professor of Horticulture and Crop Science

COMMITTEE MEMBER: David Headrick, Ph.D.

Professor of Horticulture and Crop Science

COMMITTEE MEMBER: Matt Ritter, Ph.D.

Professor of Biology 


\begin{abstract}
The Effects of Foliar Nutrient Applications on Split, Yield, and Internal Fruit Quality of

'Wonderful' Pomegranate (Punica granatum L.)

John Matthew Chater
\end{abstract}

Fruit split is the most important physiological disorder in pomegranate production, causing devastating crop losses worldwide. Foliar nutrient applications have been used experimentally to mitigate pomegranate fruit split but none have been conducted using the industry standard cultivar, Wonderful, and little is known about the effects of foliar nutrient applications on pomegranate. Additionally, investigations into putative health benefits of pomegranate fruit have increased interest in its production but limited evidence exists regarding effects of agricultural practices such as foliar fertilizer applications on internal fruit quality. 'Wonderful' pomegranate trees at 2 commercial orchards were treated with foliar applications of $\mathrm{ZnSO}_{4}\left(3000 \mathrm{mg} \cdot \mathrm{L}^{-1}\right.$, $4000 \mathrm{mg} \cdot \mathrm{L}^{-1}$, or $\left.5000 \mathrm{mg} \cdot \mathrm{L}^{-1}\right), \mathrm{MgSO}_{4}(1 \%, 2 \%$, or $3 \%), \mathrm{KNO}_{3}(1 \%, 2 \%$, or $3 \%)$, or deionized (DI) water (control). Fruit were analyzed for fruit split incidence, yield, fruit number per tree, fruit diameter, fruit mass, or mass of all arils in fruit, mass of 100 arils, total soluble solids (TSS), titratable acidity (TA), antioxidant activity (AA), total phenolics (TP), and mineral nutrient concentrations of leaves and fruit. Foliar applications of $\mathrm{MgSO}_{4}$ and $\mathrm{ZnSO}_{4}$ resulted in significantly lower fruit split incidence. Treatments had no significant effect on fruit number per tree, fruit diameter, and mass, mass of all arils in fruit, or mass of 100 arils. Leaf $\mathrm{N}, \mathrm{K}, \mathrm{S}, \mathrm{Mn}$, and $\mathrm{Zn}$ were significantly affected by the treatments. TSS and TA were not affected significantly by treatments. AA ranged from 77.8-84.3 percent inhibition of 2,2'-diphenyl-1-picrylhydrazyl and TP ranged from 2489-3046 mg. $\mathrm{L}^{-1}$ gallic acid equivalents, with some $\mathrm{KNO}_{3}$ treatments significantly affecting these parameters. Fruit mineral nutrient concentrations were characterized and $\mathrm{Zn}$-treated trees had greater fruit $\mathrm{Zn}$ concentrations. The results suggest that foliar $\mathrm{ZnSO}_{4}$ or $\mathrm{MgSO}_{4}$ could be used to decrease fruit split incidence and increase nutritional content of 'Wonderful' pomegranate and any of the three tested foliar nutrients could be applied as a foliar fertilizer without negatively impacting fruit yield, size, internal quality, bioactivity, or mineral nutrient concentration. 


\section{ACKNOWLEDGMENTS}

The author wishes to acknowledge financial support from the California State University Agricultural Research Initiative and Roll Global (now The Wonderful Company) and Wonderful Orchards' Erik Wilkins and the late Dee Slaymen of Slaymen Marketing for their efforts in facilitating the field experiments and providing the data trees and fruit for this research. The author also wishes to acknowledge his perfect parents for their support, wisdom, and love, his wife for being there for him and assisting in harsh field conditions, his brother James for assisting in the field and offering support, and his advisor and mentor Lauren Garner for taking him on as a graduate student, spending countless hours training him how to teach, write and do scientific research, and giving him the opportunity to be who he is today. He would like to thank and acknowledge J. Wyatt Brown for providing laboratory access and guidance, Mark Shelton, who gave him a chance to participate in academia and offered much guidance, the late Adel A. Kader for his guidance, support and suggestions, and the several undergraduate students who assisted in this research, including Teresa Zimmerle, Kaytlin O’Dell, Kaitlyn Liu, Kimberly Arias, Samantha Fullerton, and Julia Hayhurst. 


\section{TABLE OF CONTENTS}

Page

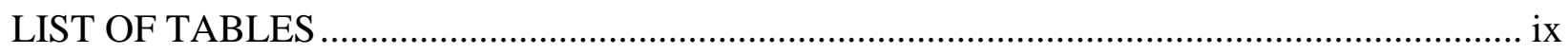

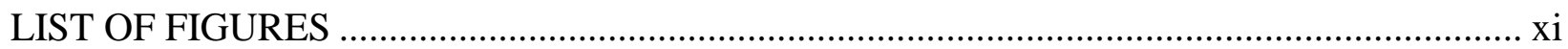

CHAPTER

1. LITERATURE REVIEW .....................................................................................

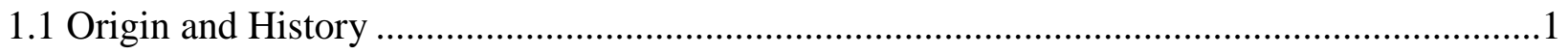

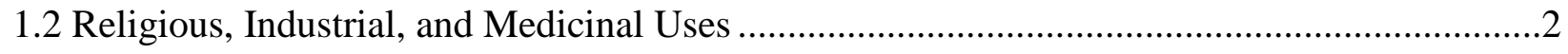

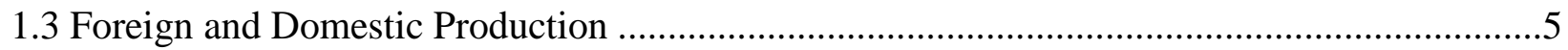

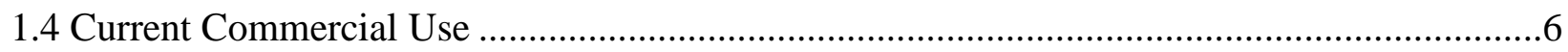

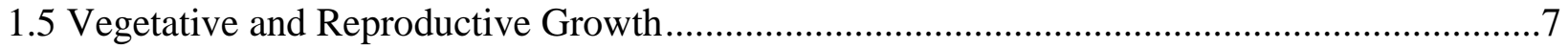

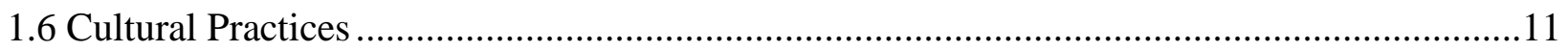

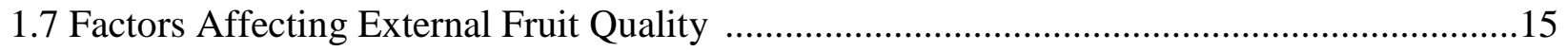

1.8 Harvest and Postharvest Requirements for Pomegranate ...............................................18

1.9 TA, Sugar, and Mineral Nutrient Concentration of Mature Pomegranate Fruit .....................19

1.10 Antioxidant Activity and Phenolic Content of Pomegranate Fruit and Juice......................20

1.11 Factors Affecting TA, Sugar, Mineral Nutrient Concentration, Antioxidant Activity, and Phenolic Content of Mature Pomegranate Fruit............................................................24

2. THE EFFECTS OF FOLIAR NUTRIENT APPLICATIONS ON FRUIT SPLIT, YIELD AND LEAF NUTRIENT CONCENTRATION OF 'WONDERFUL' POMEGRANATE

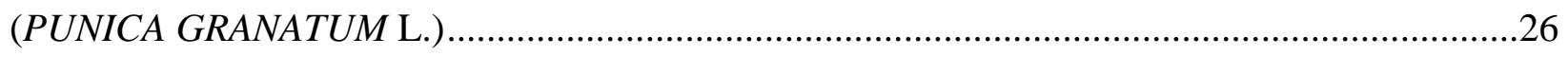

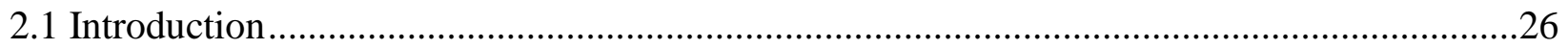




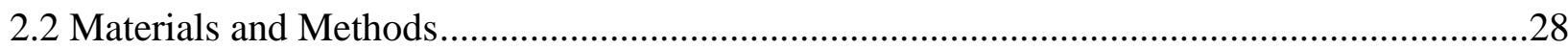

2.2.1 Plant Material and Experimental Design ..........................................................28

2.2.2 Measured Parameters .................................................................................29

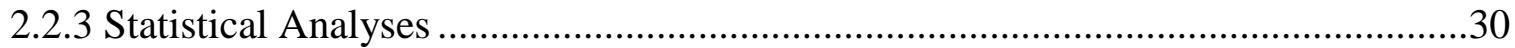

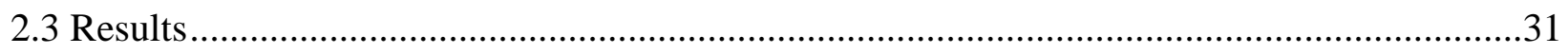

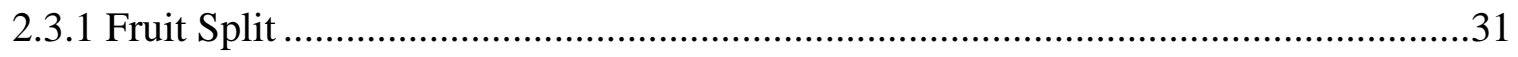

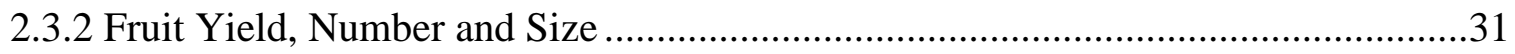

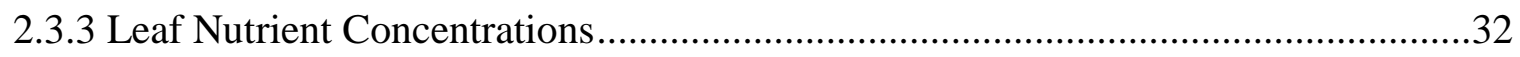

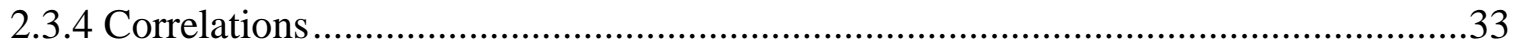

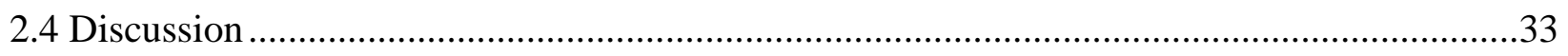

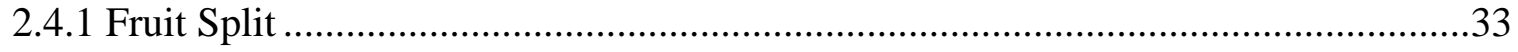

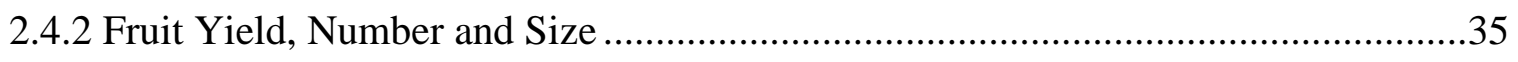

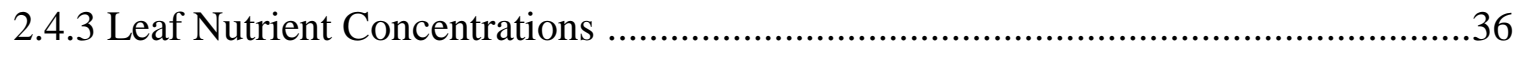

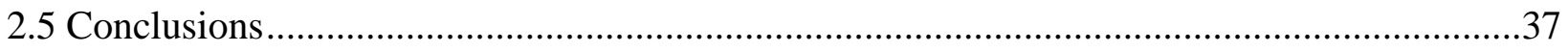

3. CHEMICAL COMPOSITION, ANTIOXIDANT ACTIVITY, TOTAL PHENOLICS, AND MINERAL NUTRIENT CONCENTRATION OF 'WONDERFUL' POMEGRANATE (PUNICA GRANATUM L.) FRUIT: CHARACTERIZATION AND EFFECTS OF FOLIAR

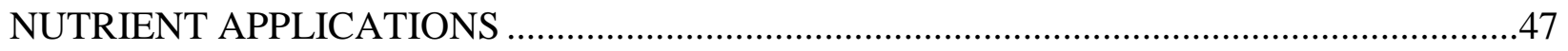

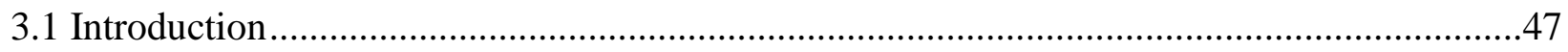

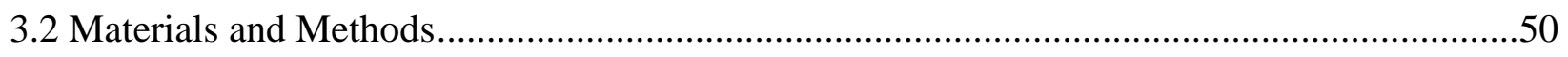

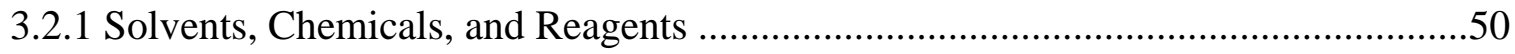

3.2.2 Plant Material and Experimental Design .....................................................51 
3.2.3 Fruit Collection and Aril and Juice Extraction

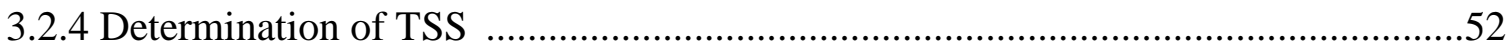

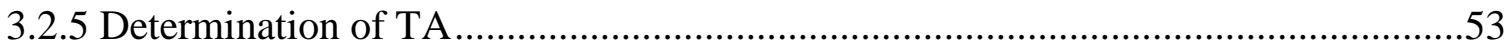

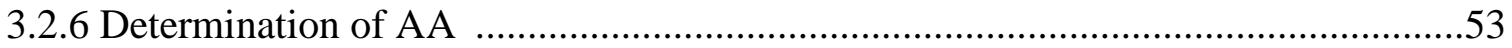

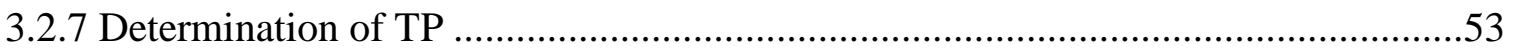

3.2.8 Determination of Fruit Nutrient Concentration ..............................................54

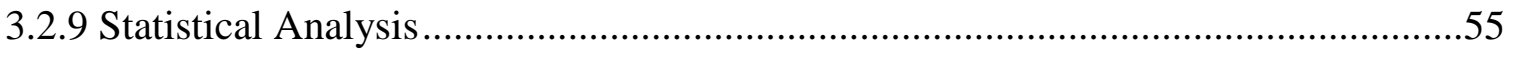

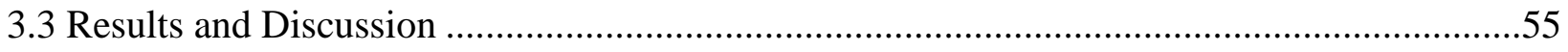

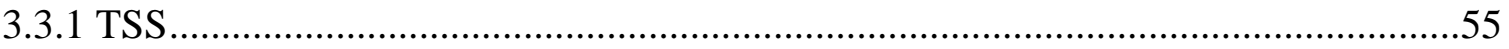

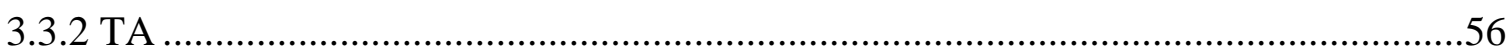

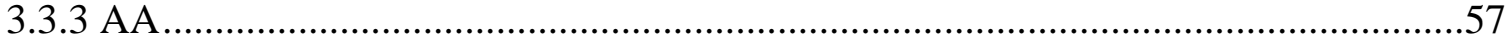

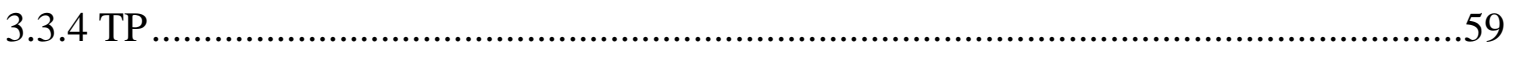

3.3.5 Relationships between TA, AA, and TP ................................................60

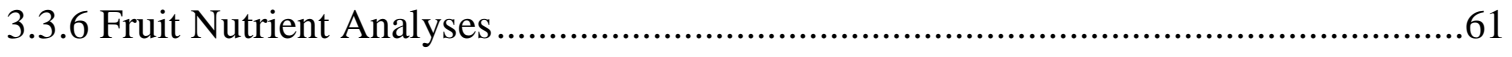

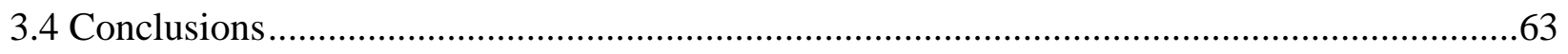

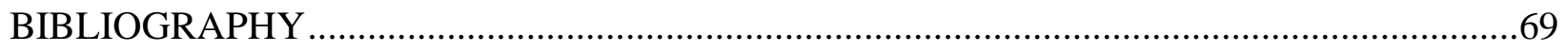

\section{APPENDICES}

A. Fruit Growth Curves 


\section{LIST OF TABLES}

Table

Page

1. Tree height, trunk diameter, within row and between row tree spacing, and date of harvest for data trees at two commercial pomegranate orchards in Kern County, CA, USA.

2. Percent fruit split of 'Wonderful' pomegranate trees treated with foliar applications of deionized water (control), $\mathrm{ZnSO}_{4}\left(3000 \mathrm{mg} \cdot \mathrm{L}^{-1}, 4000 \mathrm{mg} \cdot \mathrm{L}^{-1}\right.$, or $\left.5000 \mathrm{mg} \cdot \mathrm{L}^{-1}\right), \mathrm{MgSO}_{4}$ $(1 \%, 2 \%$, or $3 \%)$, or $\mathrm{KNO}_{3}(1 \%, 2 \%$, or $3 \%)$ at two commercial orchards in Kern County, CA, USA.

3. Yield and fruit number per tree of 'Wonderful' pomegranate treated with foliar applications of deionized water (control), $\mathrm{ZnSO}_{4}\left(3000 \mathrm{mg} \cdot \mathrm{L}^{-1}, 4000 \mathrm{mg} \cdot \mathrm{L}^{-1}\right.$, or $\left.5000 \mathrm{mg} \cdot \mathrm{L}^{-1}\right), \mathrm{MgSO}_{4}(1 \%, 2 \%$, or $3 \%)$, or $\mathrm{KNO}_{3}(1 \%, 2 \%$, or $3 \%)$ at two commercial orchards in Kern County, CA, USA

4. Fruit mass, mass of all arils, mass of 100 arils, and fruit diameter of 'Wonderful' pomegranate trees treated with foliar applications of deionized water (control), $\mathrm{ZnSO}_{4}$ (3000 mg. $\mathrm{L}^{-1}, 4000 \mathrm{mg} \cdot \mathrm{L}^{-1}$, or $\left.5000 \mathrm{mg} \cdot \mathrm{L}^{-1}\right), \mathrm{MgSO}_{4}(1 \%, 2 \%$, or $3 \%)$, or $\mathrm{KNO}_{3}(1 \%$, $2 \%$, or $3 \%$ ) at two commercial orchards in Kern County, CA, USA.

5. Leaf macronutrient concentrations (\%) from 'Wonderful' pomegranate trees treated with foliar applications of deionized water (control), $\mathrm{ZnSO}_{4}\left(3000 \mathrm{mg} \cdot \mathrm{L}^{-1}, 4000 \mathrm{mg} \cdot \mathrm{L}^{-1}\right.$, or $\left.5000 \mathrm{mg} \cdot \mathrm{L}^{-1}\right), \mathrm{MgSO}_{4}(1 \%, 2 \%$, or $3 \%)$, or $\mathrm{KNO}_{3}(1 \%, 2 \%$, or $3 \%)$ at two commercial orchards in Kern County, CA, USA. 
6. Leaf micronutrient concentrations $\left(\mathrm{mg} \cdot \mathrm{L}^{-1}\right)$ from 'Wonderful' pomegranate trees treated with foliar applications of deionized water (control), $\mathrm{ZnSO}_{4}\left(3000 \mathrm{mg} \cdot \mathrm{L}^{-1}, 4000 \mathrm{mg} \cdot \mathrm{L}^{-1}\right.$, or $\left.5000 \mathrm{mg} \cdot \mathrm{L}^{-1}\right), \mathrm{MgSO}_{4}(1 \%, 2 \%$, or $3 \%)$, or $\mathrm{KNO}_{3}(1 \%, 2 \%$, or $3 \%)$ at two commercial orchards in Kern County, CA, USA.

7. Total soluble solids (TSS; \%), titratable acidity (TA; $g \cdot \mathrm{L}^{-1}$ citric acid), antioxidant activity (\% DPPH inhibition) and total phenolics (TP; $\mathrm{mg} \cdot \mathrm{L}^{-1}$ gallic acid equivalents $(\mathrm{GAE})$ ) of fruit from 'Wonderful' pomegrante trees treated with foliar applications of deinionized water (control), $\mathrm{ZnSO}_{4}\left(3000 \mathrm{mg} \cdot \mathrm{L}^{-1}, 4000 \mathrm{mg} \cdot \mathrm{L}^{-1}\right.$, or $\left.5000 \mathrm{mg} \cdot \mathrm{L}^{-1}\right), \mathrm{MgSO}_{4}(1 \%, 2 \%$, or $3 \%)$, or $\mathrm{KNO}_{3}(1 \%, 2 \%$, or $3 \%)$ at 2 commercial orchards in Kern County, CA, USA.

8. Results of correlation analyses for titratable acidity (TA; $\mathrm{g} \cdot \mathrm{L}^{-1}$ citric acid), total phenolics (TP; $\mathrm{mg} \cdot \mathrm{L}^{-1}$ gallic acid equivalents (GAE)), and antioxidant activity (AA; \% inhibition $\mathrm{DPPH})$ of fruit from 'Wonderful' pomegrante trees treated with foliar applications of deinionized water (control), $\mathrm{ZnSO}_{4}\left(3000 \mathrm{mg} \cdot \mathrm{L}^{-1}, 4000 \mathrm{mg} \cdot \mathrm{L}^{-1}\right.$, or $\left.5000 \mathrm{mg} \cdot \mathrm{L}^{-1}\right), \mathrm{MgSO}_{4}$ $(1 \%, 2 \%$, or $3 \%)$, or $\mathrm{KNO}_{3}(1 \%, 2 \%$, or $3 \%)$ at 2 commercial orchards in Kern County, CA, USA.

9. Fruit nutrient concentrations $\left(\mathrm{mg} \cdot 100 \mathrm{~g}^{-1}\right)$ from 'Wonderful' pomegrante trees treated with foliar applications of deinionized water (control), $\mathrm{ZnSO}_{4}\left(3000 \mathrm{mg} \cdot \mathrm{L}^{-1}, 4000 \mathrm{mg} \cdot \mathrm{L}^{-1}\right.$, or $\left.5000 \mathrm{mg} \cdot \mathrm{L}^{-1}\right), \mathrm{MgSO}_{4}(1 \%, 2 \%$, or $3 \%)$, or $\mathrm{KNO}_{3}(1 \%, 2 \%$, or $3 \%)$ at a commercial orchard in Kern County, CA, USA. .68 


\section{LIST OF FIGURES}

Figure $\quad$ Page

1. Fruit growth curves $(\mathrm{mm})$ of 'Wonderful' pomegrante trees treated with foliar applications of deinionized water (control), $\mathrm{ZnSO}_{4}$ (low dosage: $3000 \mathrm{mg} \cdot \mathrm{L}^{-1}$, medium dosage: $4000 \mathrm{mg} \cdot \mathrm{L}^{-1}$, or high dosage: $5000 \mathrm{mg} \cdot \mathrm{L}^{-1}$ ), $\mathrm{MgSO}_{4}$ (low dosage: $1 \%$, medium dosage: $2 \%$, or high dosage: $3 \%$ ), or $\mathrm{KNO}_{3}$ (low dosage: $1 \%$, medium dosage: $2 \%$, or high dosage: $3 \%$ ) at two commercial orchards (site 1: Maricopa, CA, site 2: Lost Hills, CA) in Kern County, CA, USA. 


\section{Chapter 1: Literature Review}

\subsection{Origin and History}

Pomegranate (Punica granatum) is a subtropical fruit tree crop that has been cultivated for several thousand years (Holland, Hatib, \& Bar-Ya'akov, 2009; Levin, 2006) and is purported to be one of the first fruit species to be domesticated (Still, 2006). It is widely reported that pomegranate's originally ascribed botanical family, Punicaceae, is shared with only one other species, Punica protopunica, which grows solely on the island of Socotra, off the Yemeni coast (Lansky \& Newman, 2007). Recent phylogenic studies assign pomegranate to the Lythraceae family (Graham, Hall, Sytsma, \& Shi, 2005). Pomegranate cultivation is believed to have originated in the region of Central Asia now comprised of the modern-day countries of Iran, Turkmenistan and northern India (Holland \& Bar-Ya'akov, 2008; Levin, 2006), with evidence of pomegranate domestication from as early as 3000 BCE (Janick, 2005).

During the Roman Empire, the fruit was initially dubbed Malum punica, meaning "Carthage's (Phoenicia's) Apple" (Barone, Caruso, Marra, \& Sottile, 2000; Holland et al., 2009). Linnaeus is credited with assigning pomegranate's current binomial scientific name, Punica granatum, meaning "grainy or seedy apple from Carthage" (Stover \& Mercure, 2007). Phoenicians expanded cultivation of pomegranate throughout the Mediterranean region (Levin, 2006; Stover \& Mercure, 2007) and there is evidence indicating that it was grown and used in Egypt by 1600 BCE (Ward, 2003), in Rome by 800 BCE (Stover \& Mercure, 2007) and in China by 200 BCE (Levin, 2006). The Spanish brought pomegranate to North America when colonizing Florida and it was cultivated in Florida and Georgia circa 1700 and brought to California by Spanish missionaries in the late 1700's (Day \& Wilkins, 2009; Stover \& Mercure, 2007). Pomegranates are now cultivated in numerous subtemperate, temperate, tropical, and subtropical regions 
throughout the world (Glozer \& Ferguson, 2008; Jalikop, Rawal, \& Kumar, 2005; Verma, Mohanty, \& Lal, 2010; Ward, 2003).

\subsection{Religious, Industrial, and Medicinal Uses}

In addition to its use as food, pomegranate has been cultivated for religious, industrial, and medicinal purposes (Stover \& Mercure, 2007). Pomegranate is reported to have been of cultural significance prior to its widespread cultivation (Holland et al., 2009). Religions that mention and depict the fruit in holy texts and artworks include Christianity, Judaism, Islam (Janick, 2007), Buddhism (Beer, 2003), and Zoroastrianism (Langley, 2000; Lansky \& Newman, 2007). For example, some Chinese and Japanese Buddhists believe pomegranate to be one of the three blessed fruits, in addition to citron and peach (Beer, 2003; Langley, 2000). According to legend, Buddha gave a pomegranate to the demoness Hariti (named Kishimojin in Japan) to successfully stop her habitual consumption of children (Langley, 2000). In Greek mythology, pomegranate was referred to as the "fruit of the dead," as it was thought to be the only food available to those in Hades (Lansky, Shubert, \& Neeman, 2000). Another Grecian legend stated that pomegranate trees arose from Dionysus Zagreus' blood when he was assassinated (Myers, 1971). Pomegranate fruit was believed to symbolize the female aspect of the creator (Lansky et al., 2000). The fruit is used as decorations and for blessings in ceremonies in Judaism (Blumenfeld, Shaya, \& Hillel, 2000). The image of pomegranate fruit was inscribed on Jewish coinage (Janick, 2007). The fruit was often a symbol of fertility (Langley, 2000; Mars, 2000; Ward, 2003), wealth, and prosperity (Lakshmi, 2002) in many cultures throughout the world over the course of human history. 
Pomegranate has a long history of use for industrial and artistic purposes since the time of the Mesopotamians (Ward, 2003). Bark, flower, and fruit extracts, which when dried contain relatively high quantities of tannins (Levin, 2006; Ward, 2003), have been used in the manufacture of textiles, particularly for Moroccan leather (Stover \& Mercure, 2007) and Turkish dyes (Ward, 2003). Ivory finials adorned with pomegranate fruit, dating as far back as 4000 BCE, have been recovered in archaeological expeditions in the Mediterranean (Ward, 2003). Thousands of years ago, pomegranate fruit's astringent effects in perfumery were mentioned in texts (Ward, 2003). Various pomegranate parts and iconography were recovered and identified in archeological finds ranging from ancient shipwrecks to tombs constructed millennia ago (Ward, 2003). The fruit and flowers have been used to produce dyes and ink (Stover \& Mercure, 2007). Ornamental pomegranate cultivars produce large flowers with increased petal numbers (Levin, 2006).

Pomegranate and its various plant parts have been used in folk medicine in various cultures throughout history, including ancient Egypt (Lansky et al., 2000; Williamson, Evans, \& Wren, 1988) and Mesopotamia (Ward, 2003). Pomegranate is used in various heraldic crests and for symbolic purposes in the Millennium Festival of Medicine (Langley, 2000). The fruit is featured on the emblem of the United Kingdom's Royal College of Physicians (Langley, 2000). Virtually all parts of the tree, including the bark, roots, flowers, fruits, and leaves, have been utilized by cultures to treat a wide range of human diseases for millennia (Holland et al., 2009). Current investigations of the putative health benefits of pomegranate have led to increased worldwide demand and interest in the fruit (Holland \& Bar-Ya'akov, 2008). Studies have identified and quantified many of pomegranate's phytochemicals including various bioactive alkaloids such as pelletierines (Williamson et al., 1988), sex steroids (Janeczko \& Scokzowski, 2011; Lansky \& 
Newman, 2007; Yazdi \& Khorsandi, 2008), oleic acids (Lansky \& Newman, 2007), and ellagitannins (Williamson et al., 1988). These phytochemicals have putative beneficial effects on human health, including anti-inflammatory, antioxidant, and anticancer properties (Lansky \& Newman, 2007). Recent findings suggest pomegranate juice has antiviral (Sundararajan et al., 2010) and antimicrobial (Al-Zoreky, 2009) properties. The root of pomegranate has been utilized for the treatment of tapeworm by loosening the parasite from the intestinal wall (Williamson et al., 1988). Pomegranate has been a useful source of citric acid and sodium citrate (Levin, 2006). Sodium citrate extracted from pomegranates was used as a "blood stabilizer" during World War II when Leningrad was under Nazi German blockade (Levin, 2006).

Although the pomegranate is believed to be a healthy, nutritious fruit, there is evidence of allergic and other adverse reactions to pomegranate and its bioactive chemical constituents. The first reported case in the medical literature of an allergic reaction resulting from pomegranate ingestion was documented with a patient in Madrid, Spain in 1991 (Gaig et al., 1999). Other case studies have documented similar allergic reactions to pomegranate fruit, with patient demographics ranging from toddler to adult (Gaig et al., 1999). Possible pharmacological interactions resulting in adverse side effects have been reported, suggesting a possible risk to geriatric patients ingesting pomegranate juice while taking the blood-thinning drug, warfarin (Jarvis \& Bogle, 2010). A constituent in pomegranate juice is thought to have an inhibitory effect on cytochrome P450 enzymes, which function in the metabolism of warfarin (Jarvis \& Bogle, 2010). 


\subsection{Foreign and Domestic Production}

Current world production values of pomegranate are not known precisely but have been estimated at approximately 1.5 million $\mathrm{t}^{\cdot} \mathrm{yr}^{-1}$, with Iran, India, China, and the United States as the top four pomegranate producing countries, in that order (Holland \& Bar-Ya'akov, 2008). Iran produces approximately $600,000 \mathrm{t} \cdot \mathrm{yr}^{-1}$ of pomegranates on an estimated $65,000 \mathrm{ha}$. Iran is also the world's largest exporter of pomegranates, exporting approximately $60,000 \mathrm{t} \cdot \mathrm{yr}^{-1}$. India has approximately 55,000 ha of pomegranate plantings that yield approximately 500,000 $\mathrm{t} \cdot \mathrm{yr}^{-1}$ with only 22,000 t being exported. China produces 260,000 t of pomegranate fruit per year. Data regarding Chinese exportation and hectares of pomegranate production are not reported currently. The United States produces $110,000 \mathrm{t} \cdot \mathrm{yr}^{-1}$, with 17,000 t exported annually. In 2007 , there were 599 farms in the United States producing pomegranates on a total of 9,922 ha, in contrast to 369 farms with 3,859 ha of plantings in 2002 (National Agricultural Statistics Service, United States Department of Agriculture (USDA), 2007). The United States' pomegranate crop is produced almost exclusively in California (California Department of Food and Agriculture, 2013) and is valued at approximately 4.9 million dollars annually (Glozer \& Ferguson, 2008).

The majority of the United States' pomegranate production is in the cultivar Wonderful (Holland et al., 2009; Stover \& Mercure, 2007), which is considered the industry standard for the United States and Israel (Holland \& Bar-Ya'akov, 2008). 'Wonderful' is known for its fruit size, flavor, and dark red rind and juice that fit market parameters for fresh market and juice concentrate commercial applications (Stover \& Mercure, 2007). 'Wonderful' is also considered a vigorous plant that has the capacity to produce heavy yields per tree (Levin, 2006). 'Wonderful' was first cultivated in Florida and was transported to California in the 1890's for propagation and commercial production (Day \& Wilkins, 2009; Stover \& Mercure, 2007). There are many 
landraces of 'Wonderful' that are cultivated in Israel and it is still not known if those in Israel are genetically distinguishable from the 'Wonderful' originally found in the United States (Holland et al., 2009). Other cultivars grown commercially in California include Early Wonderful, Foothill, Early Foothill and Granada (Stover \& Mercure, 2007). There are nearly 200 pomegranate cultivar accessions in the USDA National Clonal Germplasm Repository (Stover \& Mercure, 2007).

\subsection{Current Commercial Use}

The primary uses for pomegranate are as fresh market fruit and valued-added products. The pomegranates typically sold for maximum value as fresh market are those that are the large and free of surface damage (Stover \& Mercure, 2007). Cultivation techniques that have been used successfully to keep the fruit rind damage-free include bagging the fruit during development (Stover \& Mercure, 2007), kaolinite foliar applications during the growing season (Weerakkody, Jobling, Infante, \& Rogers, 2010), macro- and micronutrient sprays during specific stages of fruit development (Khorsandi, Yazdi, \& Vazifehshenas, 2009; Yilmaz \& Özgüven, 2009), and plant growth regulator (PGR) applications (Yilmaz \& Özgüven, 2009).

Valued-added pomegranate products include fresh and concentrated fruit juice, mixed juices, wines, liquors, grenadine, syrup, preserves, pharmaceuticals, dyes, tanning agents, and cosmetics (Melgarejo, 2012). In the United States, the primary commercial use for pomegranate fruit in value-added products is in juice (Zhang et al., 2009). POM Wonderful ${ }^{\mathrm{TM}}$ is the primary manufacturer and supplier of pomegranate juice from concentrate in the United States (Stover \& Mercure, 2007). POM Wonderful ${ }^{\mathrm{TM}}$ juice products are produced by pressing the entire 
pomegranate fruit (Gil et al., 2000). The juice is then pasteurized and stored frozen as a concentrate for future use (Ashoush \& Gadallah, 2012).

Numerous studies have been conducted to identify bioactive compounds and quantify antioxidant activity and other putative health and nutritional benefits of pomegranate juice and/or peel (Çam et al., 2009; Fischer et al., 2011; Gil et al., 2000; Kulkarni \& Aradhya, 2005; Lansky \& Newman, 2007; Ozgen et al., 2008; Tehranifar et al., 2010; Tezcan et al., 2009; Tzulker et al., 2007). However, a recent study analyzing commercial juices labelled as $100 \%$ pomegranate juice demonstrated that some of these products contained adulterants, including added malic acid and fructose (Tezcan et al., 2009). Because the value of pomegranate juice is dependent, in part, on its perceived health benefits, researchers have developed an international multidimensional authenticity specification (IMAS) algorithm for determining pomegranate juice adulteration (Zhang et al., 2009).

\subsection{Vegetative and Reproductive Growth}

Pomegranate is typically deciduous (Holland et al., 2009), although evergreen cultivars have been reported in India (Singh \& Singh, 2004) and in greenhouse settings (Levin, 2006). It grows

naturally as a shrub, producing multiple trunks (Holland et al., 2009; Levin, 2006) and reaching heights of at least $5 \mathrm{~m}$ (Holland et al., 2009) with a tendency to sucker at the base (Holland et al., 2009; Levin, 2006). In commercial production, pomegranate is pruned to grow as a tree kept below $4 \mathrm{~m}$ in height (Holland et al., 2009) with single (Holland et al., 2009; Stover \& Mercure, 2007) or multiple trunks (Blumenfeld et al., 2000; Stover \& Mercure, 2007) with multiple scaffold branches per trunk (Holland et al., 2009). Pomegranate cultivation also benefits from 
summer pruning because of the need for full sunlight for optimum fruit quality (Glozer \& Ferguson, 2008).

New shoots produced during vegetative flushes are quadrangular, soft, and thin, with cultivardependent bark color, including green or pink with purplish striping (Holland et al., 2009). During the first year of stem growth, the periderm changes from light gray to dark gray (Holland et al., 2009). Hardened-off shoots commonly develop multiple thorns, especially at the terminal end of shoots, often in the same nodes as flowers (Holland et al., 2009), though some pomegranate cultivars develop few or no thorns (Levin, 2006).

Pomegranate has simple, elongate leaves described as either lanceolate (Levin, 2006) or oblanceolate (Holland et al., 2009) with entire leaf margins. The leaf blade is typically red at emergence, becoming green when fully expanded (Levin, 2006), and the leaf surface is glabrous (Holland et al., 2009). Typically, the petiole is bright red and has an indentation extending along its adaxial surface (Levin, 2006), though petiole color and shape are cultivar-dependent (Holland et al., 2009). The number of leaves per node is also cultivar-dependent (Holland et al., 2009). On long shoots (dolichoblasts), leaf arrangement is opposite and on shorter shoots (brachyblasts), leaves grow in bundles or rosettes (Levin, 2006).

Pomegranate is precocious as compared to other tree fruit crops (Holland et al., 2009), with a juvenile phase of only 1-2 yr (Holland et al., 2009; Levin, 2006). Fruit with adequate quality with respect to size, color, and flavor are produced 2-3 yr after planting and commercial production levels are reached within 5-6 yr (Stover \& Mercure, 2007).

Flowers develop on spurs and short branches and form singularly or in clusters (Holland et al., 2009). The flowers are either near-sessile or have a very short pedicel (Levin, 2006). Flowering 
of pomegranate occurs on branches produced in the same year (Holland et al., 2009), approximately one month following bud break, which in the Northern Hemisphere generally occurs during April or May (Holland et al., 2009; Levin, 2006), though in some climates, such as in the San Joaquin Valley of California, bud break often occurs later in the year (Stover \& Mercure, 2007). Flowering can continue throughout the summer, though in cultivars with long bloom periods, fruit mature at different times (Glozer \& Ferguson, 2008). Flowers reaching anthesis late in the season do not result in harvestable fruit because the number of degree days occurring prior to plant dormancy is insufficient for fruit maturation (Holland et al., 2009).

Each flower typically has an inferior ovary, a corolla with five to eight petals, and a calyx with five to seven orange to red, thick lobes that are smooth and triangular in shape (Levin, 2006). The corolla and calyx of pomegranate flowers are pink, white, orange, or red (Glozer \& Ferguson, 2008) or are variegated (Stover \& Mercure, 2007). Pomegranate is heterostylous, with as many as three flower types, including male, hermaphroditic, and intermediate (Chaudhari \& Desai, 1993; Holland et al., 2009). Male flowers, which are bell-shaped (Levin, 2006), contain both male and female plant parts (Wetzstein, Ravid, Wilkins, \& Martinelli, 2011a) but are considered functionally male because they have underdeveloped female parts including atrophied ovaries and a developmentally flawed or nonexistent pistil (Holland et al., 2009; Levin, 2006). Hermaphroditic flowers are vase-shaped and are responsible for the majority of fruit production due to the presence of fully functional male and female reproductive organs (Wetzstein et al., 2011a). Intermediate flowers are capable of setting fruit and are characterized by a developed ovary but a shorter style than those of hermaphroditic flowers (Holland et al., 2009). Other studies describe only two flower types, hermaphroditic and functionally male (Holland et al., 2009; Levin, 2006; Mars, 2000; Wetzstein et al., 2011a). Pomegranate flowering is, therefore, 
described as functionally andromonoecious because both hermaphroditic and functionally staminate flowers are produced on the same plant (Wetzstein et al., 2011a).

The bloom of pomegranate is protracted, typically lasting approximately 1 month (Holland et al., 2009) to 3 months (Glozer \& Ferguson, 2008), with three temporal waves of flowering (Holland et al., 2009). The stigmas are receptive for 2-3 d (Stover \& Mercure, 2007). Insect pollinators, primarily the European honeybee (Apis mellifera), are required by some cultivars for successful pollination (Glozer \& Ferguson, 2008). Pomegranate is considered self-fruitful (Glozer \& Ferguson, 2008) and, therefore, does not require pollinizer trees for successful fruit set. Fruit set, yield, and crop productivity of pomegranate trees are dependent, in part, on the number of hermaphroditic flowers produced during bloom (Holland et al., 2009), the ratio of hermaphroditic and intermediate flowers to male flowers (Wetzstein, Zhang, Ravid, \& Wetzstein, 2011b), and the percentage of flowers that senesce without setting fruit, which is typically 70-90\% (Levin, 2006).

The pomegranate is considered a fleshy (Holland et al., 2009) berry (Kader, 2006) or berry-like (Levin, 2006) fruit and has a leathery exocarp, also referred to as the rind (Stover \& Mercure, 2007), that is red, green, yellow, brown, or black at maturity (Levin, 2006). Mature fruit have a spherical/globular shape with a crown-like calyx at the blossom end (Holland et al., 2009). After successful fertilization, sepal color changes from orange-red to green and as the fruit develops, exocarp color slowly changes from green to the color characteristic of that particular cultivar at maturity (Holland et al., 2009). It takes five to eight months from anthesis for a pomegranate fruit to mature (Holland et al., 2009) and fruit growth is characterized by a sigmoid growth curve (Varasteh, Arzani, Zamani, \& Tabatabaei, 2008). The locules are separated by yellowish-white septa, membranous walls of fleshy mesocarp (Stover \& Mercure, 2007), asymmetrically 
distributed inside the fruit (Holland et al., 2009). The septa are inedible (Glozer \& Ferguson, 2008). The locules contain the fruits' edible seeds (Levin, 2006) and there are typically more locules at the stem end than in the blossom end of the fruit (Holland et al., 2009). Each seed is surrounded by a fleshy seed coat (Holland et al., 2009; Stover \& Mercure, 2007) referred to as a sarcotesta (Levin, 2006) or aril. The flavor and color of the arils are cultivar-dependent, ranging from sour to sweet and white to deep purple, respectively (Levin, 2006). The hardness of the seeds, amount of juice contained in the arils, and aril size are also cultivar-dependent (Holland et al., 2009). A large pomegranate fruit can contain up to 1300 seeds (Levin, 2006). At maturity, pomegranate fruit are typically $3.5-6.5 \mathrm{~cm}$ in diameter with a mass of at least $30 \mathrm{~g}$ (Levin, 2006), although commercially-valuable pomegranates typically weigh more than $400 \mathrm{~g}$ (Blumenfeld et al., 2000). Studies have demonstrated a large variation in mature fruit size within commercial orchards. Wetzstein et al. (2011b) reported a greater than five-fold variance in mature fruit volume and mass. Factors that influence fruit size and/or yield include aril number (Wetzstein et al., 2011b), cultivar (Levin, 2006), plant maturity, and cultural practices (Glozer \& Ferguson, 2008).

\subsection{Cultural Practices}

Pomegranate cultivation is best suited for arid, Mediterranean climates (Stover \& Mercure, 2007) with hot summers and mild winters (Levin, 2006) that remain frost-free until the harvest season is complete (Glozer \& Ferguson, 2008). The tree is frost-hardy, surviving temperatures as low as $-12{ }^{\circ} \mathrm{C}$ (Levin, 2006; Westwood, 1988). Pomegranate is also tolerant of temperatures as high as $44^{\circ} \mathrm{C}$ (Westwood, 1988). 
Typical tree spacing for a mature pomegranate orchard is $4 \mathrm{~m} \times 6 \mathrm{~m}$ (in-row spacing by betweenrow spacing, respectively) to ensure that trees get the minimum 6-8 hrs of full sun (Glozer \& Ferguson, 2008) required for optimum crop production (Blumenfeld et al., 2000). Tree spacing also varies based on cultivation equipment and practices, with in-row spacing ranging from 3.6$5.8 \mathrm{~m}$ and drive-row spacing ranging from 1.5-5.2 m (Day \& Wilkins, 2009).

Pomegranate can be grown successfully on a wide array of soil types (Blumenfeld et al., 2000). Pomegranate is also considered moderately salt-tolerant (Blumenfeld et al., 2000; Holland et al., 2009), with the yields of certain cultivars unaffected by soil electrical conductivity as high as 4 $\mathrm{dS} \cdot \mathrm{m}^{-1}$ (Holland et al., 2009).

Although there are pomegranate growers that fertilize pomegranate trees with rotted animal manure (Blumenfeld et al., 2000), most apply inorganic fertilizer by broadcast application (Glozer \& Ferguson, 2008) or fertigation (Blumenfeld et al., 2000). There is limited published evidence of grower use of foliar nutrient applications as a standard conventional cultural practice. Fertilization requirements for specific nutrients are not entirely understood for pomegranate because scientific literature on this subject is limited (Holland et al., 2009), but some studies have been conducted on nitrogen $(\mathrm{N})$, phosphorous $(\mathrm{P})$, potassium $(\mathrm{K})$, and zinc (Zn) requirements.

Reported $\mathrm{N}$ requirements for pomegranate are $0.2 \mathrm{~kg}$ (Stover \& Mercure, 2007) to $0.625 \mathrm{~kg}$ (Firake \& Deolankar, 2000) of N per tree per year. N fertilizer applications are made all at once, in split applications (Glozer \& Ferguson, 2008), or in multiple applications throughout the growing season, with the last application two weeks before harvest (Holland et al., 2009). $\mathrm{N}$ is 
applied as urea $\left(\mathrm{CO}\left(\mathrm{NH}_{2}\right)_{2}\right)$, ammonium nitrate $\left(\mathrm{NH}_{4} \mathrm{NO}_{3}\right)$, and/or ammonium sulfate $\left(\mathrm{NH}_{4}\right)_{2} \mathrm{SO}_{4}$ (Glozer \& Ferguson, 2008).

$\mathrm{P}$ is applied as phosphorus pentoxide $\left(\mathrm{P}_{2} \mathrm{O}_{5}\right)$ or phosphoric acid $\left(\mathrm{H}_{3} \mathrm{PO}_{4}\right)$, typically in split applications (Holland et al., 2009). The recommended annual dose is $250 \mathrm{~g}$ of $\mathrm{P}$ per plant applied as $\mathrm{P}_{2} \mathrm{O}_{5}$, although $75 \%$ of this recommended dose results in yields that are not significantly different from those receiving the full recommended dose (Firake \& Deolankar, 2000). It has also been reported that applications of $\mathrm{P}$ do not increase commercial pomegranate yields significantly (Glozer \& Ferguson, 2008).

K requirements for pomegranate are not fully understood (Khayyat et al., 2012), with some studies suggesting that the kilograms of $\mathrm{K}$ applied should be the same as (Blumenfeld et al., 2000) or similar to (Stover \& Mercure, 2007) the kilograms of N applied each season. Firake \& Deolankar (2000) reported that the regional recommended K fertilizer program in a pomegranate growing region of India is $250 \mathrm{~g} \mathrm{~K}$ per plant per season applied via fertigation. However, the authors found that applications of $187.5 \mathrm{~g} \mathrm{~K}$ per plant (75\% of the recommended dose) resulted in similar in yields that were not significantly different from those obtained when $250 \mathrm{~g} \mathrm{~K}$ per plant was applied. Maximum yield was attained when micronutrients were included by fertigation with $250 \mathrm{~g} \mathrm{~K}$ per plant. Khayyat et al. (2012) reported that foliar applications of 250 $\mathrm{mg} \cdot \mathrm{L}^{-1}$ of potassium nitrate $\left(\mathrm{KNO}_{3}\right)$ applied in August when fruit were $30 \mathrm{~mm}$ in diameter increased fruit diameter, fruit length, juice volume, and juice weight of 'Malas Yazdi' pomegranate fruit as compared to those from control trees sprayed with distilled water.

$\mathrm{Zn}$ deficiency of pomegranate, which is characterized by leaf chlorosis and delayed vegetative and reproductive flushing, is corrected with foliar applications of zinc sulfate $\left(\mathrm{ZnSO}_{4}\right)$ in spring 
and/or summer (Glozer \& Ferguson, 2008; Stover \& Mercure, 2007) or branch applications during winter dormancy (Glozer \& Ferguson, 2008). Foliar application of $\mathrm{Zn}$ has been shown to improve marketable yield of pomegranate, even in trees not displaying $\mathrm{Zn}$ deficiency symptoms (Afria, Pareek, Garg, \& Singh, 1999; Khorsandi et al., 2009).

Pomegranate is a crop that requires frequent irrigation during plant establishment (Stover \& Mercure, 2007). Additionally, proper irrigation is necessary for maximum fruit set, yield, and quality (Holland et al., 2009; Glozer \& Ferguson, 2008; Stover \& Mercure, 2007) and to promote return bloom (Glozer \& Ferguson, 2008). Historically, pomegranate has been furrow irrigated and this practice still takes place in some commercial growing regions, including Turkey and Afghanistan (Glozer \& Ferguson, 2008). Currently, pomegranate groves are typically irrigated via one or two lines of drip tubing per tree row or by microsprinklers (Blumenfeld et al., 2000). Irrigation requirements for pomegranate vary with time of year (Blumenfeld et al., 2000; Glozer \& Ferguson, 2008), climate (Blumenfeld et al., 2000), and soil structure (Glozer \& Ferguson, 2008). Irrigation of pomegranate does not take place in the winter months because it increases the number of non-fruitful shoots produced in spring (Blumenfeld et al., 2000; Glozer \& Ferguson, 2008). With respect to frequency, reported grower practices include irrigation daily (Holland et al., 2009), more than once a week (Blumenfeld et al., 2000), and less than once a week (Glozer \& Ferguson, 2008). For growers in Afghanistan, Glozer \& Ferguson (2008) recommended that trees be irrigated when approximately $50 \%$ of the moisture is depleted from the soil, which is equivalent to approximately $15 \mathrm{~m}^{3} \cdot \mathrm{ha}^{-1} \cdot \mathrm{d}^{-1}$ during the spring and $50 \mathrm{~m}^{3} \cdot \mathrm{ha}^{-1} \cdot \mathrm{d}^{-1}$ during the summer, for a total of $6000 \mathrm{~m}^{3} \cdot \mathrm{ha}^{-1}$ of water applied yearly via irrigation. Holland et al. (2009) reported similar irrigation requirements for Israeli pomegranate groves, with 5000$6000 \mathrm{~m}^{3} \cdot \mathrm{ha}^{-1}$ of water needed by irrigation during each growing season. 


\subsection{Factors Affecting External Fruit Quality}

External quality of pomegranate fruit can be affected by multiple factors. Biotic sources of fruit scarring include thrips, mealy bugs, flat mites (Holland et al., 2009), fruit borers (Mars, 2000), leaf rollers (Stover \& Mercure, 2007), and birds. The rind can also be damaged as a result of abiotic factors including wind, which causes thorns to rub against the fruit (Stover \& Mercure, 2007), and sun exposure, which can result in sunscald if rind temperatures become high (Glozer \& Ferguson, 2008; Stover \& Mercure, 2007). Sunscald, which is also referred to as sunburn (Holland et al., 2009), can result in up to 30\% loss in yield (Melgarejo et al., 2004). Fruit split, also referred to as cracking (Yilmaz \& Özgüven, 2006), is the rupturing of the rind and is the physiological disorder responsible for the greatest losses of pomegranate fresh market yields (Blumenfeld et al., 2000).

Pomegranate fruit split typically occurs during the final stages of fruit development (El-Rhman, 2010) although some pomegranate cultivars have a tendency to split before fruit maturity (Holland et al., 2009). However, the causes of fruit split of pomegranate are not well understood. Factors affecting the incidence of fruit split include timing of flower development and harvest, cultivar, plant and soil water content, and leaf nutrient concentration. Additionally, applications of PGRs and foliar nutrients are known to affect the incidence of fruit split.

Flowers produced 4-5 weeks later than the initial bloom produce fruit that are less susceptible to split than fruit produced from flowers produced early in the season (Glozer \& Ferguson, 2008). Singh \& Kingsly (2007) reported that removing the entire first cohort of flowers from 'Mridula' pomegranate trees significantly reduced the incidence of split as compared to the control (no flower removal), with split rates of $0.73 \%$ and $35.16 \%$, respectively. 
Incidence of fruit split varies greatly among pomegranate cultivars (Hepaksoy, Aksoy, Can, \& Ui, 2000; Levin, 2006). For example, in a study of common, commercially-grown, Turkish cultivars, Lefon was described as resistant to fruit split because it had a statistically significantly lower incidence of split (10.28\%) as compared to the cultivars with the highest rates of fruit split in the study, Siyah (19.04\%) and Koycegiz (24.54\%) (Hepaksoy et al., 2000). Lefeng et al. (2010) described pomegranate cultivars with split rates of $27.6 \%$ or higher as having a high incidence of split and cultivars with split rates of $2.3 \%$ and below as having a low incidence of split.

Soil and plant water content are also associated with pomegranate fruit split incidence. In growing locations with heavy rainfall before harvest, incidence of fruit split is higher than in areas that do not receive rainfall just prior to harvest (Holland et al., 2009). Irregular irrigation is also associated with increased incidence of fruit split (Glozer \& Ferguson, 2008). El-Rhman (2010) reported that controlled irrigation (irrigating every $2 \mathrm{~d}$ ) significantly reduced incidence of pomegranate fruit split. Hepaksoy et al. (2000) found that split-resistant pomegranate cultivars had higher water use efficiency than those that were split-susceptible. They also reported that there was a negative correlation between fruit split and water use efficiency $(r=-0.428)$ and a positive correlation between fruit split and transpiration rates $(\mathrm{r}=0.513)$. A positive relationship between transpiration rate and fruit split incidence is further supported by the fact that the antitranspirant, pinolene, applied foliarly as a $5 \%$ solution to 'Banati' and 'Manfaluti' pomegranate 4-5 weeks prior to harvest, reduced fruit split incidence by approximately 1.5-2 times as compared to untreated controls (Bacha \& Ibrahim, 1979).

Relationships have been detected between plant water status, leaf nutrient concentration, and incidence of pomegranate fruit split (Hepaksoy et al., 2000). Leaf succulence is the difference 
between leaf fresh and dry weight divided by leaf area. In a study of several pomegranate cultivars, leaf $\mathrm{N}$ concentrations were negatively correlated with leaf succulence $(\mathrm{r}=-0.407)$ and positively correlated with the ratio of unsplit to split fruit $(\mathrm{r}=0.475)$. The ratio of leaf $\mathrm{Ca}$ concentration to leaf $\mathrm{K}$ concentration was found to be negatively correlated with leaf succulence $(\mathrm{r}=-0.420)$. Leaf $\mathrm{K}$ concentration divided by leaf $\mathrm{Ca}$ concentration, plus leaf $\mathrm{Mg}$ concentration was also positively correlated with leaf succulence $(r=0.404)$. However, no significant relationships between these ratios and fruit split were reported.

Foliar PGR applications have been shown to mitigate pomegranate fruit split. Yilmaz \& Özgüven (2009) reported that foliar applications of $100 \mathrm{mg} \cdot \mathrm{L}^{-1}, 150 \mathrm{mg} \cdot \mathrm{L}^{-1}$, or $200 \mathrm{mg} \cdot \mathrm{L}^{-1} \mathrm{GA}_{3}$ in August and September reduced fruit split rates of 'Hicaz' and 'Silifke' pomegranates to approximately $1 \%$ as compared to untreated controls, which had fruit split rates of $19 \%$ and $25 \%$ for 'Hicaz' and $4.7 \%$ and $7 \%$ for 'Silifke' in two separate seasons. The anti-GA, (2RS, 3RS)-1(4-chlorophenyl)-4, 4-dimethyl-2-(1H-1,2,4 triazol-1-yl) pentan-3-ol (paclobutrazol), applied foliarly at a rate of $150 \mathrm{mg} \cdot \mathrm{L}^{-1}$ to Manfaluty, the most commercially important cultivar grown in Egypt, resulted in a statistically significant reduction in fruit split as compared to untreated controls, with paclobutrazol-sprayed trees having $26.5 \%$ and $24.1 \%$ split in two consecutive seasons and control trees having $41.04 \%$ and $37.9 \%$ split in those same two seasons, respectively (El-Khawaga, 2007). The author hypothesized that paclobutrazol reduced cell division during stage one of fruit development, resulting in enhanced cell enlargement in stage two of fruit development.

Foliar nutrient applications have also been used experimentally to mitigate pomegranate fruit split. Foliar applications of $1 \% \mathrm{ZnSO}_{4}$ significantly decreased fruit split incidence of 'Manfaluty' pomegranate as compared to controls and when used in combination with controlled 
irrigation, decreased fruit split incidence by nearly $50 \%$ as compared to controls (El-Rhman, 2010). Foliar applications of $1 \%$ magnesium sulfate $\left(\mathrm{MgSO}_{4}\right), 1 \% \mathrm{KNO}_{3}, 0.005 \%$ boric acid $\left(\mathrm{H}_{3} \mathrm{BO}_{3}\right)$, or $0.002 \% \mathrm{H}_{3} \mathrm{BO}_{3}$ resulted in significantly lower incidence of fruit split of 'Kandhari' and 'Beedana' pomegranate (Singh, Sharma, \& Awasthi, 1993). Untreated control trees had mean fruit split rates of $41 \%$, whereas mean split rates of $14.05 \%, 16.75 \%, 8 \%$, and $11.5 \%$ were obtained with the $\mathrm{KNO}_{3}, \mathrm{MgSO}_{4}$, and $0.005 \%$ and $0.002 \% \mathrm{H}_{3} \mathrm{BO}_{3}$ treatments, respectively (Singh et al., 1993). The authors hypothesized that these nutrient sprays increased the elasticity and cell wall permeability of the rind.

\subsection{Harvest and Postharvest Requirements for Pomegranate}

Pomegranate fruit are usually harvested manually by labor crews using harvesting shears (Muñoz, 2000). However, some growers snap pick to prevent the rigid pedicel from damaging the rind of other fruit (Glozer \& Ferguson, 2008), as fruit sold in fresh market should have no external scarring or blemishing (Stover \& Mercure, 2007). Additional care must be taken to avoid calyx crown damage, which would also reduce fruit market value (Muñoz, 2000).

Highest market values are obtained from cultivars with fruit that are red or pink and large (Glozer \& Ferguson, 2008) to medium in size (Mars, 2000) at maturity, harvested early-in the season, and/or have small, soft seeds (Glozer \& Ferguson, 2008). Pomegranate fruit are nonclimacteric, with optimum storage conditions of $5^{\circ} \mathrm{C}$ for 8 weeks, though they can be stored for up to three months with little effect on total soluble solids (TSS), pH, and titratable acidity (TA) (Elyatem \& Kader, 1984). 


\subsection{TA, Sugar, and Mineral Nutrient Concentration of Mature Pomegranate Fruit}

Pomegranate fruit are harvested based upon a variety of parameters, including TA (Stover \& Mercure, 2007), color, and TSS (Muñoz, 2000). Pomegranate juice TA decreases throughout fruit development (Fawole \& Opara, 2013) and TA of the juice of mature pomegranate fruit ranges from $0.35-3.36 \mathrm{wt} \cdot \mathrm{vol}^{-1}$ citric acid (Akbarpour, Hemmati, \& Sharifani, 2009). Minimum maturity guidelines established in California require that total TA be less than $1.85 \mathrm{wt} \cdot \mathrm{vol}^{-1} \mathrm{citric}$ acid and the color of the juice be darker than an established reference (Kader, 2006). Sugar concentration increases throughout fruit development (Fawole \& Opara, 2013) and in the juice of mature pomegranate fruit, the sugar concentration is highly variable, ranging from $8-21.9 \%$ TSS and $0.0-3.4 \%$ sucrose (Levin, 2006).

There is limited peer-reviewed literature regarding the mineral nutrient concentration of pomegranate fruit. In a study of 'Malas Yazdi' pomegranates in Iran, Mirdehghan \& Rahemi (2007) reported that nutrient concentrations varied with the part of the fruit tested and the stage of development of the fruit. Fruit micronutrient and macronutrient concentrations typically increased throughout fruit development, with most of the $\mathrm{Ca}$ accumulation in the peel occurring early in fruit development. Concentrations of $\mathrm{Ca}$ and $\mathrm{Na}$ in the peel were higher than that in the arils, but concentrations of $\mathrm{N}, \mathrm{P}, \mathrm{K}$, and $\mathrm{Mg}$ were higher in the arils than in the peel. Fawole \& Opara (2013) reported that for 'Ruby' pomegranates, $\mathrm{N}$ and $\mathrm{K}$ were the in the highest concentration in the arils, and that $\mathrm{N}, \mathrm{P}, \mathrm{Ca}, \mathrm{Mg}$ and $\mathrm{B}$ concentration of the arils significantly decreased between $54 \mathrm{~d}$ and $139 \mathrm{~d}$ after bloom. Fawole \& Opara (2013) also reported K, Fe, Mn, and $\mathrm{Zn}$ concentration in the aril tissues did not change significantly. Further studies of cultivarspecific pomegranate fruit nutrient concentrations are needed in order to fully understand this fruit's potential nutritional value. 


\subsection{Antioxidant Activity and Phenolic Content of Pomegranate Fruit and Juice}

Molyneux (2004) observed an increased interest in research regarding antioxidants and their presumed ability to prevent or reduce the deleterious effects of oxidizing free-radicals in the human body. Research suggests that pomegranate juice has higher levels of antioxidant activity than many other beverages known to be high in antioxidant activity, including red wine and green tea (Gil et al., 2000). Antioxidant activity can be measured by spectrophotometric analysis of the ability of a substance to inhibit, neutralize, or quench an oxidizing chemical compound such as 2,2-azino-bis-3-ethylbenzothiazoline-6-sulfonoic acid (ABTS), ferric-tripyridyltriazine (Fe ${ }^{3+-}$ TPTZ), and 2,2'-diphenyl-1-picrylhydrazyl (DPPH) (Gil et al., 2000). DPPH is typically the compound used to measure antioxidant in pomegranate. DPPH is a stable free-radical molecule, characterized by the delocalization of an electron throughout the aromatic rings of the molecule, thus allowing it to stay in a free-radical state until a substance donates an electron (He et al., 2011), a hydrogen atom, or a hydrogen radical to reduce it (Molyneux, 2004). The DPPH method was developed by Blois (1958) and adapted to modern laboratory methods by BrandWilliams, Cuvelier, \& Berset (1995) and is efficacious for the quantification of antioxidant activity of fruit and juices, including those of pomegranate (Gil et al., 2000; Ozgen, Durgaç, Serçe, \& Kaya, 2008; Tehranifar, Zarei, Nemati, Esfandiyari, \& Vazifeshenas, 2010; Tezcan et al., 2009). A sample of juice is diluted with methanol and water and then mixed with a solution of DPPH dissolved in ethanol or methanol and left to incubate in the dark (Molyneux, 2004). The absorbance is then measured at $517 \mathrm{~nm}$ and antioxidant activity is expressed as a percentage of the control, which does not contain juice (Çam, Hış1l, \& Durmaz, 2009; Gil et al., 2000; Tehranifar et al., 2010). 
The antioxidants identified in pomegranates include ascorbic acid and three known groups of polyphenolic compounds: anthocyanins, ellagic acid and its derivatives, and hydrolyzable tannins. The amount of ascorbic acid in pomegranate fruit varies greatly, with concentrations of 1.50-28.19 mg $100 \mathrm{~g}^{-1}$ of fruit, and the concentration decreases as the fruit ripens (Levin, 2006). The antioxidant activity of the ascorbic acid of pomegranate juice has not been investigated. The polyphenolic content of pomegranate juice is also variable, though pressing the entire pomegranate fruit maximizes the polyphenolic content of the resulting juice (Gil et al., 2000). Anthocyanins, part of the flavonoid family, are found in fruit and flowers of pomegranate and are responsible for their blue, orange, and red colors (Wang, Cao, \& Prior, 1997). Six anthocyanin pigments are responsible for the red to purple color of pomegranate juice (Zhang et al., 2009). The anthocyanins identified in pomegranate fruit are known to have antioxidant activity (Tehranifar et al., 2010; Wang et al., 1997). For example, utilizing high performance liquid chromatography (HPLC), the anthocyanins, delphinidin 3,5-diglucoside, cyanidin 3,5diglucoside, delphinidin 3-glucoside, cyanidin 3-glucoside, and pelargonidin 3-glucoside, were found in concentrations of $42.9,53.0,76.0,128.3$, and $5.9 \mathrm{mg} \cdot \mathrm{L}^{-1}$, respectively in juice prepared from pomegranate arils (Gil et al., 2000). In comparison, 'Pinot Noir' wine grapes were found to have $62.5-105.6 \mathrm{mg} \cdot \mathrm{L}^{-1}$ of delphinidin 3,5-diglucoside in their juice and 21.1-24.1 $\mathrm{mg} \cdot \mathrm{L}^{-1}$ cyanidin 3-glucoside concentrations in their peel extract (Mazza, Fukumoto, Delaquis, Girard, \& Ewert, 1999). Fischer, Carle, \& Kammerer (2011) reported a previously undiscovered anthocyanin, cyanidin-pentoside, in pomegranate juice and suggested that the pigment profile of pomegranate juice may not be fully elucidated. The $\mathrm{pH}$ differential method developed by Giusti \& Wrolstad (2001) utilizes spectrophotometry at a prescribed wavelength to measure anthocyanin quantity in pomegranate using cyanidin 3-glucoside as a standard for quantification 
of total anthocyanins, with total anthocyanins expressed as milligrams of cyanidin 3-glucoside per $100 \mathrm{~g}$ of juice (Tehranifar et al., 2010) or milligrams of cyanidin 3-glucoside per $1 \mathrm{~L}$ of juice (Çam et al., 2009; Ozgen et al., 2008; Tehranifar et al., 2010; Tzulker et al., 2007). Using this method, total anthocyanin content in pomegranate has been reported as low as $55.6 \mathrm{mg} \cdot \mathrm{L}^{-1}$ (Tehranifar et al., 2010) and as high as $369 \mathrm{mg} \cdot \mathrm{L}^{-1}$ (Çam et al., 2009). These anthocyanin concentrations are similar in magnitude to those found in raspberry, sour cherry, sweet cherry, and strawberry $\left(217.39,369.36,256.60\right.$, and $205.98 \mathrm{mg} \cdot \mathrm{L}^{-1}$, respectively), in contrast to the much higher concentrations found in black currant, blackberry, chokeberry, and elderberry (1543.89, 739.93, 3042.20, and 4188.63 $\mathrm{mg} \cdot \mathrm{L}^{-1}$, respectively) (Jakobek, Šeruga, Jovanović, \& Medvidović-Kosanović, 2007).

Pomegranate fruit also contain isomers and fragments of the ellagitannin, punicalagin (2,3hexahydroxy-diphenoyl-4,6-gallagylglucose), including ellagic acid, gallagic acid, dimethylellagic acid glucuronide, urolithin A, urolithin $\mathrm{B}$, and punicalin, which have been identified and quantified utilizing HPLC (Gil et al., 2000; Seeram et al., 2006). When ellagitannins are hydrolyzed, hexahydroxydiphenic acid (HHDP) is formed and then lactonized spontaneously, resulting in ellagic acid (Häkkinen, Kärenlampi, Mykkänen, Heinonen, \& Törrönen, 2000). In aril-pressed 'Wonderful' pomegranate juice, concentrations of ellagic acid and ellagic acid glucoside were $15.3 \mathrm{mg} \cdot \mathrm{L}^{-1}$ and $17.9 \mathrm{mg} \cdot \mathrm{L}^{-1}$, respectively (Gil et al., 2000). Ellagic acid antioxidant activity was detected and quantified by ultraviolet (UV) detection and HPLC and derivatives of ellagic acid, including ellagic acid glucoside, ellagic acid pentoside, and ellagic acid rhamnoside, were identified in the juice. The contribution of these compounds to pomegranate juice's antioxidant activity has not been investigated. 
Hydrolyzable tannins include both ellagitannins and gallotannins, though ellagitannins make up the majority of the hydrolyzable tannins found in pomegranate fruit (Gil et al., 2000). Hydrolyzable tannins have been identified and quantified via HPLC in aril-pressed 'Wonderful' pomegranate juice and were found to have a total concentration of $539.2 \mathrm{mg} \cdot \mathrm{L}^{-1}$ (Gil et al., 2000). Past research has indicated that hydrolyzable tannins are 15-30 times more effective than simple phenols at quenching peroxyl, a free-radical oxidizing molecule (Hagerman et al., 1998) that is the most commonplace free radical in humans (Wang, 2006). The juice is rich in ellagitannins, which give pomegranate fruit $90 \%$ of its antioxidant capacity (Gil et al., 2000) and astringent properties (Williamson et al., 1988). Of the ellagitannins, punicalagins were found to have an antioxidant activity sevenfold higher than anthocyanins and almost twentyfold higher than ellagic acid (Gil et al., 2000).

In addition to the abovementioned methods utilized to identify and/or quantify individual phenolic compounds, total phenolics can be measured by thin-layer chromatography (TLC) (Fernandez de Simon, Perez-Ilzarbe, Hernandez, Gomez-Cordoves, \& Estrella, 1992) and HPLC (Akbarpour et al., 2009; Gil et al., 2000). The current method primarily utilized to determine total phenolics in pomegranate juice is the spectrophotometric Folin-Ciocalteu method (Gil et al., 2000; Kulkarni \& Aradhya, 2005; Ozgen, et al., 2008; Tehranifar et al., 2010; Tezcan et al., 2009; Waterhouse, 2001). This method was based upon early research of Folin \& Denis (1912), whose protocol was later modified by other researchers to increase accuracy (Singleton \& Rossi, 1965), simplicity, and speed (Singleton, Orthofer, \& Lamuela-Raventós, 1999). The FolinCiocalteu method can be used with a variety of standards, but the one typically chosen is gallic acid, a naturally-occurring phenolic acid (Singleton \& Rossi, 1965; Waterhouse, 2001). Gil et al. 
(2000) reported that total phenolics measured in pomegranate juice are similar when using the HPLC and Folin-Ciocalteu methods, at $2500 \mathrm{mg} \cdot \mathrm{L}^{-1}$ and $2566 \mathrm{mg} \cdot \mathrm{L}^{-1}$, respectively.

1.11 Factors Affecting TA, Sugar, Mineral Nutrient Concentration, Antioxidant Activity, and Phenolic Content of Mature Pomegranate Fruit

Limited peer-reviewed evidence exists regarding the factors that affect TA, sugar, mineral nutrient concentration, antioxidant activity, and phenolic content of mature pomegranate fruit. TA of the juice of mature pomegranate fruit is cultivar-dependent (Akbarpour et al., 2009). Sugar concentration varies with climate, cultivar, and even among fruits produced from the same plant (Levin, 2006). Sugar concentration also varies significantly by harvest date, with lateharvested fruit having higher sugar concentration than early-harvested fruit (Fawole \& Opara, 2013). Hasani, Zamani, Savaghebi, \& Fatahi (2012) reported that foliar applications of $\mathrm{ZnSO}_{4}$ $(0.3 \%$ or $0.6 \%)$ or $\mathrm{MnSO}_{4}(0.3 \%$ or $0.6 \%)$, alone or in combination, significantly increased juice TSS as compared to controls treated with water but did not significantly affect fruit yield or diameter. In a study of six Turkish pomegranate cultivars (Lefon, Kadi, Feyiz, Seedless, Siyah, and Koycegiz), Hepaksoy et al. (2000) reported that aril pulp N and K concentrations and peel $\mathrm{Ca}$ concentrations were cultivar-dependent, but no other fruit macronutrient concentrations in the aril pulp or peel were reported to be cultivar-dependent.

Several studies have demonstrated that antioxidant activity and total phenolics of pomegranate fruit are cultivar-dependent (Akbarpour et al., 2009; Borochov-Neori et al., 2009; Tehranifar et al., 2010). Harvest date can also affect pomegranate fruit antioxidant activity. In 'Ruby' pomegranate fruit, antioxidant activity was significantly lower in fruit harvested 132 days after full bloom as compared to 139 days after full bloom (Fawole \& Opara, 2013). Borochov-Neori 
et al. (2009) found that later-harvested fruit from the cultivars, Wonderful 2, Adom, and Rosh Hapered 1, exhibited higher antioxidant activity than earlier-harvested fruit of those same cultivars, though the antioxidant activity of other cultivars tested was not affected by harvest date. Khayyat et al. (2012) reported that foliar applications of $\mathrm{KNO}_{3}$ applied during early fruit development increased ascorbic acid concentration of mature 'Malas Yazdi' pomegranate fruit as compared to those from control trees sprayed with distilled water. Fawole \& Opara (2013) found that total phenolics of 'Ruby' pomegranate increased during the final stages of fruit development (82 to 139 days after full bloom). Furthermore, Borochov-Neori et al. (2009) reported that antioxidant activity and total phenolics of pomegranate were positively linearly correlated. Little else is known about factors affecting TA, sugar concentration, mineral nutrient concentrations, antioxidant content, and total phenolics of mature pomegranate fruit.

The first objective of this study was to assess the effects of foliar applications of $\mathrm{ZnSO}_{4}, \mathrm{MgSO}_{4}$, or $\mathrm{KNO}_{3}$ on 'Wonderful' pomegranate fruit split and to determine the effects of these foliar nutrient applications on pomegranate yield parameters and leaf nutrient concentrations. The second objective of this study was to quantify fruit sugar concentration, TA, antioxidant activity, total phenolics, and fruit nutrient concentration of 'Wonderful' pomegranate fruit, and to determine the effects of foliar applications of $\mathrm{ZnSO}_{4}, \mathrm{MgSO}_{4}$, or $\mathrm{KNO}_{3}$ on these key internal fruit quality parameters. 
Chapter 2: The Effects of Foliar Nutrient Applications on Fruit Split, Yield and Leaf Nutrient Concentration of 'Wonderful' Pomegranate (Punica granatum L.)

\subsection{Introduction}

Current worldwide production of pomegranate is not known precisely but has been estimated at approximately 3 million $t^{\cdot} \cdot \mathrm{rr}^{-1}$ with 300,000 ha in production (Hernández, Legua, MelgarejoSánchez, \& Martinez Font, 2012); the total value of the crop is unknown. The majority of the United States' pomegranate production is in the cultivar Wonderful (Holland, Hatib, \& BarYa'akov, 2009; Stover \& Mercure, 2007), which is considered the industry standard for the United States and Israel (Holland \& Bar-Ya'akov, 2008).

Fruit split, also referred to as cracking (Yilmaz \& Özgüven, 2009), is the rupturing of the rind and is the physiological disorder responsible for the greatest losses of pomegranate fresh market yields (Blumenfeld, Shaya, \& Hillel, 2000). Fruit split typically occurs during the final stages of fruit development (El-Rhman, 2010) although some pomegranate cultivars have a tendency to split before fruit maturity (Holland et al., 2009). However, the causes of fruit split of pomegranate are not well understood. Factors affecting the incidence of fruit split include timing of flower development (Glozer \& Ferguson, 2008), cultivar (Hepaksoy, Aksoy, Can, \& Ui, 2000; Lefeng et al., 2010; Levin, 2006), soil water content (Holland et al., 2009), water use efficiency (Hepaksoy et al., 2000), and fruit size and shape (Saei, Sharifan, Dehghani, Seifi, \& Akbarpour, 2014). Though flower removal (Singh \& Kingsly, 2007), plant growth regulator applications (El-Khawaga, 2007; Yilmaz \& Özgüven, 2009), antitranspirant application (Bacha \& Ibrahim, 1979), and controlled irrigation (El-Rhman, 2010) have been tested as possible strategies to 
prevent fruit split of pomegranate, a commercially acceptable treatment has not yet been identified.

In a study of several pomegranate cultivars, leaf nitrogen $(\mathrm{N})$ concentrations were positively correlated with the ratio of unsplit to split fruit (Hepaksoy et al., 2000). Foliar nutrient applications have been used experimentally to mitigate pomegranate fruit split. Foliar applications of $1 \%$ zinc sulfate $\left(\mathrm{ZnSO}_{4}\right)$ significantly decreased fruit split incidence of 'Manfaluty' pomegranate and when used in combination with controlled irrigation, decreased fruit split incidence by nearly $50 \%$ as compared to controls (El-Rhman, 2010). Foliar applications of $1 \%$ potassium nitrate $\left(\mathrm{KNO}_{3}\right), 1 \%$ magnesium sulfate $\left(\mathrm{MgSO}_{4}\right), 0.005 \%$ boric acid $\left(\mathrm{H}_{3} \mathrm{BO}_{3}\right)$, or $0.002 \% \mathrm{H}_{3} \mathrm{BO}_{3}$ resulted in significantly lower incidence of fruit split of 'Kandhari' and 'Beedana' pomegranate (Singh, Sharma, \& Awasthi, 1993), with each treatment reducing the mean fruit split rate by more than $50 \%$ as compared to the control. The authors hypothesized that the foliar nutrient applications increased the elasticity and cell wall permeability of the rind, thus reducing the likelihood of fruit split. There appear to be no published studies of the use of foliar nutrient applications to decrease fruit split of 'Wonderful' pomegranate fruit.

Most pomegranate growers apply inorganic fertilizer by broadcast application (Glozer \& Ferguson, 2008) or fertigation (Blumenfeld et al., 2000). There is little published evidence of grower use of foliar nutrient applications as a standard conventional cultural practice, though $\mathrm{Zn}$ deficiency of pomegranate is corrected with foliar applications of zinc sulfate $\left(\mathrm{ZnSO}_{4}\right)$ in spring and/or summer (Glozer \& Ferguson, 2008; Stover \& Mercure, 2007). Foliar application of Zn has been shown to improve marketable yield of pomegranate, even in trees not displaying $\mathrm{Zn}$ 
deficiency symptoms (Afria, Pareek, Garg, \& Singh, 1999; Khorsandi, Yazdi, \& Vazifehshenas, 2009). Hasani, Zamani, Savaghebi, \& Fatahi (2012) reported that foliar applications of $\mathrm{ZnSO}_{4}$ resulted in significant increases in leaf $\mathrm{Zn}$ concentration and foliar applications of $\mathrm{MnSO}_{4}$ resulted in significant increases in leaf $\mathrm{Mn}$ concentration, but no other macronutrient or micronutrient leaf concentrations were significantly affected by the treatments. Khorsandi et al. (2009) also reported that foliar applications of $\mathrm{ZnSO}_{4}$ increase leaf $\mathrm{Zn}$ concentration in pomegranate. Little else is known about the effects of foliar nutrient applications on pomegranate leaf nutrient concentration. Therefore, the objectives of this study were to assess the effects of foliar applications of $\mathrm{ZnSO}_{4}, \mathrm{MgSO}_{4}$, or $\mathrm{KNO}_{3}$ on 'Wonderful' pomegranate fruit split and to determine the effects of these foliar nutrient applications on pomegranate yield parameters and leaf nutrient concentrations.

\subsection{Materials and Methods}

\subsubsection{Plant Material and Experimental Design}

The study was conducted using 9-year-old bearing 'Wonderful' pomegranate trees at 2 commercial orchards in Kern County, CA, USA (site 1: latitude: $35^{\circ} 04^{\prime} 09.20 " \mathrm{~N}$, longitude: $119^{\circ} 18^{\prime} 47.74 " \mathrm{~W}$; site 2: latitude: $35^{\circ} 40^{\prime} 33.55^{\prime \prime} \mathrm{N}$, longitude: $119^{\circ} 55^{\prime} 16.72 " \mathrm{~W}$ ) (Table 1). A randomized complete block design with 25 blocks and whole-tree experimental units was utilized for a total of 250 data trees at each site. Data trees were selected for uniform health, size, and vigor, though tree size and harvest date varied between sites (Table 1). Treatments consisted of foliar applications of $\mathrm{ZnSO}_{4}\left(3000 \mathrm{mg} \cdot \mathrm{L}^{-1}, 4000 \mathrm{mg} \cdot \mathrm{L}^{-1}\right.$, or $\left.5000 \mathrm{mg} \cdot \mathrm{L}^{-1}\right), \mathrm{MgSO}_{4}$ $(1 \%, 2 \%$, or $3 \%), \mathrm{KNO}_{3}(1 \%, 2 \%$, or $3 \%)$, or deionized (DI) water (control) for a total of 250 data trees at each site. All solutions were formulated in DI water with $0.50 \%$ non-ionic 
surfactant. Treatments were applied using a professional backpack sprayer (SP1, SP Systems International, Incorporated, Santa Monica, CA, USA) at early fruit set (July, when fruit were green to breaker with an equatorial diameter of approximately $50 \mathrm{~mm}$ ) and late fruit set (August, when fruit were red with an equatorial diameter of approximately $70 \mathrm{~mm}$ ), except for $\mathrm{ZnSO}_{4}$ treatments, which were applied only at early fruit set.

\subsubsection{Measured Parameters}

The equatorial diameter of 5 fruit per data tree was measured using a digital caliper from 2 weeks after treatment application until harvest, with an average of $24 \mathrm{~d}$ between measurements. At harvest, the number of split and unsplit pomegranates was determined for each data tree and the total fruit mass and mass of unsplit fruit from each treatment tree was determined using a field scale. Both sites were strip harvested but harvest data was not collected from undeveloped green fruit. A subsample of 10 fruit per treatment tree was selected randomly at harvest and stored at $5-8{ }^{\circ} \mathrm{C}$ in a refrigerated produce cooler. The mass and equatorial diameter of each of these 10 fruit was measured. Arils were manually extracted from the subsampled fruit from 6 blocks at each site. An additional random sample of up to 5 unsplit fruit per data tree was collected at harvest for aril mass analyses and stored at $5-8{ }^{\circ} \mathrm{C}$ for up to $19 \mathrm{~d}$ until arils could be extracted. Total aril mass was determined and the number of arils per fruit was estimated by determining the mass of 100 randomly selected arils per fruit.

To determine leaf nutrient concentrations before and after foliar nutrient applications, samples of 50-70 fully expanded leaves per study tree were taken approximately 1 week prior to the first treatment applications (late June) and again approximately 2 weeks after the last treatment applications (late August). Up to 2 leaves per shoot were collected from shoots $1.5 \mathrm{~m}$ to $1.8 \mathrm{~m}$ 
above soil level on branches without developing fruit. Leaves were washed in a solution of DI water and phosphate-free soap, rinsed with DI water, and oven-dried to a constant mass. Mineral nutrient analysis was conducted by Precision Agri Lab Inc. (Madera, CA, USA). To determine N concentrations, the P-2.20 method of Gavlak, Horneck, Miller, \& Kotuby-Amacher (2003) was conducted using a Leco Elemental Analyzer (Leco 528; Leco Corp., St. Joseph, MI, USA) with the following modification: perchloric acid $\left(\mathrm{HClO}_{4}\right)$ was used instead of hydrogen peroxide $\left(\mathrm{H}_{2} \mathrm{O}_{2}\right)$ to oxidize plant matter. To determine phosphorus (P), K, S, calcium (Ca), $\mathrm{Mg}$, sodium (Na), B, Zn, manganese $(\mathrm{Mn})$, iron $(\mathrm{Fe})$, and copper $(\mathrm{Cu})$ concentrations, the P-4.20 method (Gavlak et al., 2003) was used with the following modifications to the extraction and heating protocol and the method of detection and quantification: $700 \pm 250 \mathrm{mg}$ of sample was predigested in $8 \mathrm{ml}$ of nitric acid $\left(\mathrm{HNO}_{3}\right)$ for a minimum of $60 \mathrm{~min}$, heated at $120{ }^{\circ} \mathrm{C}$ for $60 \mathrm{~min}$, cooled, dissolved in $4 \mathrm{ml}$ of $\mathrm{H}_{2} \mathrm{O}_{2}$, heated at $110{ }^{\circ} \mathrm{C}$ for $30 \mathrm{~min}$, cooled, and filtered before samples were analyzed using an inductively coupled plasma optical emission spectrometer (ICPOES) (Model 4300, PerkinElmer Corp., Waltham, MA, USA). An additional 10 mature, unsplit fruit were collected from 5 blocks at site 2 between 31 October and 2 November in order to determine fruit nutrient concentration, as described and reported in Chapter 3.

\subsubsection{Statistical Analyses}

For each parameter, fertilizer treatments were compared using a mixed effects analysis of variance (ANOVA) using restricted maximum likelihood estimation (REML) with fertilizer concentration nested in fertilizer type as fixed effects and experimental blocks as random effects. Models for each site were fit separately. Partial F-tests to examine all terms with common factors of interest were used prior to tests for individual model terms to reduce Type I error. 
When ANOVA indicated significant differences, post-hoc comparisons were run utilizing Tukey's honestly significant difference (HSD) with an experimentwise error rate of $\alpha=0.05$. Prior to statistical analysis, values for change in leaf $\mathrm{Zn}(\Delta \mathrm{Zn})$ were transformed using $\log (\Delta \mathrm{Zn}$ +4) to satisfy normality and homogeneity of variance conditions for general linear models. Relationships between fruit, leaf and aril parameters were analyzed using linear regression $(\alpha=$ 0.05). Results for analyses are expressed as least squares mean (LSM). All statistical tests were performed using JMP, Version 10 statistical software (SAS Institute Inc., Cary, NC, USA).

\subsection{Results}

\subsubsection{Fruit Split}

The mean rate of fruit split was $3.9 \%$ and $54.0 \%$ at site 1 and 2 , respectively. There were statistically significant treatment effects on the rate of fruit split at both sites. At site $1, \mathrm{MgSO}_{4}$ and $\mathrm{ZnSO}_{4}$ treatments resulted in significantly lower fruit split incidence than all other treatments $(P=0.0031$; Table 2$)$, including the control, though there were no significant dose effects for either fertilizer type $(P>0.05)$. At site $2,3 \% \mathrm{MgSO}_{4}$ treatments resulted in significantly less incidence of fruit split as compared to all other treatments $(P=0.0236$; Table 2), including the control. No other statistically significant treatment differences in fruit split incidence were detected $(P>0.05)$.

\subsubsection{Fruit Yield, Number and Size}

Though there were highly significant differences between the two sites with respect to fruit yield $(P<0.0001 ; 25.58 \mathrm{~kg}$ and $116.51 \mathrm{~kg}$ per tree at site 1 and site 2 , respectively), number $(P<$ $0.0001 ; 55.5$ and 347.5 fruit per tree at site 1 and site 2 , respectively), and individual fruit mass $(P=0.0006 ; 459.1 \mathrm{~g}$ and $439.9 \mathrm{~g}$ at sites 1 and 2 , respectively $)$ and diameter $(P<0.0001 ; 98.4$ 
$\mathrm{mm}$ and $91.1 \mathrm{~mm}$ for site 1 and site 2, respectively), very few treatment differences were detected at either site for these parameters. At site 2, applications of $5000 \mathrm{mg} \cdot \mathrm{L}^{-1} \mathrm{ZnSO}_{4}$ or $1 \%$ $\mathrm{MgSO}_{4}$ resulted in significantly less yield than applications of $4000 \mathrm{mg} \cdot \mathrm{L}^{-1} \mathrm{ZnSO}_{4}$, with mean yields of $112.1 \mathrm{~kg}, 111.2 \mathrm{~kg}$, and $127.6 \mathrm{~kg}$, respectively $(P=0.0407$; Table 3$)$. No other significant treatment differences in yield were detected at either site $(P>0.05$; Table 3$)$. There were no significant treatment differences at either site for fruit number per tree $(P>0.05$; Table $3)$, individual fruit mass, aril mass, mass of 100 arils, or fruit diameter $(P>0.05$; Table 4$)$. Fruit diameter increased at an average rate of $0.42 \mathrm{~mm} \cdot \mathrm{d}^{-1}$ and $0.34 \mathrm{~mm} \cdot \mathrm{d}^{-1}$ at site 1 and site 2 , respectively (Appendix 1).

\subsubsection{Leaf Nutrient Concentrations}

Significant treatment effects were detected for post-treatment leaf $\mathrm{N}, \mathrm{K}, \mathrm{S}, \mathrm{Mn}$, and $\mathrm{Zn}$ concentrations (Tables 5 and 6). $\mathrm{KNO}_{3}$ applications resulted in significantly higher leaf $\mathrm{N}$ concentration (site 1 only; $P<0.0001$; Table 5) and there was a significant dose effect, with the significantly higher leaf $\mathrm{N}$ concentrations occurring in response to the $2 \%$ and $3 \% \mathrm{KNO}_{3}$ treatments. At both sites, leaf $\mathrm{K}$ concentration was highest in trees treated with $\mathrm{KNO}_{3}(P<$ 0.001; Table 5), and there was a significant dose effect at site 1 , with the $2 \%$ and $3 \% \mathrm{KNO}_{3}$ treatments resulting in the highest leaf $\mathrm{K}$ concentrations. Leaf S concentration was significantly affected by $\mathrm{MgSO}_{4}(P=0.006$ for site $1 ; P=0.011$ for site 2 ; Table 5$)$, with significantly higher leaf $\mathrm{S}$ concentrations in response to the $2 \%$ and $3 \% \mathrm{MgSO}_{4}$ treatments. There were significant treatment differences in leaf Mn concentration at site 2, with trees treated with $3 \% \mathrm{MgSO}_{4}$ having approximately twice as much as trees treated with $1 \% \mathrm{KNO}_{3}$ at site $2 . \quad(P=0.031$; Table 6). Leaf $\mathrm{Zn}$ concentration was significantly higher in trees treated with $\mathrm{ZnSO}_{4}$ regardless of dosage level $(P<0.001$; Table 6), resulting in leaf $\mathrm{Zn}$ concentrations that were approximately an 
order of magnitude higher than those of all other treatments. No other significant treatment effects on post-treatment leaf nutrient concentrations were detected $(P>0.05)$.

\subsubsection{Correlations}

Individual fruit mass was a significant predictor of fruit split incidence at site $2(P<0.0001$, partial $R^{2}=0.152$ ) and fruit diameter was a significant predictor of fruit split incidence at both sites $\left(P=0.0032\right.$, partial $\left.R^{2}=0.0963\right)$. Specifically, fruit mass and fruit diameter were each negatively correlated with fruit split incidence. No other statistically significant relationships were detected between fruit yield parameters and incidence of fruit split.

There was a significant negative relationship between fruit $\mathrm{K}$ concentration and fruit split incidence $\left(P=0.047 ; R^{2}=0.696\right)$, which was specific for treatments of $4000 \mathrm{mg} \cdot \mathrm{L}^{-1} \mathrm{ZnSO}_{4}(P=$ $0.034)$ and $2 \% \mathrm{MgSO}_{4}(P=0.019)$. This indicates that the higher the concentration of $\mathrm{K}$ in the fruit, the lower the incidence of fruit split for those specific treatments. No other statistically significant relationships were detected between fruit nutrient concentrations and incidence of fruit split.

\subsection{Discussion}

\subsubsection{Fruit Split}

The present study is the first known study to report on the effects of foliar nutrient applications on the incidence of fruit split of 'Wonderful' pomegranate. Pomegranate fruit split incidence was reduced significantly in response to foliar $\mathrm{ZnSO}_{4}$ and $\mathrm{MgSO}_{4}$ applications. These findings are consistent with previous reports of decreased fruit split incidence in other pomegranate cultivars in response to $1 \% \mathrm{ZnSO}_{4}$ (El-Rhman, 2010) or $1 \% \mathrm{MgSO}_{4}$ (Singh et al., 1993). 
However, that the $\mathrm{KNO}_{3}$ treatments did not affect fruit split incidence in the present study is inconsistent with Singh et al. (1993), who reported significant decreases in fruit split incidence in response to $1 \% \mathrm{KNO}_{3}$. In the study reported herein, the rate of fruit split incidence for trees at site 1 treated with $\mathrm{ZnSO}_{4}$ or $\mathrm{MgSO}_{4}$ was approximately one-half that of the control trees, which is consistent with the decrease in fruit split reported by El-Rhman (2010) and Singh et al. (1993). However, the only treatment to decrease fruit split incidence at site $2\left(3 \% \mathrm{MgSO}_{4}\right)$ reduced the mean fruit split incidence by only $14 \%$. The fruit split incidence at site 2 was significantly higher than that at site 1. Though the cause of this difference in fruit split incidence was not known, the difference in treatment effects between the two sites suggests that the physiological effect that $\mathrm{ZnSO}_{4}$ and/or $\mathrm{MgSO}_{4}$ have on the rind's ability to withstand internal pressure, thereby avoiding split, is limited.

In the present study, fruit diameter and mass were each negatively correlated with fruit split incidence, indicating that larger fruit were less likely to split. Though this finding appears to be inconsistent with that of Saei et al. (2014), who reported that larger fruit were associated with higher split rates, their work also demonstrated that because the mechanics of rind split are influenced by the force exerted by the fruit interior on the rind, fruit shape (e.g. oblate versus prolate), rind thickness and the ratio of rind and septa weight to aril weight also affect fruit split incidence. It was hypothesized that the albedo of the fruits' rind is responsible for fluxes in water status of the fruit and that the spongy parenchyma tissue of the rind might play a role in fruit split. Saei et al. (2014) reported that ratio of length to diameter had a significant effect of split, with pomegranates with a fruit length to diameter ratio of $<1$ being more susceptible to fruit split. It was also reported that fruit $\mathrm{Ca}$ concentration was negatively associated with rind elasticity, suggesting that fruit $\mathrm{Ca}$ concentration is positively correlated with fruit splitting. This 
relationship was not detected in the present study, though fruit $\mathrm{K}$ concentration was negatively correlated with fruit split incidence. Further research is needed to determine if fruit $\mathrm{K}$ concentration affects the biomechanical properties of pomegranate fruit.

\subsubsection{Fruit Yield, Number and Size}

There was no evidence that the foliar nutrient applications used in the study reported herein had an undesirable effect on yield. The results of previous studies utilizing foliar $\mathrm{ZnSO}_{4}, \mathrm{KNO}_{3}$, or $\mathrm{MgSO}_{4}$ applications regarding effects of yield are highly variable and are likely cultivar dependent. Hasani et al. (2012) reported that foliar applications of $\mathrm{ZnSO}_{4}$ had no effect on yield on 'Malas e Torsh e Saveh' pomegranates. Similarly, El-Rhman (2010) reported that foliar $\mathrm{ZnSO}_{4}$ applications had no effect in yield of 'Manfaluty' pomegranates. Khorsandi et al. (2009) also reported that foliar $\mathrm{ZnSO}_{4}$ did not increase yield, but did decrease unmarketable yield. Conversely, Afria et al. (1999) reported that foliar $\mathrm{ZnSO}_{4}$ increased yields for 'Ganesh' pomegranate. Foliar applications of $\mathrm{KNO}_{3}$ or $\mathrm{MgSO}_{4}$ have been reported to increase yield in some cultivars (Singh et al, 1993) but have no effect on yield in others (Yilmaz \& Özgüven, 2009). El-Rhman (2010) reported that $\mathrm{ZnSO}_{4}$ significantly increased fruit diameter and mass and 100 seeds weight as compared to the control, whereas Hasani et al. (2010) reported that $\mathrm{ZnSO}_{4}$ did not have a significant effect on these parameters. The study reported herein is the first to describe the effects of foliar nutrient applications on fruit yield, number and size of California-grown 'Wonderful' pomegranate. Other researchers have reported that the effects of foliar fertilizer treatments are cultivar dependent (Khorsandi et al., 2009). However, another possibility for the lack of consistency within the pomegranate literature is a lack of available foliar nutrient reference standards that would better enable researchers to determine if foliar 
nutrient applications are merely correcting a nutrient deficiency or promoting a physiological response in the plant independent of providing sufficient nutrient concentrations.

It is interesting to note that the trees at site 2 produced a significantly higher mass and number of fruit per tree than those at site 1 . This was a much larger difference than was anticipated considering the proximity of the two sites to one another and that the trees at both sites were of the same age and cultivar. Wassel, Gobara, Ibrahiem, \& Shaaban-Mai (2015) reported 'Wonderful' pomegranate yields similar to those of site 1 of the present study. The yields at site 2 of the present study were almost twice as high as those estimated for mature commercial orchards of 'Wonderful' pomegranate in California (Day et al., 2005). The cultural methods utilized by the grower at site 2 warrant further investigation to determine which method or methods are having the greatest impact on yield.

\subsubsection{Leaf Nutrient Concentrations}

Despite its long history of cultivation, fertilization requirements for specific nutrients are not entirely understood for pomegranate because scientific literature on this subject is limited (Holland et al., 2009). There are currently no accepted leaf tissue nutrient sufficiency reference ranges for pomegranate (K. Day, personal communication, November 16, 2015) and there is limited information published regarding pomegranate leaf nutrient concentrations and nutrient uptake. In a study of 6 pomegranate cultivars, Hepaksoy et al. (2000) reported that leaf nutrient concentrations of $\mathrm{N}, \mathrm{K}, \mathrm{Ca}$, and $\mathrm{Mg}$ varied significantly among cultivar and sample date. Additionally, Giménez, Martínez, Oltra, Martínez, \& Ferrández (2000) found that leaf nutrient concentrations of the majority of macronutrients and micronutrients are cultivar dependent. 
The leaf nutrient concentrations reported in the study herein were similar to those reported by Hepaksoy et al. (2000) and Hasani et al. (2012). Hasani et al. (2012) had similar values for all mineral nutrients for 'Malas e Torsh e Saveh' except for Fe, Mn and Zn, which were much higher than those reported in the present study. The present study is the first to document the effects of foliar nutrient sprays on leaf nutrient concentration of 'Wonderful' pomegranate. The data reported herein adds to the body of the knowledge regarding leaf macronutrient and micronutrient concentrations detected in late summer in 'Wonderful' pomegranate. This is significant because this is the time of year during which growers of deciduous trees collect leaf samples to determine the nutrient status of their trees for the purposes of getting fertilization recommendations for the current and upcoming growing season. Further studies are needed to determine leaf nutrient sufficiency standards for pomegranate, including 'Wonderful.'

\subsection{Conclusions}

Although this experiment and others have reported reduced fruit split rates for trees treated with foliar applications of macro- and micronutrient solutions, limited scientific literature is available regarding cultivar-specific effects of these treatments or mineral nutrition of pomegranate and its relationship to pomegranate fruit production. In the present study, treatments of foliar $\mathrm{ZnSO}_{4}$, $\mathrm{MgSO}_{4}$, or $\mathrm{KNO}_{3}$ resulted in significant changes in leaf nutrient concentrations of 'Wonderful' pomegranate significantly and foliar applications of $\mathrm{ZnSO}_{4}$ or $\mathrm{MgSO}_{4}$ were found to be a promising and feasible cultural practice to mitigate fruit split of 'Wonderful' pomegranate, but more research is needed to elucidate the relationship between pomegranate fruit split rates and mineral nutrition of pomegranate. 


\section{Table 1}

Tree height, trunk diameter, within row and between row tree spacing, and date of harvest for data trees at two commercial pomegranate orchards in Kern County, CA, USA.

\begin{tabular}{llll}
\hline Parameter & Site 1 & Site 2 & $p$-value \\
\hline Tree height $(\mathrm{m})$ & $2.45 \mathrm{~b}^{\mathrm{A}}$ & $2.82 \mathrm{a}$ & $<0.001$ \\
Trunk diameter $(\mathrm{mm})$ & $122.9 \mathrm{a}$ & $107.5 \mathrm{~b}$ & 0.005 \\
Tree spacing within row $(\mathrm{m})$ & 3.35 & 4.27 & N/A $^{\mathrm{B}}$ \\
Tree spacing between row $(\mathrm{m})$ & 4.88 & 5.18 & $\mathrm{~N} / \mathrm{A}$ \\
Harvest date & 22 October & 04 November & N/A \\
\hline${ }^{\mathrm{A}}$ Values followed by different letters within a row are significantly different $(P<0.05)$.
\end{tabular}


Table 2

Percent fruit split of 'Wonderful' pomegranate trees treated with foliar applications of deionized water (control), $\mathrm{ZnSO}_{4}\left(3000 \mathrm{mg} \cdot \mathrm{L}^{-1}, 4000 \mathrm{mg} \cdot \mathrm{L}^{-1}\right.$, or $\left.5000 \mathrm{mg} \cdot \mathrm{L}^{-1}\right), \mathrm{MgSO}_{4}(1 \%, 2 \%$, or $3 \%)$, or $\mathrm{KNO}_{3}(1 \%, 2 \%$, or $3 \%)$ at two commercial orchards in Kern County, CA, USA.

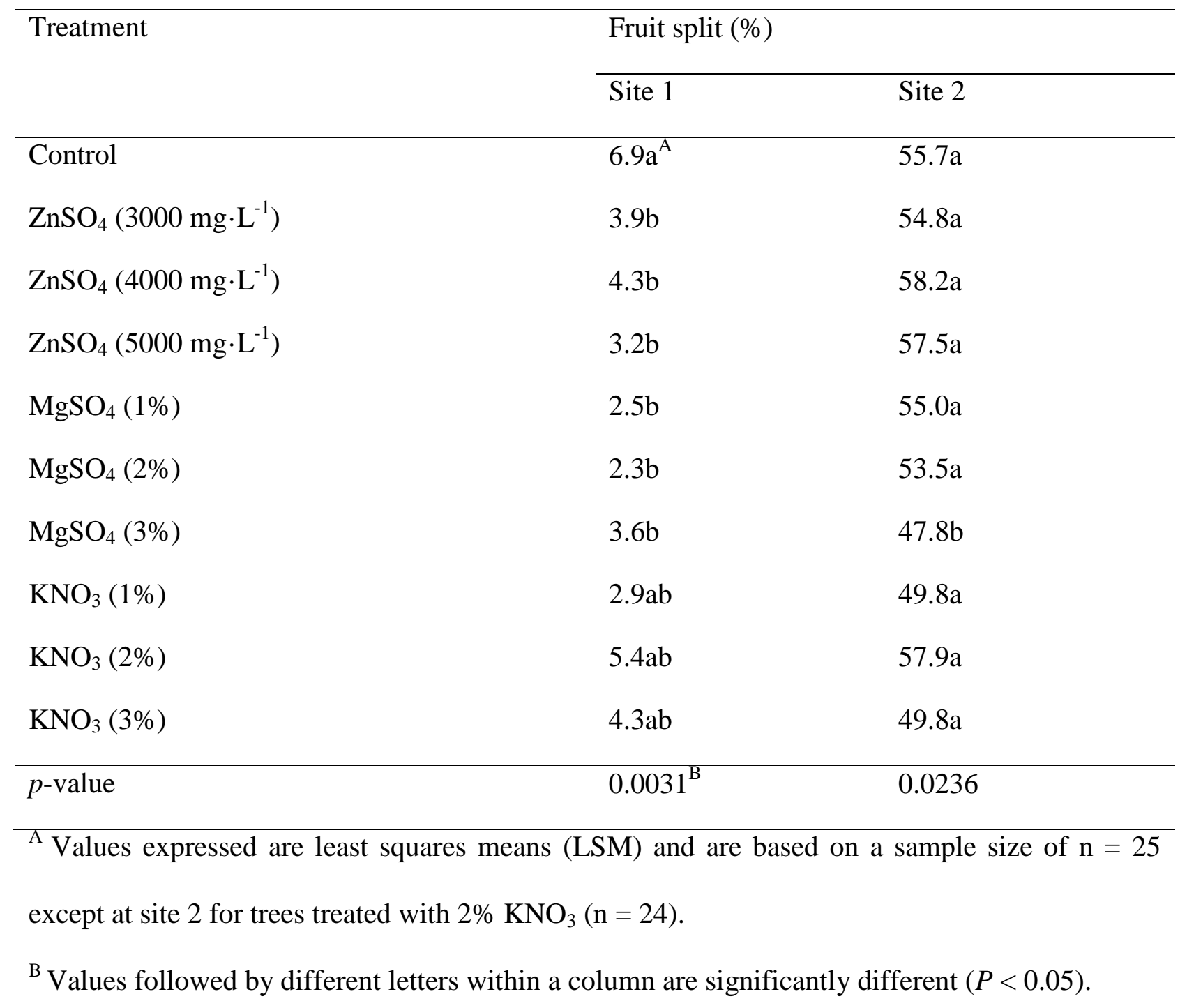




\section{Table 3}

Yield and fruit number per tree of 'Wonderful' pomegranate treated with foliar applications of deionized water (control), $\mathrm{ZnSO}_{4}\left(3000 \mathrm{mg} \cdot \mathrm{L}^{-1}, 4000 \mathrm{mg} \cdot \mathrm{L}^{-1}\right.$, or $\left.5000 \mathrm{mg} \cdot \mathrm{L}^{-1}\right), \mathrm{MgSO}_{4}(1 \%, 2 \%$, or $3 \%$ ), or $\mathrm{KNO}_{3}(1 \%, 2 \%$, or $3 \%)$ at two commercial orchards in Kern County, CA, USA.

\begin{tabular}{|c|c|c|c|c|}
\hline \multirow[t]{2}{*}{ Treatment } & \multicolumn{2}{|l|}{ Yield (kg) } & \multicolumn{2}{|c|}{ Fruit number } \\
\hline & Site 1 & Site 2 & Site 1 & Site 2 \\
\hline Control & $23.74 a^{A, B}$ & $116.19 \mathrm{ab}$ & $52.7 \mathrm{a}$ & $360.8 \mathrm{a}$ \\
\hline $\mathrm{ZnSO}_{4}\left(3000 \mathrm{mg} \cdot \mathrm{L}^{-1}\right)$ & $26.72 \mathrm{a}$ & $115.51 \mathrm{ab}$ & $59.0 \mathrm{a}$ & $336.0 \mathrm{a}$ \\
\hline $\mathrm{ZnSO}_{4}\left(4000 \mathrm{mg} \cdot \mathrm{L}^{-1}\right)$ & $26.31 \mathrm{a}$ & $127.57 \mathrm{a}$ & $51.9 \mathrm{a}$ & $359.6 \mathrm{a}$ \\
\hline $\mathrm{ZnSO}_{4}\left(5000 \mathrm{mg} \cdot \mathrm{L}^{-1}\right)$ & $25.26 \mathrm{a}$ & $112.09 \mathrm{~b}$ & $57.0 \mathrm{a}$ & $339.5 a$ \\
\hline $\mathrm{MgSO}_{4}(1 \%)$ & $28.24 \mathrm{a}$ & $111.19 b$ & $58.2 \mathrm{a}$ & $327.9 a$ \\
\hline $\mathrm{MgSO}_{4}(2 \%)$ & $24.52 \mathrm{a}$ & $114.29 \mathrm{ab}$ & $53.4 \mathrm{a}$ & $334.1 \mathrm{a}$ \\
\hline $\mathrm{MgSO}_{4}(3 \%)$ & $24.72 \mathrm{a}$ & $114.80 \mathrm{ab}$ & $55.3 \mathrm{a}$ & $352.0 \mathrm{a}$ \\
\hline $\mathrm{KNO}_{3}(1 \%)$ & $26.50 \mathrm{a}$ & $119.38 \mathrm{ab}$ & $58.8 \mathrm{a}$ & $352.7 \mathrm{a}$ \\
\hline $\mathrm{KNO}_{3}(2 \%)$ & $23.80 \mathrm{a}$ & $115.62 \mathrm{ab}$ & $51.5 \mathrm{a}$ & $366.7 \mathrm{a}$ \\
\hline $\mathrm{KNO}_{3}(3 \%)$ & $25.95 \mathrm{a}$ & 118.36ab & $56.0 \mathrm{a}$ & $345.8 \mathrm{a}$ \\
\hline$p$-value & $\mathrm{NS}^{\mathrm{C}}$ & 0.0407 & NS & NS \\
\hline \multicolumn{5}{|c|}{$\begin{array}{l}{ }^{\text {A }} \text { Values expressed are least squares means (LSM) and are based on a sample size of } \mathrm{n}=25 \\
\text { except for fruit number at site } 1 \text { for trees treated with } 3000 \mathrm{mg} \cdot \mathrm{L}^{-1} \mathrm{ZnSO}_{4} \text { and for yield and fruit }\end{array}$} \\
\hline${ }^{\mathrm{B}}$ Values followed by $\mathrm{d}$ & letters withi & olumn are & ficantly & $(P<0.05)$ \\
\hline
\end{tabular}


Table 4

Fruit mass, mass of all arils, mass of 100 arils, and fruit diameter of 'Wonderful' pomegranate trees treated with foliar applications of deionized water (control), $\mathrm{ZnSO}_{4}\left(3000 \mathrm{mg} \cdot \mathrm{L}^{-1}, 4000 \mathrm{mg} \cdot \mathrm{L}^{-1}\right.$, or $\left.5000 \mathrm{mg} \cdot \mathrm{L}^{-1}\right), \mathrm{MgSO}_{4}(1 \%, 2 \%$, or $3 \%)$, or $\mathrm{KNO}_{3}(1 \%, 2 \%$, or $3 \%)$ at two commercial orchards in Kern County, CA, USA.

\begin{tabular}{|c|c|c|c|c|c|c|c|c|}
\hline \multirow[t]{2}{*}{ Treatment } & \multicolumn{2}{|c|}{ Fruit mass $(\mathrm{g})$} & \multicolumn{2}{|c|}{ Aril mass (g) } & \multicolumn{2}{|c|}{ Mass of 100 arils (g) } & \multicolumn{2}{|c|}{ Fruit diameter $(\mathrm{mm})$} \\
\hline & Site 1 & Site 2 & Site 1 & Site 2 & Site 1 & Site 2 & Site 1 & Site 2 \\
\hline Control & $441.6 \mathrm{a}^{\mathrm{A}, \mathrm{B}}$ & $424.9 \mathrm{a}$ & $233.3 \mathrm{a}$ & $231.6 \mathrm{a}$ & $32.3 \mathrm{a}$ & $35.0 \mathrm{a}$ & $99.04 a$ & $90.96 a$ \\
\hline $\mathrm{ZnSO}_{4}\left(3000 \mathrm{mg} \cdot \mathrm{L}^{-1}\right)$ & $444.0 \mathrm{a}$ & $433.1 \mathrm{a}$ & $207.2 \mathrm{a}$ & $236.7 \mathrm{a}$ & $32.2 \mathrm{a}$ & $37.1 \mathrm{a}$ & $97.37 \mathrm{a}$ & $90.70 \mathrm{a}$ \\
\hline $\mathrm{ZnSO}_{4}\left(4000 \mathrm{mg} \cdot \mathrm{L}^{-1}\right)$ & $461.1 \mathrm{a}$ & $449.5 \mathrm{a}$ & $224.3 \mathrm{a}$ & $248.6 \mathrm{a}$ & $32.8 \mathrm{a}$ & $37.3 \mathrm{a}$ & $97.65 a$ & $91.14 \mathrm{a}$ \\
\hline $\mathrm{ZnSO}_{4}\left(5000 \mathrm{mg} \cdot \mathrm{L}^{-1}\right)$ & $454.3 \mathrm{a}$ & $440.9 \mathrm{a}$ & $231.9 \mathrm{a}$ & $300.3 \mathrm{a}$ & $31.7 \mathrm{a}$ & $35.6 \mathrm{a}$ & $97.93 \mathrm{a}$ & $91.89 \mathrm{a}$ \\
\hline $\mathrm{MgSO}_{4}(1 \%)$ & $472.9 \mathrm{a}$ & $432.6 \mathrm{a}$ & $240.4 \mathrm{a}$ & $274.9 \mathrm{a}$ & $31.0 \mathrm{a}$ & $36.9 \mathrm{a}$ & $99.51 \mathrm{a}$ & $91.11 \mathrm{a}$ \\
\hline $\mathrm{MgSO}_{4}(2 \%)$ & $467.9 \mathrm{a}$ & $452.8 \mathrm{a}$ & $237.2 \mathrm{a}$ & $248.5 \mathrm{a}$ & $32.0 \mathrm{a}$ & $32.8 \mathrm{a}$ & $99.09 \mathrm{a}$ & $91.45 \mathrm{a}$ \\
\hline $\mathrm{MgSO}_{4}(3 \%)$ & $458.5 \mathrm{a}$ & $435.4 \mathrm{a}$ & $207.2 \mathrm{a}$ & $264.9 a$ & $32.8 \mathrm{a}$ & $35.2 \mathrm{a}$ & $98.52 \mathrm{a}$ & $90.98 \mathrm{a}$ \\
\hline $\mathrm{KNO}_{3}(1 \%)$ & $459.8 \mathrm{a}$ & $450.0 \mathrm{a}$ & $208.3 \mathrm{a}$ & $262.2 \mathrm{a}$ & $32.5 \mathrm{a}$ & $36.7 \mathrm{a}$ & $98.65 a$ & $92.12 \mathrm{a}$ \\
\hline $\mathrm{KNO}_{3}(2 \%)$ & $462.5 \mathrm{a}$ & $430.1 \mathrm{a}$ & $227.4 \mathrm{a}$ & $261.5 \mathrm{a}$ & $31.5 \mathrm{a}$ & $33.5 \mathrm{a}$ & $97.63 \mathrm{a}$ & $90.70 \mathrm{a}$ \\
\hline $\mathrm{KNO}_{3}(3 \%)$ & $468.4 \mathrm{a}$ & $448.7 \mathrm{a}$ & $243.6 \mathrm{a}$ & $242.4 \mathrm{a}$ & $31.6 \mathrm{a}$ & $35.8 \mathrm{a}$ & $98.82 \mathrm{a}$ & $90.22 \mathrm{a}$ \\
\hline$p$-value & $\mathrm{NS}^{\mathrm{C}}$ & NS & NS & NS & NS & NS & NS & NS \\
\hline
\end{tabular}


${ }^{A}$ Values expressed are least squares means (LSM) and are based on sample sizes of $n=25$ for fruit mass (except for trees treated with $5000 \mathrm{mg} \cdot \mathrm{L}^{-1} \mathrm{ZnSO}_{4}$ at site 1 and 2 or with $2 \% \mathrm{KNO}_{3}$ at site $\left.2(\mathrm{n}=24)\right), \mathrm{n}=6$ for aril mass (except at site 2 for $5000 \mathrm{mg} \cdot \mathrm{L}^{-1} \mathrm{ZnSO} 4(\mathrm{n}$ $=3), 1 \% \mathrm{KNO}_{3}(\mathrm{n}=5)$, or $\left.2 \% \mathrm{KNO}_{3}(\mathrm{n}=5)\right), \mathrm{n}=6$ for mass of 100 arils (except at site 1 for the control, $2 \% \mathrm{KNO}_{3}$, or $3 \% \mathrm{KNO}_{3}(\mathrm{n}=$ 5) and at site 2 for $5000 \mathrm{mg} \cdot \mathrm{L}^{-1} \mathrm{ZnSO}_{4}(\mathrm{n}=3), 1 \% \mathrm{KNO}_{3}(\mathrm{n}=5)$, or $2 \% \mathrm{KNO}_{3}(\mathrm{n}=5)$ ), and $\mathrm{n}=25$ for fruit diameter (except at site 1 for $5000 \mathrm{mg} \cdot \mathrm{L}^{-1} \mathrm{ZnSO}_{4}(\mathrm{n}=23)$ or $\left.2 \% \mathrm{KNO}_{3}(\mathrm{n}=24)\right)$.

${ }^{\mathrm{B}}$ Values followed by the same letter within a column are not significantly different $(P>0.05)$.

${ }^{\mathrm{C}} \mathrm{NS}=$ not significant $(P>0.05)$. 
Table 5

Leaf macronutrient concentrations (\%) from 'Wonderful' pomegranate trees treated with foliar applications of deionized water (control), $\mathrm{ZnSO}_{4}\left(3000 \mathrm{mg} \cdot \mathrm{L}^{-1}, 4000 \mathrm{mg} \cdot \mathrm{L}^{-1}\right.$, or $\left.5000 \mathrm{mg} \cdot \mathrm{L}^{-1}\right), \mathrm{MgSO}_{4}(1 \%, 2 \%$, or $3 \%)$, or $\mathrm{KNO}_{3}(1 \%, 2 \%$, or $3 \%)$ at two commercial orchards in Kern County, CA, USA.

\begin{tabular}{|c|c|c|c|c|c|c|c|c|c|c|c|c|}
\hline \multirow[t]{2}{*}{ Treatment } & \multicolumn{2}{|l|}{ Nitrogen } & \multicolumn{2}{|c|}{ Phosphorus } & \multicolumn{2}{|c|}{ Potassium } & \multicolumn{2}{|c|}{ Calcium } & \multicolumn{2}{|c|}{ Magnesium } & \multicolumn{2}{|l|}{ Sulfur } \\
\hline & Site 1 & Site 2 & Site 1 & Site 2 & Site 1 & Site 2 & Site 1 & Site 2 & Site 1 & Site 2 & Site 1 & Site 2 \\
\hline Control & $1.45 b^{A}$ & $2.04 a$ & $0.11 \mathrm{a}$ & $0.14 \mathrm{a}$ & $0.94 c$ & $0.74 d$ & $3.49 \mathrm{a}$ & $4.74 a$ & $0.20 \mathrm{a}$ & $0.40 \mathrm{a}$ & $0.14 b$ & $0.19 \mathrm{ab}$ \\
\hline $\mathrm{ZnSO}_{4}\left(3000 \mathrm{mg} \cdot \mathrm{L}^{-1}\right)$ & $1.64 \mathrm{ab}$ & $2.04 \mathrm{a}$ & $0.13 \mathrm{a}$ & $0.14 \mathrm{a}$ & $0.88 \mathrm{c}$ & $0.70 \mathrm{~d}$ & $3.30 \mathrm{a}$ & $4.75 \mathrm{a}$ & $0.23 \mathrm{a}$ & $0.41 \mathrm{a}$ & $0.15 \mathrm{ab}$ & $0.19 \mathrm{ab}$ \\
\hline $\mathrm{ZnSO}_{4}\left(4000 \mathrm{mg} \cdot \mathrm{L}^{-1}\right)$ & $1.64 \mathrm{ab}$ & $2.02 \mathrm{a}$ & $0.13 \mathrm{a}$ & $0.13 \mathrm{a}$ & $0.86 \mathrm{c}$ & $0.77 \mathrm{~cd}$ & $3.22 \mathrm{a}$ & $4.85 \mathrm{a}$ & $0.21 \mathrm{a}$ & $0.39 \mathrm{a}$ & $0.15 \mathrm{ab}$ & $0.19 \mathrm{ab}$ \\
\hline $\mathrm{ZnSO}_{4}\left(5000 \mathrm{mg} \cdot \mathrm{L}^{-1}\right)$ & $1.65 \mathrm{ab}$ & $2.00 \mathrm{a}$ & $0.13 \mathrm{a}$ & $0.13 \mathrm{a}$ & $0.93 \mathrm{c}$ & $0.80 \mathrm{bcd}$ & $3.51 \mathrm{a}$ & $4.76 \mathrm{a}$ & $0.23 \mathrm{a}$ & $0.38 \mathrm{a}$ & $0.15 \mathrm{ab}$ & $0.19 \mathrm{ab}$ \\
\hline $\mathrm{MgSO}_{4}(1 \%)$ & $1.56 \mathrm{ab}$ & $1.99 \mathrm{a}$ & $0.12 \mathrm{a}$ & $0.14 \mathrm{a}$ & $0.93 \mathrm{c}$ & $0.74 \mathrm{~d}$ & $3.42 \mathrm{a}$ & $4.83 \mathrm{a}$ & $0.22 \mathrm{a}$ & $0.40 \mathrm{a}$ & $0.16 \mathrm{ab}$ & $0.19 \mathrm{ab}$ \\
\hline $\mathrm{MgSO}_{4}(2 \%)$ & $1.53 \mathrm{ab}$ & $2.03 \mathrm{a}$ & $0.12 \mathrm{a}$ & $0.13 \mathrm{a}$ & $0.86 \mathrm{c}$ & $0.82 \mathrm{bcd}$ & $3.41 \mathrm{a}$ & $4.65 \mathrm{a}$ & $0.22 \mathrm{a}$ & $0.42 \mathrm{a}$ & $0.16 \mathrm{ab}$ & $0.20 \mathrm{a}$ \\
\hline $\mathrm{MgSO}_{4}(3 \%)$ & $1.65 \mathrm{ab}$ & $2.07 \mathrm{a}$ & $0.14 \mathrm{a}$ & $0.14 \mathrm{a}$ & $0.92 \mathrm{c}$ & $0.74 d$ & $3.17 \mathrm{a}$ & $4.51 \mathrm{a}$ & $0.24 \mathrm{a}$ & $0.42 \mathrm{a}$ & $0.17 \mathrm{a}$ & $0.20 \mathrm{a}$ \\
\hline $\mathrm{KNO}_{3}(1 \%)$ & $1.46 b$ & $2.10 \mathrm{a}$ & $0.11 \mathrm{a}$ & $0.15 \mathrm{a}$ & $0.96 b c$ & $0.94 \mathrm{ab}$ & $3.65 \mathrm{a}$ & $4.04 \mathrm{a}$ & $0.20 \mathrm{a}$ & $0.37 \mathrm{a}$ & $0.14 b$ & $0.18 \mathrm{ab}$ \\
\hline $\mathrm{KNO}_{3}(2 \%)$ & $1.77 \mathrm{a}$ & $2.07 \mathrm{a}$ & $0.14 \mathrm{a}$ & $0.14 \mathrm{a}$ & $1.22 \mathrm{a}$ & $0.93 \mathrm{abc}$ & $2.90 \mathrm{a}$ & $4.71 \mathrm{a}$ & $0.22 \mathrm{a}$ & $0.40 \mathrm{a}$ & $0.15 \mathrm{ab}$ & $0.19 \mathrm{ab}$ \\
\hline $\mathrm{KNO}_{3}(3 \%)$ & $1.74 \mathrm{a}$ & $2.03 \mathrm{a}$ & $0.13 \mathrm{a}$ & $0.14 \mathrm{a}$ & $1.20 \mathrm{ab}$ & $1.08 \mathrm{a}$ & $3.44 \mathrm{a}$ & $4.34 \mathrm{a}$ & $0.23 \mathrm{a}$ & $0.36 \mathrm{a}$ & $0.15 \mathrm{ab}$ & $0.17 \mathrm{~b}$ \\
\hline$p$-value & $<0.001$ & $\mathrm{NS}^{\mathrm{B}}$ & NS & $\mathrm{NS}$ & $<0.001$ & $<0.001$ & NS & NS & NS & $\mathrm{NS}$ & 0.006 & 0.011 \\
\hline
\end{tabular}

${ }^{\text {A }}$ Values expressed are least squares means (LSM) and are based on a sample size of $(\mathrm{n}=5)$. 
${ }^{\text {B }}$ Values followed by different letters within a column are significantly different $(P<0.05)$.

${ }^{\mathrm{C}} \mathrm{NS}=$ not significant $(P>0.05)$ 
Table 6

Leaf micronutrient concentrations $\left(\mathrm{mg} \cdot \mathrm{L}^{-1}\right)$ from 'Wonderful' pomegranate trees treated with foliar applications of deionized water (control), $\mathrm{ZnSO}_{4}\left(3000 \mathrm{mg} \cdot \mathrm{L}^{-1}, 4000 \mathrm{mg} \cdot \mathrm{L}^{-1}\right.$, or $\left.5000 \mathrm{mg} \cdot \mathrm{L}^{-1}\right), \mathrm{MgSO}_{4}(1 \%, 2 \%$, or $3 \%)$, or $\mathrm{KNO}_{3}(1 \%, 2 \%$, or $3 \%)$ at two commercial orchards in Kern County, CA, USA.

\begin{tabular}{|c|c|c|c|c|c|c|c|c|c|c|}
\hline \multirow[t]{2}{*}{ Treatment } & \multicolumn{2}{|l|}{ Boron } & \multicolumn{2}{|l|}{ Copper } & \multicolumn{2}{|l|}{ Iron } & \multicolumn{2}{|c|}{ Manganese } & \multicolumn{2}{|l|}{ Zinc } \\
\hline & Site 1 & Site 2 & Site 1 & Site 2 & Site 1 & Site 2 & Site 1 & Site 2 & Site 1 & Site 2 \\
\hline Control & $20.4 a^{A}$ & $20.4 \mathrm{a}$ & $6.8 \mathrm{a}$ & $5.0 \mathrm{abc}$ & $60.6 a$ & $85.2 \mathrm{a}$ & $52.4 \mathrm{a}$ & $31.2 \mathrm{ab}$ & $13.6 \mathrm{c}$ & $12.2 \mathrm{~b}$ \\
\hline $\mathrm{ZnSO}_{4}\left(3000 \mathrm{mg} \cdot \mathrm{L}^{-1}\right)$ & $21.0 \mathrm{a}$ & $21.8 \mathrm{a}$ & $7.2 \mathrm{a}$ & $3.6 b c$ & $63.0 \mathrm{a}$ & $72.8 \mathrm{a}$ & $48.4 \mathrm{a}$ & $36.0 \mathrm{ab}$ & $91.6 b$ & $152.8 \mathrm{a}$ \\
\hline $\mathrm{ZnSO}_{4}\left(4000 \mathrm{mg} \cdot \mathrm{L}^{-1}\right)$ & $20.8 \mathrm{a}$ & $21.6 \mathrm{a}$ & $6.2 \mathrm{a}$ & $2.6 \mathrm{c}$ & $59.6 \mathrm{a}$ & $70.4 \mathrm{a}$ & $49.2 \mathrm{a}$ & $35.6 \mathrm{ab}$ & $117.2 \mathrm{ab}$ & $207.0 \mathrm{a}$ \\
\hline $\mathrm{ZnSO}_{4}\left(5000 \mathrm{mg} \cdot \mathrm{L}^{-1}\right)$ & $21.4 \mathrm{a}$ & $20.6 \mathrm{a}$ & $6.6 \mathrm{a}$ & $3.4 \mathrm{bc}$ & $59.6 \mathrm{a}$ & $77.6 \mathrm{a}$ & $51.8 \mathrm{a}$ & $29.6 a b$ & $143.8 \mathrm{a}$ & $233.8 \mathrm{a}$ \\
\hline $\mathrm{MgSO}_{4}(1 \%)$ & $21.0 \mathrm{a}$ & $21.0 \mathrm{a}$ & $7.6 \mathrm{a}$ & $5.4 \mathrm{ab}$ & $62.8 \mathrm{a}$ & $77.2 \mathrm{a}$ & $52.4 \mathrm{a}$ & $33.8 \mathrm{ab}$ & $15.0 \mathrm{c}$ & $11.6 \mathrm{~b}$ \\
\hline $\mathrm{MgSO}_{4}(2 \%)$ & $20.0 \mathrm{a}$ & $20.6 \mathrm{a}$ & $7.4 \mathrm{a}$ & $4.6 \mathrm{abc}$ & $58.4 \mathrm{a}$ & $67.2 \mathrm{a}$ & $50.6 \mathrm{a}$ & $32.6 \mathrm{ab}$ & $13.4 \mathrm{c}$ & $13.4 \mathrm{~b}$ \\
\hline $\mathrm{MgSO}_{4}(3 \%)$ & $20.6 \mathrm{a}$ & $21.8 \mathrm{a}$ & $7.8 \mathrm{a}$ & $6.2 \mathrm{a}$ & $55.8 \mathrm{a}$ & $73.0 \mathrm{a}$ & $43.8 \mathrm{a}$ & $45.0 \mathrm{a}$ & $26.2 \mathrm{c}$ & $28.6 b$ \\
\hline $\mathrm{KNO}_{3}(1 \%)$ & $21.0 \mathrm{a}$ & $21.0 \mathrm{a}$ & $6.8 \mathrm{a}$ & $6.8 \mathrm{a}$ & $58.6 \mathrm{a}$ & $74.4 \mathrm{a}$ & $54.4 \mathrm{a}$ & $28.2 b$ & $13.8 \mathrm{c}$ & $10.2 b$ \\
\hline $\mathrm{KNO}_{3}(2 \%)$ & $22.6 \mathrm{a}$ & $21.6 \mathrm{a}$ & $9.0 \mathrm{a}$ & $4.6 \mathrm{abc}$ & $60.8 \mathrm{a}$ & $70.6 \mathrm{a}$ & $42.8 \mathrm{a}$ & $40.8 \mathrm{ab}$ & $13.6 \mathrm{c}$ & $12.2 \mathrm{~b}$ \\
\hline $\mathrm{KNO}_{3}(3 \%)$ & $20.2 \mathrm{a}$ & $20.4 \mathrm{a}$ & $7.0 \mathrm{a}$ & $5.4 \mathrm{ab}$ & $60.2 \mathrm{a}$ & $76.6 \mathrm{a}$ & $48.2 \mathrm{a}$ & $32.4 \mathrm{ab}$ & $17.6 \mathrm{c}$ & $11.6 b$ \\
\hline
\end{tabular}




\begin{tabular}{llllllllllll}
\hline$p$-value & $\mathrm{NS}^{\mathrm{B}}$ & $\mathrm{NS}$ & $\mathrm{NS}$ & $\mathrm{NS}$ & $\mathrm{NS}$ & $\mathrm{NS}$ & $\mathrm{NS}$ & 0.031 & $<0.001$ & $<0.001$ \\
\hline
\end{tabular}

${ }^{\text {A }}$ Values expressed are least squares means (LSM) and are based on a sample size of $\mathrm{n}=5$.

${ }^{\text {B }}$ Values followed by different letters within a column are significantly different $(P<0.05)$.

${ }^{\mathrm{C}} \mathrm{NS}=$ not significant $(P>0.05)$. 
Chapter 3: Chemical Composition, Antioxidant Activity, Total Phenolics, and Mineral Nutrient Concentration of 'Wonderful' Pomegranate (Punica granatum L.) Fruit: Characterization and Effects of Foliar Nutrient Applications

\subsection{Introduction}

Pomegranate (Punica granatum) is a subtropical fruit tree crop that has been cultivated for several thousand years (Holland, Hatib, \& Bar-Ya'akov, 2009; Levin, 2006). Pomegranates are now cultivated in numerous subtemperate, temperate, tropical, and subtropical regions throughout the world (Verma, Mohanty, \& Lal, 2010). The majority of the United States' pomegranate production is with the cultivar Wonderful (Holland et al., 2009; Stover \& Mercure, 2007), which is known for its fruit size, flavor, and dark red rind and juice that fit market parameters for fresh market and juice concentrate commercial applications (Stover \& Mercure, 2007). The primary uses for pomegranate are as fresh market fruit and valued-added products, which include fresh and concentrated fruit juice, mixed juices, wines, liquors, grenadine, syrup, and preserves (Melgarejo, 2012). In the United States, the primary commercial use for pomegranate fruit in value-added products is in juice.

Pomegranate fruit are harvested and evaluated based upon a variety of internal parameters, including total soluble solids (TSS) (Fawole \& Opara, 2013) and titratable acidity (TA) (Kader, Chordas, \& Elyatem, 1984). In the juice of mature pomegranate fruit, sugar concentration is highly variable, ranging from $8-21.9 \%$ TSS and $0.0-3.4 \%$ sucrose (reviewed in Levin, 2006). Sugar concentration varies with harvest date (Fawole \& Opara, 2013), climate, cultivar, and even among fruits produced from the same plant (Levin, 2006). TA of the juice of mature pomegranate fruit is also highly variable and cultivar-dependent, ranging from $0.35-3.36 \mathrm{wt} \cdot \mathrm{vol}^{-1}$ 
citric acid (Akbarpour, Hemmati, \& Sharifani, 2009). Minimum maturity guidelines established in California require that total TA be less than $1.85 \% \mathrm{wt}^{-} \mathrm{vol}^{-1}$ citric acid (Kader, 2006). In other countries, maturity indices are based on the sugar to acid ratio of the juice (Fawole \& Opara, 2013). Before recommending any new agricultural practice to growers, cultivar-specific effects of such practices on TSS and TA will, therefore, be critical to ensure that fruit quality is not negatively impacted, especially with respect to proper determination of harvest maturity.

Current investigations regarding the putative health benefits of pomegranate, including antiinflammatory, anticancer, and antioxidant properties (reviewed in Lansky \& Newman, 2007), have led to increased worldwide demand and interest in pomegranate fruit. Numerous studies have been conducted to identify bioactive compounds and quantify putative health and nutritional benefits of pomegranate juice and/or peel (Çam, Hış1l, \& Durmaz, 2009; Gil, TomásBarberán, Hess-Pierce, Holcroft, \& Kader, 2000; Ozgen, Durgaç, Serçe, \& Kaya, 2008; Tehranifar, Zarei, Nemati, Esfandiyari, \& Vazifeshenas, 2010; Tezcan, Gültekin-Özgüven, Diken, Özçelik, \& Erim, 2009). Molyneux (2004) observed an increased interest in research regarding antioxidants and their presumed ability to prevent or reduce the deleterious effects of oxidizing free-radicals in the human body. Research suggests that pomegranate juice has greater levels of antioxidant activity (AA) than many other beverages known to be high in AA, including red wine and green tea (Gil et al., 2000). The antioxidants identified in pomegranates include ascorbic acid and three known groups of polyphenolic compounds, anthocyanins (Tehranifar et al., 2010), ellagic acid and its derivatives, and hydrolyzable tannins (Gil et al., 2000). The polyphenolic content of pomegranate fruit varies greatly and is often quantified in total phenolics (TP) (Gil et al., 2000). Previous research indicates that hydrolyzable tannins are 15-30 times more effective than simple phenols at quenching peroxyl, a free-radical oxidizing molecule 
(Hagerman et al., 1998) that is the most commonplace free radical in humans (Wang, 2006). Ellagitannins make up the majority of the hydrolyzable tannins found in pomegranate fruit and give pomegranate fruit $90 \%$ of its antioxidant capacity (Gil et al., 2000). The combined AA of the juice can be measured by its ability to quench an oxidizing chemical compound such as 2,2 'diphenyl-1-picrylhydrazyl (DPPH) and the polyphenolic content of pomegranate fruit can be collectively quantified as total phenolics (TP) (Gil et al., 2000). Previous studies have demonstrated that AA and TP of pomegranate fruit are cultivar-dependent (Akbarpour et al., 2009; Tehranifar et al., 2010). Harvest date can also affect pomegranate fruit AA. Fawole \& Opara (2013) found that TP of 'Ruby' pomegranate increased during the final stages of fruit development. Little else is known about factors affecting AA and TP of mature pomegranate fruit.

There is limited peer-reviewed literature regarding the mineral nutrient concentrations of mature pomegranate fruit. In a study of 'Malas Yazdi' pomegranates in Iran, Mirdehghan \& Rahemi (2007) reported that nutrient concentrations varied with the part of the fruit tested and the stage of development of the fruit. Concentrations of calcium $(\mathrm{Ca})$ and sodium $(\mathrm{Na})$ in the peel were greater than that in the arils, but concentrations of nitrogen $(\mathrm{N})$, phosphorus $(\mathrm{P})$, potassium $(\mathrm{K})$, and magnesium $(\mathrm{Mg})$ were greater in the arils than in the peel. Fawole \& Opara (2013) reported that for 'Ruby' pomegranates, $\mathrm{N}$ and $\mathrm{K}$ were in the greatest concentration in the arils. In a study of six Turkish pomegranate cultivars, Hepaksoy, Aksoy, Can, \& Ui (2000) reported that aril pulp $\mathrm{N}$ and $\mathrm{K}$ concentrations and peel $\mathrm{Ca}$ concentrations were cultivar-dependent, but no other fruit macronutrient concentrations in the aril pulp or peel were reported to be cultivar-dependent. Cultivar-specific studies of pomegranate fruit nutrient concentrations are needed in order to more fully characterize the potential nutritional value of pomegranate fruit. 
With increased interest in the potential benefits of pomegranates to human health, the use of more intensive agricultural practices, including foliar fertilizer applications, is likely to increase. However, limited peer-reviewed evidence exists regarding the effects of such agricultural practices on TSS, TA, AA, TP, and mineral nutrient concentration of mature pomegranate fruit. Increases in pomegranate fruit TSS have been reported in response to applications of foliar fertilizers, including zinc sulfate $\left(\mathrm{ZnSO}_{4}\right)$ (Hasani, Zamani, Savaghebi, \& Fatahi, 2012), manganese sulfate $\left(\mathrm{MnSO}_{4}\right)$ (Hasani et al., 2012), potassium silicate $\left(\mathrm{K}_{2} \mathrm{O}_{3} \mathrm{Si}\right)$ (Wassel, Gobara, Ibrahiem, \& Shaaban-Mai, 2015), and K applied as soluble potash (Tehranifar \& Tabar, 2009). Foliar applications of $\mathrm{K}$ as soluble potash also increased pomegranate juice TA (Tehranifar \& Tabar, 2009). Khayyat et al. (2012) reported that foliar applications of potassium nitrate $\left(\mathrm{KNO}_{3}\right)$ resulted in increased concentrations of the antioxidant, ascorbic acid, in pomegranate fruit. Of these studies, only Wassel et al. (2015) used 'Wonderful' pomegranate. Little else is known about the effects of foliar fertilizer applications on the pomegranate fruit characteristics that contribute to its internal quality, putative health benefits and nutritional value. Therefore, the objectives of this study were to quantify TSS, TA, AA, TP, and fruit nutrient concentration of 'Wonderful' pomegranate fruit, and to determine the effects of three commonly used foliar fertilizers, $\mathrm{ZnSO}_{4}$, magnesium sulfate $\left(\mathrm{MgSO}_{4}\right)$, and $\mathrm{KNO}_{3}$, on these key internal fruit quality parameters.

\subsection{Materials and Methods}

\subsubsection{Solvents, Chemicals, and Reagents}

Solvents, chemicals, and reagents used to measure TA, AA, and TP of filtered pomegranate juice were of analytical grade. Solvents used were ethanol (Acros Organics, Morris Plains, NJ, USA) 
and methanol (Fisher Scientific, Pittsburgh, PA, USA). Chemicals used were gallic acid (Acros Organics) and 2,2-diphenyl-1-picrylhydrazle (EMD Chemicals, San Diego, CA, USA). Reagents used were Folin-Ciocalteu reagent (MP Biomedicals, LLC, Solon, OH, USA), sodium carbonate $\left(\mathrm{Na}_{2} \mathrm{CO}_{3}\right)$ (Aqua Solutions, Deer Park, TX, USA), and sodium hydroxide $(\mathrm{NaOH})$ (Fisher Scientific). The chemicals used to treat the pomegranate trees included $\mathrm{ZnSO}_{4}$ (Zinc Nacional, S.A. Monterrey, NL, Mexico), $\mathrm{MgSO}_{4}$ (PQ Corporation, Valley Forge, PA, USA), and $\mathrm{KNO}_{3}$ (Haifa Chemicals, Haifa Bay, Israel), applied with a non-ionic surfactant consisting of the active ingredients, methyl esters of fatty acids, [N,N-bis 2-(omega-hydroxypolyoxyethylene) ethyl alkylamine], and tall oil fatty acids (Miller Chemical and Fertilizer, LLC, Hanover, PA, USA).

\subsubsection{Plant Material and Experimental Design}

This study was conducted using 9-year-old bearing 'Wonderful' pomegranate trees at 2 commercial orchards in Kern County, CA, USA (site 1: latitude: $35^{\circ} 04^{\prime} 09.20 " \mathrm{~N}$, longitude: $119^{\circ} 18^{\prime} 47.74^{\prime \prime W}$; site 2: latitude: $35^{\circ} 40^{\prime} 33.55^{\prime \prime} \mathrm{N}$, longitude: $119^{\circ} 55^{\prime} 16.72 " \mathrm{~W}$ ) that had early- and late-season harvested crops (site 1 and site 2, respectively). The experiment was conducted using whole-tree experimental units and a randomized complete block design with 6 blocks at each site for TSS analyses, 7 blocks at each site for TA, AA, and TP analyses, and 5 blocks at site 2 for fruit nutrient concentration analyses.

Treatments consisted of foliar applications of $\mathrm{ZnSO}_{4}\left(3000 \mathrm{mg} \cdot \mathrm{L}^{-1}, 4000 \mathrm{mg} \cdot \mathrm{L}^{-1}\right.$, or $5000 \mathrm{mg} \cdot \mathrm{L}^{-}$ $\left.{ }^{1}\right), \mathrm{MgSO}_{4}(1 \%, 2 \%$, or $3 \%), \mathrm{KNO}_{3}(1 \%, 2 \%$, or $3 \%)$, or deionized water (control) for a total of 70 data trees at each site. All solutions were formulated in deionized water with $0.50 \%$ nonionic surfactant. Treatments were applied to runoff with a professional backpack sprayer (SP1, SP Systems International, Incorporated, Santa Monica, CA, USA) at early fruit set (July, when 
fruit were green to breaker with an equatorial diameter of approximately $50 \mathrm{~mm}$ ) and late fruit set (August, when fruit were red with an equatorial diameter of approximately $70 \mathrm{~mm}$ ), except for $\mathrm{ZnSO}_{4}$ treatments, which were applied only at early fruit set.

\subsubsection{Fruit collection and aril and juice extraction}

At harvest (in early October and early November at site 1 and 2, respectively), a random sample of up to 5 unsplit fruit per data tree was collected for TSS determination and stored at $5-8{ }^{\circ} \mathrm{C}$ for up to $19 \mathrm{~d}$ until arils could be manually extracted and pressed immediately to quantify TSS of unfiltered juice. An additional random sample of up to 5 unsplit fruit per data tree was collected at harvest for TA, AA, and TP analyses and stored at $5-8{ }^{\circ} \mathrm{C}$ for up to $19 \mathrm{~d}$ until arils could be

extracted. Arils were pooled per data tree and stored for approximately $1-1.25 \mathrm{yr}$ at $-80{ }^{\circ} \mathrm{C}$ until conducting analyses. Just prior to these analyses, arils were defrosted in a $0-2{ }^{\circ} \mathrm{C}$ cold water ice bath in a controlled atmosphere refrigeration unit maintained at $4.4^{\circ} \mathrm{C}$ with $99 \%$ humidity. Arils thawed to $0.8-4.5{ }^{\circ} \mathrm{C}$ were pressed using a heavy-duty hand operated juice extractor (StriteAnderson Manufacturing Company, Minneapolis, MN, USA). The juice was filtered through a $2.7 \mu \mathrm{m}$ silica mesh syringe filter (Whatman PLC; Pittsburg, PA, USA). Immediately after filtration, each aliquot was analyzed at room temperature for TA, AA, and TP. To determine fruit nutrient concentrations, 10 additional mature unsplit fruit were collected at harvest from each data tree.

\subsubsection{Determination of TSS}

TSS of juiced arils was measured using a hand-held refractometer. One analysis was performed per sample. 


\subsubsection{Determination of TA}

TA of juice was determined using an automatic titrator (AT-610, Kyoto Electronics Manufacturing Co., Ltd., Tokyo, Japan) equipped with a multiple sample changer (CHA-600, Kyoto Electronics Manufacturing Co., Ltd.) and was expressed in $\mathrm{g} \cdot \mathrm{L}^{-1}$ of citric acid. Samples consisted of $5 \mathrm{~mL}$ of filtered pomegranate juice diluted with $45 \mathrm{~mL}$ deionized (DI) water. Titrations were performed using $0.1 \mathrm{~N} \mathrm{NaOH}$. One analysis was performed per sample.

\subsubsection{Determination of AA}

AA of juice was quantified utilizing the methods described in Gil et al. (2000) with modifications specified by Molyneux (2004). Aliquots of $2 \mathrm{~mL}$ of juice were diluted 100 -fold in a 6:4 methanol:nanopure water solution and added to $2 \mathrm{~mL}$ of $0.1 \mathrm{mM} \mathrm{DPPH}$ dissolved in spectrophotometric grade ethanol and left in the dark for $0.5 \mathrm{~h}$ at room temperature. A control solution was produced by adding $2 \mathrm{~mL}$ of $6: 4$ methanol:nanopure water solution to $2 \mathrm{~mL}$ of 0.1 mM DPPH. Absorbance of the juice solutions $\left(A_{b}\right)$ and the control $\left(A_{0}\right)$ were measured at 517 nm with a spectrophotometer (UV-1700; Shimadzu Scientific Instruments). Samples were run in triplicate. AA was expressed as an inhibition percentage calculated using the following equation:

$$
\mathrm{AA}=\left(1-\mathrm{A}_{\mathrm{b}} / \mathrm{A}_{0}\right) \times 100
$$

\subsubsection{Determination of TP}

Juice TP were quantified via spectrophotometry utilizing the Folin-Ciocalteu method with modifications (Singleton, Orthofer, \& Lamuela-Raventós, 1999). In $4 \mathrm{~mL}$ cuvettes, $1.5 \mathrm{~mL}$ of Folin-Ciocalteu reagent diluted 1:10 in nanopure water was mixed with $300 \mu \mathrm{L}$ of filtered juice 
diluted 100-fold in a 6:4 methanol:nanopure water solution. After $3 \mathrm{~min}, 1.2 \mathrm{~mL}$ of $7.5 \%$ $\mathrm{Na}_{2} \mathrm{CO}_{3}$ was added and the solution was left in the dark for $1.5 \mathrm{~h}$ at room temperature. Absorbance was measured at $760 \mathrm{~nm}$ with a spectrophotometer (UV-1700; Shimadzu Scientific Instruments, Columbia, MD, USA) and quantified using gallic acid as a standard. Results were expressed as milligrams of gallic acid equivalents (GAE) per liter. Samples were run in triplicate.

\subsubsection{Determination of Fruit Nutrient Concentration}

Fruit were sent to Fruit Growers Lab, Inc. (Santa Paula, CA) for whole-fruit analysis of nutrients, including $\mathrm{N}, \mathrm{P}, \mathrm{K}, \mathrm{Ca}, \mathrm{Mg}, \mathrm{Na}$, boron $(\mathrm{B})$, copper $(\mathrm{Cu})$, iron $(\mathrm{Fe}), \mathrm{Mn}$, and $\mathrm{Zn}$ using the Leggingwell Nutrient Analysis System (NAS) and software, procedure S-2001. Total N concentration was determined based on AOAC Combustion Method 993.13 using a Leco Analyzer Nitrogen Determinator (PP428, Leco Corporation, St. Joseph, MI, USA). Fruit were washed, cut, blended for $2 \mathrm{~min}$, and dried in a forced-air drying oven at $110{ }^{\circ} \mathrm{C}$ for $12 \mathrm{~h}$. Samples were then placed in glass jars, transferred to a $50{ }^{\circ} \mathrm{C}$ vacuum oven for $1 \mathrm{~h}$ and then run in the analyzer. The dry ash method was used to determine the concentration of all other elements. Dried, ground samples (2-3 g) were placed in a muffle furnace and the temperature was incrementally increased by $2{ }^{\circ} \mathrm{C}$ per minute until it reached $300{ }^{\circ} \mathrm{C}$. Samples were held at $300{ }^{\circ} \mathrm{C}$ for $2 \mathrm{~h}$ and then the temperature was increased incrementally by $2{ }^{\circ} \mathrm{C}$ per minute until it reached $550{ }^{\circ} \mathrm{C}$ for $12 \mathrm{~h}$ or until samples were completely composed of ash. Ashed samples are allowed to dry and then mixed with $1: 1$ ultrapure water: $\mathrm{HCl}$ on a $175^{\circ} \mathrm{C}$ hot plate for $10-15 \mathrm{~min}$,

until samples were completely dissolved. Scandium was added and samples were analyzed with an inductively coupled plasma analyzer (Optima 3000, PerkinElmer, Waltham, MA, USA). 


\subsubsection{Statistical Analysis}

For each of TSS, TA, AA, TP and fruit nutrient concentration, fertilizer treatments were compared using a mixed effects analysis of variance (ANOVA) using restricted maximum likelihood estimation (REML) with fertilizer concentration nested in fertilizer type as fixed effects and experimental blocks as random effects. Models for each site were fit separately. Partial F-tests to examine all terms with common factors of interest were used prior to tests for individual model terms to reduce Type I error. When ANOVA indicated significant differences, post-hoc comparisons were run utilizing Tukey's honestly significant difference (HSD) with an experimentwise error rate of $\alpha=0.05$. Relationships between TP, AA, and TA were analyzed using linear regression $(\alpha=0.05)$. Results for analyses are expressed as least squares means (LSM). All statistical tests were performed using JMP, Version 10 statistical software (SAS Institute Inc., Cary, NC, USA).

\subsection{Results and Discussion}

\subsubsection{TSS}

No significant differences in TSS were detected between treatments or between sites $(P=0.05)$ and TSS ranged from 16.54-18.02\% (Table 1). Though the study reported herein was conducted in a semi-arid climate, the values were consistent with those previously reported for 'Wonderful' pomegranate grown in Mediterranean climates. Shwartz et al. (2009) reported 17.1-18.3\% TSS for fruit of a landrace of 'Wonderful' pomegranate grown in Israel and Beaulieu et al. (2015) reported a mean TSS of $17.7 \%$ for 'Wonderful' pomegranate grown in Winters, CA, USA. Additionally, Elyatem \& Kader (1984) reported a similar range of TSS for 'Wonderful' pomegranate (16.7-18.1\%), even under different storage temperatures and durations. Taken 
together, this suggests that the TSS of mature 'Wonderful' pomegranate fruit is not highly variable, which might explain the lack of significant differences in TSS detected between the treatments in the current study. However, Wassel et al. (2015) reported that foliar applications of $0.1 \% \mathrm{~K}_{2} \mathrm{O}_{3} \mathrm{Si}$ resulted in significantly greater TSS of 'Wonderful' pomegranate fruit as compared to untreated control trees $(15.00 \%$ and $14.00 \%$, respectively), though the relatively low TSS and high acid content they reported suggests that the fruit used in that study might not have been mature at harvest. Additionally, the amount of K applied in the study by Wassel et al. (2015) was 10 times lower than the lowest concentration in the study reported herein, suggesting that the change in TSS might have been as a result of the Si, which is known to affect many aspects of plant growth. Hasani et al. (2012) reported that foliar applications of $\mathrm{ZnSO}_{4}(0.3 \%$ or $0.6 \%)$ significantly increased juice TSS of 'Malas-e-Torsh-e-Saveh' pomegranates as compared to

controls treated with water. As the $\mathrm{ZnSO}_{4}$ concentrations used by Hasani et al. (2012) were similar to those used in the study reported herein, this suggests that certain cultivars are more susceptible than 'Wonderful' to changes in TSS in response to foliar $\mathrm{ZnSO}_{4}$ applications. The current study is the first known published research regarding the effects of foliar $\mathrm{MgSO}_{4}$ or $\mathrm{KNO}_{3}$ on the TSS of pomegranate fruit.

\subsubsection{TA}

All fruit tested met the California minimum maturity standard for picking, as they had less than $1.85 \mathrm{wt} \cdot \mathrm{vol}^{-1}$ citric acid (Kader, 2006). TA ranged from 1.02-1.48 wt $\cdot \mathrm{vol}^{-1}$ citric acid (Table 1). These TA values are consistent with those reported by Beaulieu et al. (2015), who reported that 'Wonderful' pomegranates harvested in two growing regions of CA, USA had a mean TA of 1.10 and $1.32 \mathrm{wt}^{\mathrm{t}} \cdot \mathrm{vol}^{-1}$ citric acid. 
In the current study, no significant differences in TA were detected between treatments or between sites ( $P=0.05$; Table 1$)$. Using lower concentrations of $\mathrm{K}\left(3 \mathrm{~g} \cdot \mathrm{L}^{-1} \mathrm{~K}\right.$ applied foliarly as soluble potash), Tehranifar \& Tabar (2009) reported significant increases in TA of 'Shishe Kabe Ferdows' pomegranate juice as compared to juice from control trees treated with water. This suggests that the effects of foliar $\mathrm{K}$ applications on pomegranate TA might be dependent on cultivar or on the type of $\mathrm{K}$ fertilizer used. The study reported herein appears to be the first published study on the effects of foliar nutrient applications on TA of 'Wonderful' pomegranate fruit and the first known published research regarding the effects of foliar-applied $\mathrm{Zn}$ or $\mathrm{Mg}$ on TA of pomegranate fruit. It is important to both growers and the beverage industry that cultural practices such as foliar nutrient applications not negatively impact TA, as it is an indicator of fruit maturity (Kader, 2006) and an important factor affecting fruit juice sourness and flavor intensity (Kader, Stevens, Albright-Holton, Morris, \& Algazi, 1977) and consumer preference.

\subsubsection{AA}

The juice exhibited considerable radical scavenging abilities across all treatments at both field sites with AA ranging from 77.8-84.3\% DPPH inhibition (Table 1). Inhibition of the free radical, DPPH, is an indication of the effectiveness of chemical compounds to reduce free radicals in solution (Molyneux, 2004). The data reported in the study herein are consistent with that of Çam et al. (2009), who reported that AA of several pomegranate cultivars, including 'Zivzik', a commercially important Turkish cultivar, ranged from 73.0-91.8\% DPPH inhibition.

Kaur, Jabbar, Athar, \& Alam (2006) also reported that peel extract of pomegranate exhibited 81.6\% DPPH inhibition. However, other researchers have reported lower AA in pomegranate fruit. The juice of several Iranian pomegranate cultivars, including 'Malas Yazdi' and 'Malas Save', which are important commercial cultivars, had AA of only 15.59-40.72\% DPPH 
inhibition (Tehranifar et al., 2010). The smaller diluted juice aliquots utilized by Tehranifar et al. (2010) (compare $100 \mu \mathrm{L}$ to $2000 \mu \mathrm{L}$ used in the current study) might have resulted in an underestimation of juice AA in their study. According to Molyneux (2004), equal volumes of reductant to DPPH solution in the reaction vessel help ensure optimal analytical accuracy when quantifying antioxidant activity. Though the AA levels reported herein were determined using juice of arils frozen at $-80{ }^{\circ} \mathrm{C}$ for more than 1 year, they were on par with those based on fresh samples (Zhuang, Du, \& Wang, 2011). Though Gil et al. (2000) reported that juice AA of arils stored at $-20^{\circ} \mathrm{C}$ for 9 months were lower than fresh unfrozen samples, Çam et al. (2009) reported AA of pomegranate juice stored at $-40{ }^{\circ} \mathrm{C}$ for four months that were similar to those of other researchers analyzing fresh fruit. Taken together, this suggests that freezing arils at -80 to $-40{ }^{\circ} \mathrm{C}$ is a viable option for researchers processing large quantities of pomegranates for AA quantification.

At site 1 , foliar applications of $5000 \mathrm{mg} \cdot \mathrm{L}^{-1} \mathrm{ZnSO}_{4}$ or $3 \% \mathrm{MgSO}_{4}$ resulted in significantly greater fruit AA than applications of $1 \% \mathrm{KNO}_{3}($ Table $1 ; P=0.0302)$. No other statistically significant differences in AA were detected between any other treatments at either site $(P=$ 0.05). These results suggest that foliar applications of $\mathrm{KNO}_{3}$ to pomegranate might reduce AA in pomegranate fruit. Skupien, Ochmian, \& Grajkowski (2008) reported that foliar applications of nutrient mixes that included $\mathrm{K}$ and $\mathrm{N}$ significantly decreased AA of Aronia berries as compared to those of control plants treated with DI water. However, Khayyat et al. (2012) reported that foliar applications of $0.025 \% \mathrm{KNO}_{3}$ applied during early fruit development increased the concentration of the antioxidant, ascorbic acid, of mature 'Malas Yazdi' pomegranate fruit as compared to those from control trees sprayed with distilled water. Foliar $\mathrm{KNO}_{3}$ applications might increase pomegranate fruit ascorbic acid concentrations but reduce 
concentrations of other antioxidants. Additionally, the effect of foliar $\mathrm{KNO}_{3}$ applications on pomegranate fruit AA could be concentration- or cultivar-dependent. The study reported herein is the first known study to document the effects of foliar nutrients on AA of 'Wonderful' pomegranate fruit and is the first known published research regarding the effects of foliar $\mathrm{ZnSO}_{4}$ or $\mathrm{MgSO}_{4}$ on the AA of pomegranate fruit. The results of the current study suggest that foliar $\mathrm{KNO}_{3}$ applications to 'Wonderful' pomegranate might not be appropriate, but applications of $\mathrm{ZnSO}_{4}$ or $\mathrm{MgSO}_{4}$ within the tested concentration ranges could be used as part of a pomegranate fertility plan without negatively affecting AA. Though AA is not known to affect the sensory profile of food commodities (Preedy, 2014), value-added pomegranate products, such as juice, are often marketed based on their high AA. The AA levels detected in the study reported herein were substantially greater than those reported for commercial juices labeled as $100 \%$ pomegranate juice (Tezcan et al., 2009). If processing and/or storing pomegranate juice decreases AA, it will be critical that grower practices such as foliar fertilizer applications not also decrease AA.

\subsubsection{TP}

Pomegranate juice TP ranged from 2489-3046 mg. $\mathrm{L}^{-1} \mathrm{GAE}$ (Table 1). TP of pomegranate varies greatly with cultivar. Hmid, Elothmani, Hanine, Oukabli, \& Mehinagic (2013) reported that for 18 pomegranate cultivars, juice TP ranged from $1284-9476 \mathrm{mg} \cdot \mathrm{L}^{-1} \mathrm{GAE}$ with $4100 \mathrm{mg} \cdot \mathrm{L}^{-1} \mathrm{GAE}$ for 'Wonderful'. Gil et al. (2000) reported that 'Wonderful' pomegranate juice from pressed arils had a mean TP of $2117 \mathrm{mg} \cdot \mathrm{L}^{-1} \mathrm{GAE}$. Therefore, the juice TP in the study reported herein was consistent with that previously reported for 'Wonderful' pomegranate. 
Foliar applications of $2 \% \mathrm{KNO}_{3}$ resulted in statistically significantly greater TP at site 2 (Table $1 ; P=0.0382$ ). No other statistically significant differences in TP were detected between any other treatments at either site $(P=0.05)$. This appears to be the first peer-reviewed study to document the effects of foliar applications of essential plant nutrients on TP of pomegranate fruit. Increased rates of $\mathrm{N}$ and $\mathrm{K}$ fertilization also results in increased anthocyanin synthesis in Tempranillo grape berry skins, thus increasing antioxidant content in the fruit (Delgado, Martín, del Álamo, \& González, 2004). If the increased TP in response to $\mathrm{KNO}_{3}$ in the current study was also due to increased anthocyanin production, this would be important in the pomegranate beverage industry, as anthocyanins influence beverage color.

\subsubsection{Relationships Between TA, AA, and TP}

There was a significant, positive correlation between TA and TP at site $1(\mathrm{r}=0.4236, P=$ $0.0005)$ but not at site $2(P=0.4740)$ (Table 2$)$. There were no significant correlations between TA and AA or between TP and AA, though at site 1, there was a weak, negative correlation between TP and AA $(r=-0.2329, P=0.0708)$. These findings are consistent with Çam et al. (2009), who reported that the relationship between TP and AA of pomegranate was not significant $(\mathrm{r}=0.634, P>0.05)$. However, significant, positive correlations between TP and AA of 'Wonderful' pomegranate fruit have been reported previously (Ozgen et al., 2008; Tezcan et al., 2009). Pomegranate juice is rich in ellagitannins and this phenolic compound is responsible for the majority of pomegranate juice AA (Gil et al., 2000). In the study reported herein, the effects of the fertilization treatments on $\mathrm{AA}$ and $\mathrm{TP}$ could be obscuring an underlying relationship between AA and TP. 


\subsubsection{Fruit Nutrient Analyses}

Fruit macronutrient (N, P, K, Ca, and Mg) concentrations (Table 3) were typically similar to those reported previously for mature fruit of pomegranate cultivars other than Wonderful (Fawole \& Opara, 2013; Hepaksoy et al., 2000; Mirdehghan \& Rahemi, 2007). However, in the current study, fruit $\mathrm{K}$ concentrations were several times greater than those reported previously for whole fruit of 'Ruby' (Fawole \& Opara, 2013) or 'Malas Yazdi' (Mirdehghan \& Rahemi, 2007) pomegranate, and for the pulp of several different Turkish pomegranate cultivars (Hepaksoy et al., 2000). Additionally, fruit $\mathrm{Ca}$ and $\mathrm{Mg}$ concentrations in the study reported herein were both several times greater than those reported for 'Ruby' pomegranate (Fawole \& Opara, 2013).

Fruit micronutrient ( $\mathrm{Na}, \mathrm{B}, \mathrm{Cu}, \mathrm{Fe}$, and $\mathrm{Mn}$ ) concentrations (Table 3) were typically also consistent with those reported previously for mature fruit of pomegranate cultivars other than Wonderful (Fawole \& Opara, 2013; Mirdehghan \& Rahemi, 2007). However, fruit Na concentrations in the study reported herein were much lower than those reported previously for 'Malas Yazdi' (Mirdehghan \& Rahemi, 2007) and 'Ruby’ (Fawole \& Opara, 2013) pomegranate. Additionally, fruit Fe concentrations in the current study were much lower than those reported previously for 'Ruby’ pomegranate (Fawole \& Opara, 2013).

The study reported herein is the first known peer-reviewed study to document fruit nutrient concentrations of 'Wonderful' pomegranate fruit. Differences in fruit macronutrient and micronutrient concentrations between the current study and previous studies could be cultivardependent or could be the result soil nutrient availability at different study sites. 
Fruit $\mathrm{Zn}$ concentrations were significantly greater for fruit from trees treated with foliar $\mathrm{ZnSO}_{4}$ (Table 3; $P=0.0003$ ) and were up to $77.7 \%$ greater than those of the control trees. Khorsandi, Yazdi, \& Vazifehshenas (2009) reported that three of four pomegranate cultivars treated with $4000 \mathrm{mg} \cdot \mathrm{L}^{-1} \mathrm{ZnSO}_{4}$ had significantly greater levels of juice $\mathrm{Zn}$ concentration than the control, though their fruit $\mathrm{Zn}$ concentrations were approximately ten times lower than those reported in the current study. This difference was likely due to the fact that Khorsandi et al. (2009) quantified $\mathrm{Zn}$ only in juice separated from the seed, whereas in the study reported herein, $\mathrm{Zn}$ concentrations were determined using the entire fruit.

No other significant differences in fruit nutrient concentrations were detected (Table 3; $P=$ 0.05). This is in contrast to Tehranifar \& Tabar (2009), who reported that K concentrations of peel and aril juice of 'Shishe Kabe Ferdows' pomegranate increased significantly when trees were sprayed with 1.5 or $3.0 \mathrm{~g} \cdot \mathrm{L}^{-1} \mathrm{~K}$ as compared to controls sprayed with water. Khayyat et al. (2012) reported that foliar applications of $250 \mathrm{mg} \cdot \mathrm{L}^{-1}$ or $500 \mathrm{mg} \cdot \mathrm{L}^{-1} \mathrm{KNO}_{3}$ applied during early fruit development significantly increased $\mathrm{K}$ concentration and reduced $\mathrm{N}$ concentration in the peel of 'Malas Yazdi' pomegranate as compared to control trees. The study reported herein is the first known peer-reviewed study to examine the effects of foliar nutrient applications on fruit nutrient concentrations of 'Wonderful' pomegranate fruit.

When fruit nutrient concentrations were calculated on a fresh mass basis for the control trees (data not shown), minerals of particular importance to human health (K, $\mathrm{Fe}, \mathrm{Zn}, \mathrm{Cu}, \mathrm{Ca}$, and $\mathrm{Mg}$ ) were typically equivalent to or greater than fruit nutrient concentrations reported by the United States Department of Agriculture (USDA) for fresh pomegranates or pomegranate juice (USDA, 2014). For example, fruit $\mathrm{K}$ concentrations in the current study were approximately $25 \%$ greater than those reported by the USDA. However, the USDA database did not state whether nutrient 
concentrations of pomegranate fruit were based on whole fruit or arils only, or whether pomegranate juice was obtained from arils only or by juicing whole fruit, which is commonplace in the California pomegranate juice industry (Gil et al., 2000).

Human deficiencies in Ca (Kumssa, et al., 2015), Cu (White \& Broadley, 2009), Fe (Kumssa, et al., 2015), Mg (White \& Broadley, 2009), and Zn (Kumssa, et al., 2015) are still prevalent in many parts of the world. Many fruits are rich sources of mineral nutrients important to human health, but to recommend pomegranate as a mineral-rich food source, cultivar-specific fruit mineral nutrient concentrations were needed. The results of the current study suggest that pomegranate fruit were a good source of each of these nutrients. Based on the current study, approximately 6-9 pomegranate fruit meet the daily mineral nutrient requirements (averaged between adult men and women) for $\mathrm{Ca}, \mathrm{Fe}, \mathrm{Mg}$, and $\mathrm{Zn}$ and the fruit nutrient concentrations were well below the upper limits for human consumption (National Institutes of Health, 2013), even for fruit treated with foliar nutrient applications. The results of the study reported herein suggest that foliar $\mathrm{Zn}$ fertilization of pomegranate may serve to improve human mineral nutrition.

\subsection{Conclusions}

Increased interest in pomegranate consumption and production has resulted in growing interest in maximizing tree productivity, and as such, the use of foliar fertilizer applications in pomegranate production will likely rise. This study added to the body of knowledge regarding the TSS, TA, AA, TP and nutrient concentration of 'Wonderful' pomegranate fruit and is the first to report on the effects of foliar fertilizers on TSS, TA, AA, TP and nutrient concentration of 'Wonderful' pomegranate fruit. Taken together, the results suggest that foliar applications of $\mathrm{ZnSO}_{4}, \mathrm{MgSO}_{4}$, 
or $\mathrm{KNO}_{3}$ to 'Wonderful' pomegranate had few to no negative side effects on measures of fruit internal quality (TSS and TA), putative health benefits (AA and TP), and mineral nutrient concentrations. 
Table 7

Total soluble solids (TSS; \%), titratable acidity (TA; $\mathrm{g} \cdot \mathrm{L}^{-1}$ citric acid), antioxidant activity (\% DPPH inhibition) and total phenolics (TP; $\mathrm{mg} \cdot \mathrm{L}^{-1}$ gallic acid equivalents (GAE)) of fruit from 'Wonderful' pomegrante trees treated with foliar applications of deinionized water (control), $\mathrm{ZnSO}_{4}\left(3000 \mathrm{mg} \cdot \mathrm{L}^{-1}, 4000 \mathrm{mg} \cdot \mathrm{L}^{-1}\right.$, or $\left.5000 \mathrm{mg} \cdot \mathrm{L}^{-1}\right), \mathrm{MgSO}_{4}(1 \%, 2 \%$, or $3 \%)$, or $\mathrm{KNO}_{3}(1 \%, 2 \%$, or $3 \%)$ at 2 commercial orchards in Kern County, CA, USA.

\begin{tabular}{|c|c|c|c|c|c|c|c|c|}
\hline Treatment & \multicolumn{2}{|c|}{ TSS } & \multicolumn{2}{|c|}{ TA } & \multicolumn{2}{|c|}{ AA } & \multicolumn{2}{|c|}{$\mathrm{TP}$} \\
\hline Control & $17.89 \mathrm{a}^{\mathrm{A}, \mathrm{B}}$ & $17.51 \mathrm{a}$ & $1.14 \mathrm{a}$ & $1.20 \mathrm{a}$ & $83.2 \mathrm{ab}$ & $81.8 \mathrm{a}$ & $2616 a$ & $2547 \mathrm{~b}$ \\
\hline $\mathrm{n}$ & 6 & 5 & 7 & 7 & 6 & 5 & 7 & 7 \\
\hline $\mathrm{ZnSO}_{4}\left(3000 \mathrm{mg} \cdot \mathrm{L}^{-1}\right)$ & $17.09 \mathrm{a}$ & $17.15 \mathrm{a}$ & $1.16 \mathrm{a}$ & $1.17 \mathrm{a}$ & $82.3 \mathrm{ab}$ & $82.0 \mathrm{a}$ & $2553 a$ & $2703 b$ \\
\hline $\mathrm{ZnSO}_{4}\left(4000 \mathrm{mg} \cdot \mathrm{L}^{-1}\right)$ & $18.00 \mathrm{a}$ & $17.35 \mathrm{a}$ & $1.16 \mathrm{a}$ & $1.13 \mathrm{a}$ & $80.5 \mathrm{ab}$ & $80.5 \mathrm{a}$ & $2749 a$ & $2663 b$ \\
\hline $\mathrm{n}$ & 6 & 6 & 7 & 6 & 7 & 4 & 7 & 6 \\
\hline $\mathrm{ZnSO}_{4}\left(5000 \mathrm{mg} \cdot \mathrm{L}^{-1}\right)$ & $17.42 \mathrm{a}$ & $17.60 \mathrm{a}$ & $1.25 \mathrm{a}$ & $1.30 \mathrm{a}$ & $84.3 \mathrm{a}$ & $81.9 \mathrm{a}$ & $2616 a$ & $2877 b$ \\
\hline $\mathrm{n}$ & 6 & 4 & 6 & 6 & 6 & 4 & 6 & 6 \\
\hline $\mathrm{n}$ & 6 & 6 & 6 & 7 & 6 & 5 & 6 & 7 \\
\hline
\end{tabular}




\begin{tabular}{|c|c|c|c|c|c|c|c|c|}
\hline $\mathrm{MgSO}_{4}(3 \%)$ & $17.17 \mathrm{a}$ & $17.54 \mathrm{a}$ & $1.17 \mathrm{a}$ & $1.21 \mathrm{a}$ & $84.1 \mathrm{a}$ & $81.6 a$ & $2750 \mathrm{a}$ & $2676 b$ \\
\hline $\mathrm{n}$ & 6 & 6 & 6 & 7 & 6 & 5 & 6 & 7 \\
\hline $\mathrm{KNO}_{3}(1 \%)$ & $17.57 \mathrm{a}$ & $16.54 \mathrm{a}$ & $1.02 \mathrm{a}$ & $1.13 \mathrm{a}$ & $77.8 \mathrm{~b}$ & $81.2 \mathrm{a}$ & $2489 \mathrm{a}$ & $2698 b$ \\
\hline $\mathrm{n}$ & 6 & 5 & 7 & 6 & 7 & 5 & 7 & 6 \\
\hline $\mathrm{KNO}_{3}(2 \%)$ & $17.79 \mathrm{a}$ & $16.72 \mathrm{a}$ & $1.05 \mathrm{a}$ & $1.48 \mathrm{a}$ & $82.8 \mathrm{ab}$ & $81.7 \mathrm{a}$ & $2548 \mathrm{a}$ & $3046 a$ \\
\hline $\mathrm{n}$ & 6 & 6 & 7 & 6 & 6 & 4 & 7 & 6 \\
\hline$p$-value & $\mathrm{NS}^{\mathrm{C}}$ & NS & NS & NS & 0.0302 & NS & NS & 0.0382 \\
\hline
\end{tabular}

${ }^{\mathrm{A}}$ Values expressed as least squares means (LSM).

${ }^{\text {B }}$ Values followed by different letters within a column are significantly different $(P<0.05)$.

${ }^{\mathrm{C}} \mathrm{NS}=$ not significant $(P>0.05)$ 
Table 8

Results of correlation analyses for titratable acidity (TA; $g \cdot \mathrm{L}^{-1}$ citric acid), total phenolics (TP; $\mathrm{mg} \cdot \mathrm{L}^{-1}$ gallic acid equivalents $(\mathrm{GAE})$ ), and antioxidant activity (AA; \% inhibition DPPH) of fruit from 'Wonderful' pomegrante trees treated with foliar applications of deinionized water (control), $\mathrm{ZnSO}_{4}\left(3000 \mathrm{mg} \cdot \mathrm{L}^{-1}, 4000 \mathrm{mg} \cdot \mathrm{L}^{-1}\right.$, or $\left.5000 \mathrm{mg} \cdot \mathrm{L}^{-1}\right), \mathrm{MgSO}_{4}(1 \%, 2 \%$, or $3 \%)$, or $\mathrm{KNO} 3(1 \%, 2 \%$, or $3 \%)$ at 2 commercial orchards in Kern County, CA, USA.

\begin{tabular}{llcccccc}
\hline Parameter & Parameter & \multicolumn{2}{c}{$\mathrm{n}$} & \multicolumn{2}{c}{$p$-value } \\
\cline { 3 - 8 } & & Site 1 & Site 2 & Site 1 & Site 2 & Site 1 & Site 2 \\
\hline TP & AA & 61 & 43 & -0.2329 & -0.0876 & 0.0708 & 0.5766 \\
TA & AA & 61 & 43 & 0.1679 & 0.1169 & 0.1960 & 0.4553 \\
TA & TP & 64 & 60 & 0.4236 & 0.0942 & 0.0005 & 0.4740 \\
\hline
\end{tabular}


Table 9

Fruit nutrient concentrations $\left(\mathrm{mg} \cdot 100 \mathrm{~g}^{-1}\right)$ from 'Wonderful' pomegrante trees treated with foliar applications of deinionized water (control), $\mathrm{ZnSO}_{4}\left(3000 \mathrm{mg} \cdot \mathrm{L}^{-1}, 4000 \mathrm{mg} \cdot \mathrm{L}^{-1}\right.$, or $\left.5000 \mathrm{mg} \cdot \mathrm{L}^{-1}\right), \mathrm{MgSO}_{4}(1 \%, 2 \%$, or $3 \%)$, or $\mathrm{KNO}_{3}(1 \%, 2 \%$, or $3 \%)$ at a commercial orchard in Kern County, CA, USA.

\begin{tabular}{lcccccccccccc}
\hline Treatment & $\mathrm{N}$ & $\mathrm{P}$ & $\mathrm{K}$ & $\mathrm{Ca}$ & $\mathrm{Mg}$ & $\mathrm{Na}$ & $\mathrm{B}$ & $\mathrm{Cu}$ & $\mathrm{Fe}$ & $\mathrm{Mn}$ & $\mathrm{Zn}$ & $\mathrm{n}$ \\
\hline Control (DI water) & $1139^{\mathrm{A}}$ & 141 & 1256 & 174 & 60 & 7.6 & 3.2 & 0.81 & 1.3 & 0.89 & 1.0 & 4 \\
$\mathrm{ZnSO}_{4}\left(3000 \mathrm{mg} \cdot \mathrm{L}^{-1}\right)$ & 1204 & 140 & 1242 & 164 & 61 & 7.2 & 3.2 & 0.86 & 1.4 & 1.0 & 1.6 & 5 \\
$\mathrm{ZnSO}_{4}\left(4000 \mathrm{mg} \cdot \mathrm{L}^{-1}\right)$ & 1260 & 161 & 1292 & 195 & 68 & 7.5 & 3.2 & 0.86 & 1.7 & 0.97 & 1.7 & 3 \\
$\mathrm{ZnSO}_{4}\left(5000 \mathrm{mg} \cdot \mathrm{L}^{-1}\right)$ & 1222 & 151 & 1262 & 192 & 65 & 8.2 & 3.2 & 0.84 & 1.5 & 0.90 & 1.8 & 5 \\
$\mathrm{MgSO}_{4}(1 \%)$ & 1160 & 141 & 1314 & 195 & 62 & 8.2 & 3.2 & 0.84 & 1.4 & 0.92 & 1.0 & 5 \\
$\mathrm{MgSO}_{4}(2 \%)$ & 1134 & 134 & 1226 & 180 & 60 & 7.2 & 3.1 & 0.74 & 1.3 & 0.92 & 0.94 & 5 \\
$\mathrm{MgSO}_{4}(3 \%)$ & 1106 & 144 & 1308 & 169 & 61 & 7.2 & 3.1 & 0.80 & 1.4 & 0.92 & 1.3 & 5 \\
$\mathrm{KNO}_{3}(1 \%)$ & 1084 & 138 & 1290 & 193 & 61 & 8.6 & 3.2 & 0.78 & 1.5 & 0.90 & 1.1 & 5 \\
$\mathrm{KNO}_{3}(2 \%)$ & 1100 & 135 & 1276 & 186 & 61 & 8.0 & 2.8 & 0.82 & 1.4 & 0.98 & 0.94 & 5 \\
$\mathrm{KNO}_{3}(3 \%)$ & 1040 & 138 & 1304 & 181 & 60 & 9.4 & 3.3 & 0.80 & 1.3 & 0.90 & 0.95 & 5 \\
\hline$p$-value & $\mathrm{NS}$ & $\mathrm{NS}$ & $\mathrm{NS}$ & $\mathrm{NS}$ & $\mathrm{NS}$ & $\mathrm{NS}$ & $\mathrm{NS}$ & $\mathrm{NS}$ & $\mathrm{NS}$ & $\mathrm{NS}$ & 0.0003 \\
\hline
\end{tabular}

${ }^{\text {A }}$ Values expressed as least squares means (LSM).

${ }^{\mathrm{B}} \mathrm{NS}=$ not significant $(P>0.05)$. 


\section{BIBLIOGRAPHY}

Afria, B. S., Pareek, C. S., Garg, D. K., \& Singh, K. (1999). Effect of foliar spray of micronutrients and their combinations on yield of pomegranate. Annals of Arid Zone, 38(2), 189-190.

Akbarpour, V., Hemmati, K., \& Sharifani, M. (2009). Physical and chemical properties of pomegranate (Punica granatum L.) fruit in maturation stage. AmericanEurasian Journal of Agricultural and Environmental Science, 6(4), 411-416.

Al-Zoreky, N. S. (2009). Antimicrobial activity of pomegranate (Punica granatum L.) fruit peels. International Journal of Food Microbiology, 134(3), 244-248.

Ashoush, I. S., \& Gadallah, M. G. (2012). Effects of different heating methods on the quality characteristics of pomegranate juice concentrates. Egyptian Journal of Food Science, 40, 1-14.

Bacha, M. A., \& Ibrahim, I. M. (1979). Effects of pinolene on splitting, yield and fruit quality of 'Banati' and 'Malfaluti' pomegranate trees. Egyptian Journal of Horticulture, 6(2), 135-140.

Barone E, Caruso T., Marra F. P., \& Sottile F. (2000). Preliminary observations on some Sicilian pomegranate (Punica granatum L.) varieties. Options méditerranéennes. Série A, Séminaires méditerranéens, 42, 137-141.

Beaulieu, J. C., Lloyd, S. W., Preece, J. E., Moersfelder, J. W., Stein-Chisholm, R. E., \& Obando-Ulloa, J. M. (2015). Physicochemical properties and aroma volatile 
profiles in a diverse collection of California-grown pomegranate (Punica granatum L.) germplasm. Food Chemistry, 181, 354-364.

Beer, R. (2003). The handbook of Tibetan Buddhist symbols. Chicago, United States: Serindia Publications, Inc.

Blois, M. S. (1958). Antioxidant determinations by the use of a stable free radical. Nature, 181, 1199-1200.

Blumenfeld, A., Shaya, F., \& Hillel, R. (2000). Cultivation of pomegranate. Options méditerranéennes. Série A, Séminaires méditerranéens, 42, 143-147.

Borochov-Neori, H., Judeinstein, S., Tripler, E., Harari, M., Greenberg, A., Shomer, I., \& Holland, D. (2009). Seasonal and cultivar variations in antioxidant and sensory quality of pomegranate (Punica granatum L.) fruit. Journal of Food Composition and Analysis, 22(3), 189-195.

Brand-Williams, W., Cuvelier, M., \& Berset, C. (1995). Use of a free radical method to evaluate antioxidant activity. LWT-Food Science and Technology, 28(1), 25-30.

California Department of Food and Agriculture (2013). California Agricultural Statistics Review 2012-2013. Retrieved from http://www.cdfa.ca.gov/statistics.

Çam, M., Hışıl, Y., \& Durmaz, G. (2009). Classification of eight pomegranate juices based on antioxidant capacity measured by four methods. Food Chemistry, 112(3), 721-726. 
Day, K. R., Andris, H. L., Klonsky, K. M., \& De Moura, R. L. (2005). Sample costs to establish and produce pomegranates. (Pamphlet PG-VS-05). Davis, CA: University of California Cooperative Extension.

Day, K. R., \& Wilkins, E. D. (2009). Commercial pomegranate (Punica granatum L.) production in California. Acta Horticulturae, 890, 275-285.

Delgado, R., Martín, P., del Álamo, M., \& González, M. R. (2004). Changes in the phenolic composition of grape berries during ripening in relation to vineyard nitrogen and potassium fertilization rates. Journal of the Science of Food and Agriculture, 84(7), 623-630.

El-Khawaga, A. S. (2007). Reduction in fruit cracking in 'Manfaluty' pomegranate following a foliar application with paclobutrazol and zinc sulphate. Journal of Applied Sciences Research, 3(9), 837-840.

El-Rhman, I. E. (2010). Physiological studies on cracking phenomena of pomegranates. Journal of Applied Sciences Research, 6(6), 696-703.

Elyatem, S. M., \& Kader, A. A. (1984). Post-harvest physiology and storage behaviour of pomegranate fruits. Scientia Horticulturae, 24(3), 287-298.

Fawole, O. A., \& Opara, U. L. (2013). Changes in physical properties, chemical and elemental composition and antioxidant capacity of pomegranate (cv. Ruby) fruit at five maturity stages. Scientia Horticulturae, 150, 37-46. 
Fernandez de Simon, B., Perez-Ilzarbe, J., Hernandez, T., Gomez-Cordoves, C., \& Estrella, I. (1992). Importance of phenolic compounds for the characterization of fruit juices. Journal of Agricultural and Food Chemistry, 40(9), 1531-1535.

Firake, N., \& Deolankar, K. (2000). Response of pomegranate to soluble fertilizers through drip. Journal of Maharashtra Agricultural Universities, 25(2), 196-197.

Fischer, U. A., Carle, R., \& Kammerer, D. R. (2011). Identification and quantification of phenolic compounds from pomegranate (Punica granatum L.) peel, mesocarp, aril and differently produced juices by HPLC-DAD-ESI/MS. Food Chemistry, 127, 807-821.

Folin, O., \& Denis, W. (1912). On phosphotungstic-phosphomolybdic compounds as color reagents. Journal of Biological Chemistry, 12(2), 239-243.

Gaig, P., Bartolome, B., Lleonart, R., García-Ortega, P., Palacios, R., \& Richart, C. (1999). Allergy to pomegranate (Punica granatum). Allergy, 54(3), 287-288.

Gavlak, R., Horneck, D., Miller, R. O., \& Kotuby-Amacher, J. (2003). Soil, plant and water reference methods for the western region. WCC-103 Publication, WREP$125,17-36$.

Gil, M. I., Tomás-Barberán, F. A., Hess-Pierce, B., Holcroft, D. M., \& Kader, A. A. (2000). Antioxidant activity of pomegranate juice and its relationship with phenolic composition and processing. Journal of Agricultural and Food Chemistry, 48(10), 4581-4589. 
Giménez, M., Martínez, J., Oltra, M. A., Martínez, J. J., \& Ferrández, M. (2000). Pomegranate (Punica granatum L.) leaf analysis: Correlation with harvest. Options Méditerranéennes. Série A: Séminaires Méditerranéens, 42, 179-185.

Giusti, M., \& Wrolstad, R. E. (2001). Characterization and measurement of anthocyanins by UV-visible spectroscopy. Current protocols in food analytical chemistry, F:F1:F1.2.

Glozer, K., \& Ferguson, L. (2008). Pomegranate production in Afghanistan. University of California, Davis. College of Agricultural and Environmental Sciences, 32.

Graham, S. A., Hall, J., Sytsma, K., \& Shi, S. H. (2005). Phylogenetic analysis of the Lythraceae based on four gene regions and morphology. International Journal of Plant Sciences, 166(6), 995-1017.

Hagerman, A. E., Riedl, K. M., Jones, G. A., Sovik, K. N., Ritchard, N. T., Hartzfeld, P. W., \& Riechel, T. L. (1998). High molecular weight plant polyphenolics (tannins) as biological antioxidants. Journal of Agricultural and Food Chemistry, 46(5), 1887-1892.

Häkkinen, S. H., Kärenlampi, S. O., Mykkänen, H. M., Heinonen, I. M., \& Törrönen, A. R. (2000). Ellagic acid content in berries: influence of domestic processing and storage. European Food Research and Technology, 212(1), 75-80. 
Hasani, M., Zamani, Z., Savaghebi, G., \& Fatahi, R. (2012). Effects of zinc and manganese as foliar spray on pomegranate yield, fruit quality and leaf minerals. Journal of Soil Science and Plant Nutrition, 12(3), 471-480.

He, L., Xu, H., Liu, X., He, W., Yuan, F., Hou, Z., \& Gao, Y. (2011). Identification of phenolic compounds from pomegranate (Punica granatum L.) seed residues and investigation into their antioxidant capacities by HPLC-ABTS assay. Food Research International, 44(5), 1161-1167.

Hepaksoy, S., Aksoy, U., Can, H. Z., \& Ui, M. A. (2000). Determination of relationship between fruit cracking and some physiological responses, leaf characteristics and nutritional status of some pomegranate varieties. Options méditerranéennes. Série A, Séminaires méditerranéens, 42, 81-86.

Hernández, F., Legua, P., Melgarejo-Sánchez, P., \& Martinez Font, R. (2012). The pomegranate tree in the world: Its problems and uses. Options méditerranéennes. Série A, Séminaires méditerranéens, 103, 11-26.

Hmid, I., Elothmani, D., Hanine, H., Oukabli, A., \& Mehinagic, E. (2013). Comparative study of phenolic compounds and their antioxidant attributes of eighteen pomegranate (Punica granatum L.) cultivars grown in Morocco. Arabian Journal of Chemistry, http://dx.doi.org/10.1016/j.arabjc.2013.10.011

Holland, D., \& Bar-Ya'akov, I. (2008). The pomegranate: new interest in an ancient fruit. Chronica Horticulturae, 48(3), 12-15. 
Holland, D., Hatib, K., \& Bar-Ya'akov, I. (2009). Pomegranate: botany, horticulture, breeding. Horticultural Reviews, 35, 127-191.

Jakobek, L., Šeruga, M., Jovanović, I. N., \& Medvidović-Kosanović, M. (2007). Flavonols, phenolic acids and antioxidant activity of some red fruits. Deutsche Lebensmittel-Rundschau, 103(8), 369-378.

Jalikop, S., Rawal, R., \& Kumar, R. (2005). Exploitation of sub-temperate pomegranate Daru in breeding tropical varieties. Acta Horticulturae, 696, 107-112.

Janeczko, A., \& Skoczowski, A. (2011). Mammalian sex hormones in plants. Folia Histochemica et cytobiologica, 43(2), 71-70.

Janick, J. (2005). The origins of fruits, fruit growing, and fruit breeding. Plant Breeding Reviews, 25, 255-320.

Janick, J. (2007). Fruits of the bibles. HortScience, 1072-1076.

Jarvis, S., Li, C., \& Bogle, R. G. (2010). Possible interaction between pomegranate juice and warfarin. Emergency Medicine Journal, 27(1), 74-75.

Kader, A. A. (2006). Postharvest biology and technology of pomegranates. Pomegranates: Ancient roots to modem medicine. Florida: CRC Press, 211-220.

Kader, A. A., Chordas, A., \& Elyatem, S. (1984). Responses of pomegranates to ethylene treatment and storage temperature. California Agriculture, 38(7), 14-15. 
Kader, A. A., Stevens, M. A., Albright-Holton, M., Morris, L. L., \& Algazi, M. (1977). Effect of fruit ripeness when picked on flavor and composition in fresh market tomatoes. Journal of the American Society for Horticultural Science, 102(6), 724731.

Kaur, G., Jabbar, Z., Athar, M., \& Alam, M. S. (2006). Punica granatum (pomegranate) flower extract possesses potent antioxidant activity and abrogates Fe-NTA induced hepatotoxicity in mice. Food and Chemical Toxicology, 44(7), 984-993.

Khayyat, M., Tehranifar, A., Zaree, M., Karimian, Z., Aminifard, M., Vazifeshenas, M., Amini, S., Noori, Y., \& Shakeri, M. (2012). Effects of potassium nitrate spraying on fruit characteristics of 'Malas Yazdi' pomegranate. Journal of Plant Nutrition, 35(9), 1387-1393.

Khorsandi, F., Yazdi, F. A., \& Vazifehshenas, M. R. (2009). Foliar zinc fertilization improves marketable fruit yield and quality attributes of pomegranate. Journal of Agricultural and Biology, 11, 766-770.

Kulkarni, A. P., \& Aradhya, S. M. (2005). Chemical changes and antioxidant activity in pomegranate arils during fruit development. Food Chemistry, 93(2), 319-324.

Kumssa, D. B., Joy, E. J., Ander, E. L., Watts, M. J., Young, S. D., Walker, S., \& Broadley, M. R. (2015). Dietary calcium and zinc deficiency risks are decreasing but remain prevalent. Scientific Reports, 5. 
Lakshmi, V. (2005). Pomegranate Dreams \& Other Stories. New Delhi, India: Indialog Publications.

Langley, P. (2000). Why a pomegranate? British Medical Journal, 321(7269), 11531154.

Lansky, E. P., \& Newman, R. A. (2007). Punica granatum (pomegranate) and its potential for prevention and treatment of inflammation and cancer. Journal of Ethnopharmacology, 109(2), 177-206.

Lansky, E., Shubert, S., \& Neeman, I. (2000). Pharmacological and therapeutic properties of pomegranate. Options Méditerranéennes. Série A: Séminaires Méditerranéens, $42,231-235$.

Lefeng, H., Yanxia, Z., Lijuan, F., Yanlei, Y., Zhaohe, Y., \& Xueqing, Z. (2010). The preliminary studies on fruit cracking characteristic and bagging cultivation in pomegranate cultivars. Chinese Agricultural Science Bulletin, 2, 181-184.

Levin, G. M. (2006). Pomegranate. Arizona, United States: Third Millennium Publishing.

Mars, M. (2000). Pomegranate plant material: Genetic resources and breeding, a review. Options Méditerranéennes. Série A: Séminaires Méditerranéens, 42, 55-62.

Mazza, G., Fukumoto, L., Delaquis, P., Girard, B., \& Ewert, B. (1999). Anthocyanins, phenolics, and color of Cabernet Franc, Merlot, and Pinot Noir wines from British Columbia. Journal of Agricultural and Food Chemistry, 47(10), 4009-4017. 
Melgarejo, P., Martínez, J. J., Hernández, F., Legua, P., Melgarejo-Sánchez, P., \& Martínez Font, R. (2012). The pomegranate tree in the world: its problems and uses. Options Méditerranéennes Série A: II International Symposium on the Pomegranate, 103, 11-26.

Melgarejo, P., Martínez, J., Hernández, F., Martínez-Font, R., Barrows, P., \& Erez, A. (2004). Kaolin treatment to reduce pomegranate sunburn. Scientia Horticulturae, 100(1), 349-353.

Mirdehghan, S. H., \& Rahemi, M. (2007). Seasonal changes of mineral nutrients and phenolics in pomegranate (Punica granatum L.) fruit. Scientia Horticulturae, 111(2), 120-127.

Molyneux, P. (2004). The use of the stable free radical diphenylpicrylhydrazyl (DPPH) for estimating antioxidant activity. Songklanakarin Journal of Science and Technology, 26(2), 211-219.

Muñoz, J. (2000). Harvest, manipulation and commercialisation systems of pomegranate (Punica granatum L.). Options Méditerranéennes Série A: Séminaires Méditerranéens, 42, 37-39.

Myers, D. (1971). The questing fear: Christian allegory in John Updike's "The Centaur". Twentieth Century Literature, 17(2), 73-82. 
National Agricultural Statistics Service, United States Department of Agriculture. (2007).

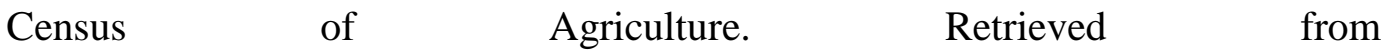
http://www.nass.usda.gov/Census_of_Agriculture/index.asp

National Institutes of Health (2013). Dietary Supplement Fact Sheets. Retrieved from https://ods.od.nih.gov/factsheets/list-all/

Ozgen S., M., Durgaç, C., Serçe, S., \& Kaya, C. (2008). Chemical and antioxidant properties of pomegranate cultivars grown in the Mediterranean region of Turkey. Food Chemistry, 111(3), 703-706.

Preedy, V. R. (2014). Processing and Impact on Antioxidants in Beverages. London, UK: Elsevier.

Saraf, R., Samaiya, R., Shukla, K., Sahu, T., \& Sahu, P. (2004). Effect of different sources of nutrients on growth of pomegranate (Punica granatum L.). Proceedings of a National Conference on Biodiversity and Sustainable Utilization of Biological Resources, Sagar, Madhya Pradesh, India, 203-208.

Seeram, N. P., Henning, S. M., Zhang, Y., Suchard, M., Li, Z., \& Heber, D. (2006). Pomegranate juice ellagitannin metabolites are present in human plasma and some persist in urine for up to 48 hours. The Journal of Nutrition, 136(10), 2481-2485.

Shwartz, E., Glazer, I., Bar-Ya'akov, I., Matityahu, I., Bar-Ilan, I., Holland, D., \& Amir, R. (2009). Changes in chemical constituents during the maturation and ripening of 
two commercially important pomegranate accessions. Food Chemistry, 115(3), 965-973.

Singh, D., \& Kingsly, A. (2007). Regulation of bahar in pomegranate (Punica granatum) to control of fruit cracking and improve the quality. Indian Journal of Agricultural Sciences, 77(10), 692.

Singh, R. P., Sharma, Y. P., \& Awasthi, R. P. (1993). Influence of different cultural practices on pre-mature fruit cracking of pomegranate. Progressive Horticulture, 22(14), 92-96.

Singh, D., \& Singh, R. K. (2004). Processed products of pomegranate. Magnesium, 44, 200.

Singleton, V. L., Orthofer, R., \& Lamuela-Raventós, R. M. (1999). Analysis of total phenols and other oxidation substrates and antioxidants by means of FolinCiocalteu reagent. Methods in Enzymology, 299, 152-178.

Singleton, V. L., \& Rossi Jr., J. A. (1965). Colorimetry of total phenolics with phosphomolybdic-phosphotungstic acid reagents. American Journal of Enology and Viticulture, 16(3), 144-158.

Skupień, K., Ochmian, I., \& Grajkowski, J. (2008). Influence of mineral fertilization on selected physical features and chemical composition of aronia fruit. Acta Agrophysica, 11(1), 213-226. 
Still, D. W. (2006). Pomegranates: A botanical perspective. Pomegranates: Ancient Roots to Modern Medicine. Boca Raton, FL: CRC Press, 200, 199-207.

Stover, E., \& Mercure, E. W. (2007). The pomegranate: a new look at the fruit of paradise. HortScience, 42(5), 1088-1092.

Sundararajan, A., Ganapathy, R., Huan, L., Dunlap, J. R., Webby, R. J., Kotwal, G. J., \& Sangster, M. Y. (2010). Influenza virus variation in susceptibility to inactivation by pomegranate polyphenols is determined by envelope glycoproteins. Antiviral Research, 88(1), 1-9.

Tehranifar, A., Zarei, M., Nemati, Z., Esfandiyari, B., \& Vazifeshenas, M. R. (2010). Investigation of physico-chemical properties and antioxidant activity of twenty Iranian pomegranate (Punica granatum L.) cultivars. Scientia Horticulturae, 126(2), 180-185.

Tezcan, F., Gültekin-Özgüven, M., Diken, T., Özçelik, B., \& Erim, F. B. (2009). Antioxidant activity and total phenolic, organic acid and sugar content in commercial pomegranate juices. Food Chemistry, 115(3), 873-877.

Tzulker, R., Glazer, I., Bar-Ilan, I., Holland, D., Aviram, M., \& Amir, R. (2007). Antioxidant activity, polyphenol content, and related compounds in different fruit juices and homogenates prepared from 29 different pomegranate accessions. Journal of Agricultural and Food Chemistry, 55(23), 9559-9570. 
United States Department of Agriculture. (2014). USDA National Nutrient Database for Standard Reference, Release 27 [Data file]. Retrieved from https://www.ars.usda.gov/SP2UserFiles/Place/80400525/Data/SR27/reports/sr27f g09.pdf

Varasteh, F., Arzani, K., Zamani, Z., \& Tabatabaei, S. Z. (2008). Physico-chemical seasonal changes of pomegranate (Punica granatum L.) fruit 'Malas-e-Torsh-eSaveh' in Iran. Acta Horticulturae, 769, 255-258.

Verma, N., Mohanty, A., \& Lal, A. (2010). Pomegranate genetic resources and germplasm conservation: a review. Fruit, Vegetable and Cereal Science and Biotechnology, 4(2), 120-125.

Wang, S. (2006). Effect of pre-harvest conditions on antioxidant capacity in fruits. Acta Horticulturae, 712, 299-306.

Wang, H., Cao, G., \& Prior, R. L. (1997). Oxygen radical absorbing capacity of anthocyanins. Journal of Agricultural and Food Chemistry, 45(2), 304-309.

Ward, C. (2003). Pomegranates in eastern Mediterranean contexts during the late Bronze Age. World Archaeology, 34(3), 529-541.

Wassel, A. H. M., Gobara, A. A., Ibrahiem, H. I. M., \& Shaaban-Mai, M. (2015). Response of Wonderful pomegranate trees to foliar application of amino acids, vitamins B and silicon. World Rural Observations, 7(3), 91-95. 
Waterhouse, A. L. (2001). Determination of total phenolics. Current Protocols in Food Analytical Chemistry, John Wiley \& Sons Inc., New York, 2002, I1.1.1-I1.1.7.

Weerakkody, P., Jobling, J., Infante, M. M. V., \& Rogers, G. (2010). The effect of maturity, sunburn and the application of sunscreens on the internal and external qualities of pomegranate fruit grown in Australia. Scientia Horticulturae, 124(1), $57-61$.

Westwood, M. N. (1988). Temperate-zone pomology. Oregon, United States: Timber Press.

Wetzstein, H. Y., Ravid, N., Wilkins, E., \& Martinelli, A. P. (2011a). A morphological and histological characterization of bisexual and male flower types in pomegranate. Journal of the American Society for Horticultural Science, 136(2), 83-92.

Wetzstein, H. Y., Zhang, Z., Ravid, N., \& Wetzstein, M. E. (2011b). Characterization of attributes related to fruit size in pomegranate. HortScience, 46(6), 908-912.

White, P. J., \& Broadley, M. R. (2009). Biofortification of crops with seven mineral elements often lacking in human diets-iron, zinc, copper, calcium, magnesium, selenium and iodine. New Phytologist, 182(1), 49-84.

Williamson, E., Evans, F., \& Wren, R. (1988). Potter's new cyclopaedia of botanical drugs and preparations. Saffron Walden (UK): CW Daniel Company Limited. 
Yazdi, F. A., \& Khorsandi, F. (2008). Zinc effect on the phytoestrogen content of pomegranate fruit tree. Trace Elements as Contaminants and Nutrients: Consequences in Ecosystems and Human Health, John Wiley \& Sons, Inc., Hoboken, NJ, USA. 217-231.

Yilmaz, C., \& Özgüven, A. (2009). The effects of some plant nutrients, gibberellic acid and pinolene treatments on the yield, fruit quality and cracking in pomegranate. Acta Horticulturae, 818, 205-212.

Zhang, Y., Krueger, D., Durst, R., Lee, R., Wang, D., Seeram, N., \& Heber, D. (2009). International multidimensional authenticity specification (IMAS) algorithm for detection of commercial pomegranate juice adulteration. Journal of Agricultural and Food Chemistry, 57(6), 2550-2557.

Zhang, L. X., Zhai, Y. L., Liu, Y. Z., Wang, Y. W., Gao, M., \& Zhou, J. (2012). Effects of single and combining application of $\mathrm{N}, \mathrm{P}, \mathrm{K}$ fertilizers on yield, quality and economical benefit of pomegranate. Soil and Fertilizer Sciences in China, 1, 9.

Zhuang, H., Du, J., \& Wang, Y. (2011). Antioxidant capacity changes of 3 cultivar Chinese pomegranate (Punica granatum L.) juices and corresponding wines. Journal of Food Science, 76(4), 606-611. 


\section{APPENDICES}

\section{APPENDIX A: FRUIT GROWTH CURVES}

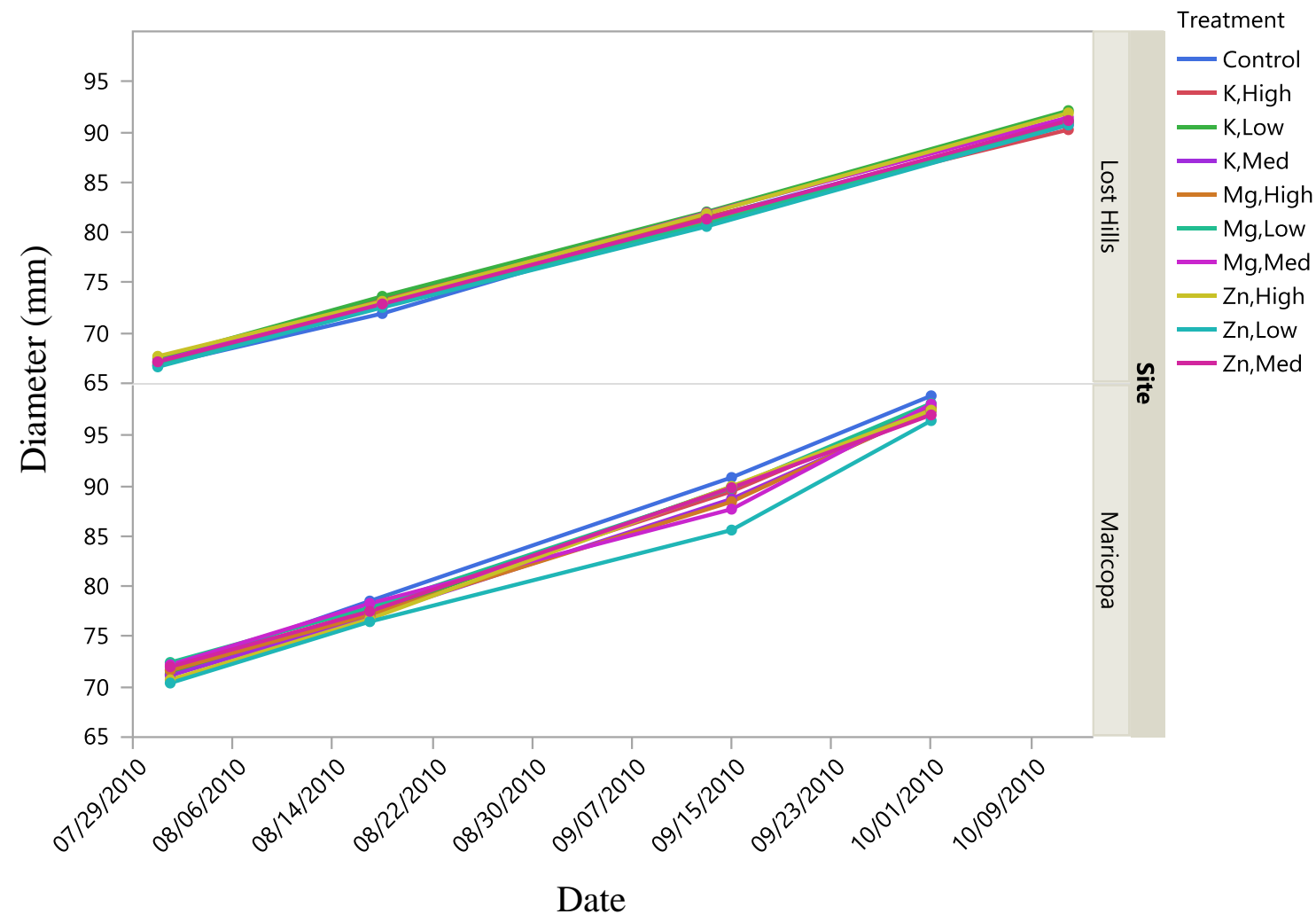

Figure 1: Fruit growth curves $(\mathrm{mm})$ of 'Wonderful' pomegrante trees treated with foliar applications of deinionized water (control), $\mathrm{ZnSO}_{4}$ (low dosage: $3000 \mathrm{mg} \cdot \mathrm{L}^{-1}$, medium dosage: $4000 \mathrm{mg} \cdot \mathrm{L}^{-1}$, or high dosage: $5000 \mathrm{mg} \cdot \mathrm{L}^{-1}$ ), $\mathrm{MgSO}_{4}$ (low dosage: $1 \%$, medium dosage: $2 \%$, or high dosage: $3 \%$ ), or $\mathrm{KNO}_{3}$ (low dosage: $1 \%$, medium dosage: $2 \%$, or high dosage: $3 \%$ ) at two commercial orchards (site 1: Maricopa, CA, site 2: Lost Hills, CA) in Kern County, CA, USA. 